\title{
BOOSTER DIPOLE PRODUCTION MEASUREMENTS
}

BOOSTER TECHNICAL NOTE

NO. 190

\section{R. THERN}

MARCH 13, 1991

ALTERNATING GRADIENT SYNCHROTRON DEPARTMENT BROOKHAVEN NATIONAL LABORATORY

UPTON, NEW YORK 11973 


\title{
BOOSTER DIPOLE PRODUCTION MEASUREMENTS
}

\author{
R. Thern \\ March 11, 1991
}

\section{INTRODUCTION}

This note describes the production control measurements and presents the results of those measurements for the Booster ring dipoles. Only the standard magnets are included in the averages and statistics given here. The unusual magnets-the C5 injection magnet, the BTA line magnets, and the spares-are excluded.

The measurements were made by the Testing and Measuring Group of ADD (TMG), and the results reported in their TMG Series of reports, in their standard format with one report per magnet. The data, both raw and analyzed, are stored by the TMG on a VAX computer (presently BNLWAG). These data have been moved to a PC and reanalyzed by the author for the results in this report. All data files are available for anyone who is interested - see Appendix A for a description.

\section{DESCRIPTION OF DATA}

There are three sets of measurements made for each magnet:

1. "Short coil" measurements made with a rotating coil with a radius of 0.866 inches and 36.5 inches long, placed at nine standard positions in the magnet ${ }^{1}$ (see Figure B1 in Appendix B). Measurements are made for a series of currents from zero to $5000 \mathrm{~A}$. This coil has several windings, and the data are analyzed to give the harmonic components of the magnetic field. This same coil has been used for the Booster quadrupoles and sextupoles. The data in this report, unless otherwise stated, are from this short coil measurement.

2. "Long coil" measurements made by a fixed long coil which lies along the central particle trajectory through the entire length of the magnet (and fringe field). The power supply is ramped for the measurement, with final currents from 250 to $5100 \mathrm{~A}$.

3. NMR (nuclear magnetic resonance) measurements at the center of the magnet, at a few currents from 3000 to $5000 \mathrm{~A}$.

All of the measurements are effectively DC. For the ramped long coil measurements, the results are read not "on the fly", but after the ramp has stopped and the results have stabilized. Also, there is no vacuum chamber present in any of this data. The ramping measurements, with the vacuum chamber, will be reported later.

Before each set of measurements, the magnet was prepared by cycling the current several times between zero and the high limit, ending finally at zero. All static measurements were made with the current monotonically increased to the measurement value. Thus the data are all taken on the bottom of the positive current hysteresis curve, starting from zero current. 
The short coil measurements give the only data that have field shapes or harmonics. The results, as graphs of the harmonic components $v s$. current (separately for each coil position), are given for each magnet in the TMG series of reports. For this report the data from the nine coil positions are combined to give an overall picture of the magnet. How this is done is described briefly in Appendix B.

Magnet BMD033 has been retained for use as a standard and has been remeasured several times, providing a means to detect changes in the measuring apparatus or technique.

\section{RESULTS}

The nomenclature we shall use ${ }^{2}$ describes the fields in the median plane ${ }^{*}$ as

$$
\begin{aligned}
& B_{x}(x)=A_{0}+A_{1} x+A_{2} x^{2}+A_{3} x^{3}+\ldots \\
& B_{y}(x)=B_{0}+B_{1} x+B_{2} x^{2}+B_{3} x^{3}+\ldots
\end{aligned}
$$

or alternatively as

$$
\begin{aligned}
& B_{x}(x)=B\left(a_{0}+a_{1} x+a_{2} x^{2}+a_{3} x^{3}+\ldots\right) \\
& B_{y}(x)=B\left(b_{0}+b_{1} x+b_{2} x^{2}+b_{3} x_{3}+\ldots\right)
\end{aligned}
$$

where $a_{0}^{2}+b_{0}^{2}=1$. In a dipole, the only allowed terms are $B_{0}, B_{2}, B_{4}$, etc. Since the exact leftright symmetry is broken by the curvature of the dipoles and the arrangement of the power leads, we should not be surprised to see some small amount of the A terms and odd B terms also.

The data in this report are generally for a fictitious magnet which is the 'average' of most of the production magnets. A separate short report will be generated individually for each magnet and stored as part of that magnet's permanent record - some samples are included in this note.

${ }^{*}$ At an arbitrary position, the field is given by

$$
\vec{B}(r, \theta)=\sum_{n=1} C_{n}\left(\frac{r}{R}\right)^{n-1}\left[\overrightarrow{1}_{r} \sin n\left(\theta-\alpha_{n}\right)+\overrightarrow{1}_{\theta} \cos n\left(\theta-\alpha_{n}\right)\right],
$$

where $C_{n}$ is the magnitude and $\alpha_{n}$ the angular orientation of the $n^{\text {th }}$ multipole at a reference radius $R$. This form implicitly satisfies Maxwell's equations for a two-dimensional field. The sets of coefficients are related by

$$
\begin{gathered}
C_{n}=R^{n-1} \sqrt{A_{n-1}^{2}+B_{n-1}^{2}} \\
\tan n \alpha_{n}=-A_{n-1} / B_{n-1} .
\end{gathered}
$$




\section{Magnetic length and transfer function}

The data are presented both as central field values for the middle of the magnet (well away from the ends of the iron), and as integrated field values for the entire magnet. Obviously the integrated (average) values are the most interesting, but the central values have been measured also and help in understanding the behavior of the magnet. length:

The field values for the entire magnet are presented as averages over a defined magnetic

$$
\begin{gathered}
B_{\text {middle }} \equiv \text { field measured at center, away from ends, } \\
B_{\text {entire }} \equiv \frac{\int B d l}{L_{\text {magnetic }}} \text { where } L_{\text {magnetic }} \equiv 2.42 \mathrm{~m} .
\end{gathered}
$$

The actual magnetic length varies slightly with current because the ends of the magnet saturate differently from the center. The actual value for the average magnet is shown in Figure 1. We have chosen $2.42 \mathrm{~m}$ as a definition of the magnetic length. This matches the actual value for intermediate excitations.

Figure 2 shows the excitation curve (transfer function) for the average magnet,as determined by the short coil measurements. Figures 3 and 4 present this same data in ways that more clearly show the residual field at low currents and the saturation at high currents. At $5000 \mathrm{~A}$, the middle of the magnet, away from the ends, shows a $2.6 \%$ loss of field due to saturation. For the entire magnet, the loss is higher at $3.6 \%$, because the ends saturate more and the actual magnetic length decreases slightly, as mentioned earlier.

The excitation data are given in a tabular form in Table 1. (These tables are not final - they sorely need some data points above $5000 \mathrm{~A}$, which are not available yet.) Also given are the parameters for a cubic spline interpolation for $B(I)$ and for the inverse function $I(B)$ which may be used by the magnet control program. The cubic interpolation of $\mathrm{B}(\mathrm{I})$ or $\mathrm{I}(\mathrm{B})$ is given by ${ }^{3}$

$$
y(x)=a y_{i}+b y_{i+1}+\frac{h}{6}\left[\left(a^{3}-a\right) y_{i}^{\prime \prime}+\left(b^{3}-b\right) y_{i+1}^{\prime \prime}\right],
$$

where

$$
\begin{aligned}
& x_{i} \leq x \leq x_{i+1} \\
& h=x_{i+1}-x_{i} \\
& a=\left(x_{i+1}-x\right) / h \\
& b=\left(x-x_{i}\right) / h .
\end{aligned}
$$

\section{Magnet-to-magnet variations}

The uniformity desired for the dipole magnets is that the rms spread in the field strength be less than $1.5 \times 10^{-4}$. This is a rather tight requirement, and while it appears that we are at or close to this level, there are problems with reproducibility in the measuring process that preclude showing this unequivocally. The data will be presented here separately for the middle of the 
magnet-away from the ends-and for the entire magnet, and a statistical argument will be used to separate the underlying magnet variations from the measurement errors.

Uniformity of the central field:

The most straight-forward measurement is the NMR measurement which is made at the center of the magnet. Figure 5 shows, for each magnet, the ratio of the measured field to the average for all magnets. The data have a relative rms spread of $0.8 \times 10^{-4}$ at $3000 \mathrm{~A}$.

The short coil measurement at the middle of the magnet, away from the ends, is almost as straight-forward as the NMR. The results for each magnet are shown in Figure 6. These data have a similar relative rms of $1.1 \times 10^{-4}$ at $3000 \mathrm{~A}$.

However, a careful examination of the $3000 \mathrm{~A}$ data in Figures 5 and 6 shows that the deviations in the two cases are poorly correlated. In fact, a scatter plot of the deviations for the two cases, Figure 7, shows essentially no correlation between the two measurements. Thus the deviations at $3000 \mathrm{~A}$ are mostly measuring errors. The actual spread in the magnets themselves is probably less than half these measured deviations, or else the scatter plot would be noticeably elongated along the $45^{\circ}$ line.

At $5000 \mathrm{~A}$ the situation is different. The deviations are larger, and the scatter plot, Figure 8, and its projections, Figure 9, show a strong correlation between the two measurement techniques. The magnets appear to have a real spread in dipole strength, at this current (where the saturation field loss is about $2.6 \%$ ). The projection along the diagonal gives a measure of the scatter due to the measuring process itself. If there is no correlation between the measuring error in the two types of measurements, then

$$
\begin{aligned}
& \sigma_{\text {measured, coil }}^{2}=\sigma_{\text {magnet }}^{2}+\sigma_{\text {coil }}^{2} \\
& \sigma_{\text {measured,NMR }}^{2}=\sigma_{\text {magnet }}^{2}+\sigma_{N M R}^{2} \\
& \sigma_{\text {measured,45 }}^{2}=\frac{\left(\sigma_{\text {coil }}^{2}+\sigma_{N M R}^{2}\right)}{2}
\end{aligned}
$$

and thus

$$
\sigma_{\text {magnet }}^{2}=\frac{\left(\sigma_{\text {measured, coil }}^{2}+\sigma_{\text {measured, NMR }}^{2}\right)}{2}-\sigma_{\text {measured,45 }}^{2} .
$$

At 3000 and $5000 \mathrm{~A}$, the numbers from Figures 9 and 10 yield, for the underlying magnet variations (in units of $10^{-4}$ ),

$$
\begin{aligned}
& 3000 A: \quad \sigma=\sqrt{\left(0.8^{2}+1.1^{2}\right) / 2-1.0^{2}} \approx 0 \\
& 5000 A: \quad \sigma=\sqrt{\left(2.7^{2}+2.8^{2}\right) / 2-1.1^{2}}=2.5
\end{aligned}
$$

Thus the central field strengths of the magnets are essentially identical at $3000 \mathrm{~A}$, but differ at the top current measured. Appendix $\mathrm{C}$ describes one possible cause of this magnet-to-magnet variation in saturation. 
Uniformity of the entire magnet:

Figures 11 and 12 show the deviation of the (spatially) integrated field from the average for all magnets, using both the long coil and the short coil data. The data show large random and systematic field errors which are not correlated between the two types of measurements. (Appendix D has a short discussion of why the measuring errors may be so large.) The scatter plots and projections of these data (Figures 13-16) show evidence of measuring errors of about $2.5 \times 10^{-4}$, which will mask any true magnet errors which are significantly smaller than this. But again we have two independent measurements, and can disentangle the measuring errors from the magnet variations. Applying the same reasoning used above, we get, for the underlying magnet variations (in units of $10^{-4}$ ),

$$
\begin{aligned}
& 2600 A: \quad \sigma=\sqrt{\left(2.7^{2}+3.0^{2}\right) / 2-2.7^{2}}=0.9 \\
& 4200 A: \quad \sigma=\sqrt{\left(4.8^{2}+3.3^{2}\right) / 2-3.1^{2}}=2.7
\end{aligned}
$$

Thus at intermediate fields, the magnets meet the tolerance of $1.5 \times 10^{4}$. At higher field the variation is larger by a factor of two, but this should not lead to intolerable orbit errors, as the beam size will be smaller at the higher momentum.

Another statement about the uniformity of the entire magnet may be made from the central field measurements and the known length of the magnet. Although the final assembled length of the magnet is not measured, the individual parts are controlled so the final length of the iron laminations will be \pm 20 mils in the extreme, or $<10$ mils $(.25 \mathrm{~mm}) \mathrm{rms}^{4}$. Adding this $10^{-4}$ length variation in quadrature with the central field variations noted above again leads us to believe that the integrated field is uniform to $<1.5 \times 10^{-4}$ at $2600 \mathrm{~A}$ and $<3 \times 10^{-4}$ at $5000 \mathrm{~A}$.

\section{Field shape and harmonics}

The field shape is shown in Figures 17 and 18 (for the entire magnet, and for the middle only, respectively). At low and intermediate currents the field in the interior of the magnet is quite flat, while the shape for the entire magnet is dominated by a sextupole curve, which must therefore be due mainly to the ends. At $5000 \mathrm{~A}$, however, saturation has led to a large $\mathrm{b}_{2}$ component throughout the magnet. There is also some quadrupole component at all currents.

The main quadrupole and sextupole magnets in the Booster can compensate for this $b_{1}$ and $b_{2}$ in the dipoles (in an average way only, since the quad and sextupole magnets are not individually powered). Thus a more realistic picture of the magnet has these two components subtracted, as in Figures 19 and 20. With this subtraction the magnets meet the field uniformity requirement of

$$
\frac{\Delta B}{B} \leq 10^{-4} \text { for }|x| \leq\left\{\begin{array}{l}
5.0 \mathrm{~cm} \text { for } I \leq 2500 \mathrm{~A} \\
2.5 \mathrm{~cm} \text { for } I \leq 5000 \mathrm{~A} .
\end{array}\right.
$$

The variation of the harmonics with current, up to $b_{6}$, is shown in Figure 21 . Table 2 compares these harmonics at two currents with the stated tolerances ${ }^{5}$. The systematic error is 
the average over all the magnets, while the random error is the standard deviation of this same set. All the tolerances are met with substantial margins, except for the $\mathrm{B}_{0}$ term at high current.

\section{CONCLUSIONS}

We can conclude, for the purposes of the Booster, that the integrated field strengths of all the dipoles are identical at the required theoretical accuracy, even though the measurement system does not have the accuracy to demonstrate this directly and we have had to use somewhat indirect arguments. The overall field shape of the average magnet is also within the required theoretical accuracy, and the variations from magnet to magnet are well within the required tolerances. 


\begin{tabular}{|c|c|c|c|c|c|}
\hline I (Amp) & B (Tesla) & $\mathrm{B} / \mathrm{I}$ & $B^{\prime \prime}(I)$ & $\mathrm{I}^{\prime \prime}(\mathrm{B})$ & $B^{\prime}(I)$ \\
\hline 0 & 0.000775 & - & $2.73430 \mathrm{E}-08$ & $-2.00187 E+03$ & $2.39000 E-04$ \\
\hline 50 & 0.012757 & $2.55136 \mathrm{E}-04$ & $2.25028 \mathrm{E}-08$ & $-1.62001 E+03$ & \\
\hline 100 & 0.024791 & $2.47913 E-04$ & $8.19685 E-09$ & $-5.84458 E+02$ & \\
\hline 200 & 0.048930 & $2.44652 E-04$ & $6.21227 \mathrm{E}-09$ & $-4.39226 E+02$ & \\
\hline 400 & 0.097380 & $2.43451 E-04$ & $3.07127 E-09$ & $-2.14402 E+02$ & \\
\hline 600 & 0.145961 & $2.43268 E-04$ & $1.04474 \mathrm{E}-09$ & $-7.27295 E+01$ & \\
\hline 800 & 0.194595 & $2.43244 \mathrm{E}-04$ & $8.65126 \mathrm{E}-10$ & $-6.00772 E+01$ & \\
\hline 1000 & 0.243258 & $2.43258 E-04$ & $-3.41278 E-10$ & $2.36822 \mathrm{E}+01$ & \\
\hline 1400 & 0.340551 & $2.43251 \mathrm{E}-04$ & $-5.79780 E-10$ & $4.03461 E+01$ & \\
\hline 1800 & 0.437762 & $2.43201 \mathrm{E}-04$ & $-4.36129 E-10$ & $3.03927 E+01$ & \\
\hline 2200 & 0.534881 & $2.43128 E-04$ & $-1.10928 E-09$ & 7.76517E+01 & \\
\hline 2600 & 0.631827 & $2.43010 E-04$ & $-1.62831 E-09$ & $1.14532 E+02$ & \\
\hline 3000 & 0.728478 & $2.42826 \mathrm{E}-04$ & $-3.41573 E-09$ & $2.43356 \mathrm{E}+02$ & \\
\hline 3400 & 0.824546 & $2.42514 \mathrm{E}-04$ & $-6.59044 E-09$ & $4.78375 E+02$ & \\
\hline 3800 & 0.919469 & $2.41966 \mathrm{E}-04$ & $-1.31431 E-08$ & $1.00205 E+03$ & \\
\hline 4000 & 0.966159 & $2.41540 \mathrm{E}-04$ & $-2.37693 E-08$ & $1.90351 \mathrm{E}+03$ & \\
\hline 4200 & 1.011873 & $2.40922 E-04$ & $-3.80791 E-08$ & $3.27654 \mathrm{E}+03$ & \\
\hline 4400 & 1.055960 & $2.39991 \mathrm{E}-04$ & $-6.80291 E-08$ & $6.65744 E+03$ & \\
\hline 4600 & 1.097414 & $2.38568 \mathrm{E}-04$ & $-8.47584 E-08$ & $1.07457 E+04$ & \\
\hline 4800 & 1.135614 & $2.36586 \mathrm{E}-04$ & $-8.09470 E-08$ & $1.25004 \mathrm{E}+04$ & \\
\hline 5000 & 1.170678 & $2.34136 \mathrm{E}-04$ & $-6.19933 E-08$ & $1.62053 \mathrm{E}+04$ & $1.68486 \mathrm{E}-04$ \\
\hline
\end{tabular}

Table 1. Dipole excitation curve, with cubic spline parameters (see text). Finding spline parameters requires two constraints in addition to the $x-y$ values; these are given here as the slopes at the ends. All data are from short coil measurements.

\begin{tabular}{|c|c|c|c|c|c|c|}
\hline \multirow[b]{3}{*}{$B_{n}$} & \multicolumn{3}{|c|}{ Systematic Errors } & \multicolumn{3}{|c|}{ Random Errors } \\
\hline & \multirow[t]{2}{*}{ Tolerance } & \multicolumn{2}{|c|}{\begin{tabular}{cc}
\multicolumn{2}{c}{ Measured } \\
$2600 \mathrm{~A}$ & $5000 \mathrm{~A}$
\end{tabular}} & \multirow{2}{*}{\begin{tabular}{r|} 
Tolerance \\
$1.5 E-04$
\end{tabular}} & \multicolumn{2}{|c|}{\begin{tabular}{cc}
\multicolumn{2}{c}{ Measured } \\
$2600 \mathrm{~A}$ & $5000 \mathrm{~A}$
\end{tabular}} \\
\hline & & & & & $1.5 E-04$ & $3.0 E-04$ \\
\hline$b_{1}$ & & & & $2.0 E-07$ & $9.1 E-08$ & $8.6 E-08$ \\
\hline$b_{2}$ & $1.0 E-08$ & $-2.4 \mathrm{E}-09$ & $-6.4 \mathrm{E}-09$ & $5.0 E-10$ & $8.9 E-11$ & $8.3 E-11$ \\
\hline$b_{3}$ & $1.5 \mathrm{E}-10$ & $2.1 \mathrm{E}-13$ & $5.3 E-13$ & $7.0 \mathrm{E}-12$ & $1.4 E-13$ & $1.3 E-13$ \\
\hline$b_{4}$ & $1.0 E-14$ & $-9.8 E-16$ & $-8.7 E-15$ & $1.0 E-14$ & $1.1 E-16$ & $1.1 E-16$ \\
\hline$b_{5}$ & $3.0 E-17$ & $5.5 E-19$ & $1.2 E-18$ & $1.0 \mathrm{E}-17$ & $5.9 E-19$ & $5.4 E-19$ \\
\hline$b_{6}$ & $1.0 E-20$ & $-2.4 E-23$ & $-9.1 E-21$ & $5.0 \mathrm{E}-20$ & $5.6 \mathrm{E}-22$ & $4.9 E-22$ \\
\hline$a_{0}$ & & & & $1.5 \mathrm{E}-04$ & $4.9 E-05$ & $5.4 E-05$ \\
\hline$a_{1}$ & $1.0 \mathrm{E}-07$ & $2.4 \mathrm{E}-08$ & $6.0 E-08$ & $2.0 \mathrm{E}-07$ & $4.0 E-08$ & $4.8 E-08$ \\
\hline$a_{2}$ & $1.0 \mathrm{E}-08$ & $-7.5 \mathrm{E}-12$ & $-1.4 E-12$ & $5.0 E-10$ & $4.2 E-11$ & $5.6 E-11$ \\
\hline$a_{3}$ & $1.5 E-10$ & $1.1 \mathrm{E}-13$ & $1.5 \mathrm{E}-13$ & $7.0 E-12$ & $7.9 E-14$ & $9.4 E-14$ \\
\hline$a_{4}$ & $1.0 E-14$ & $1.4 \mathrm{E}-17$ & $4.7 \mathrm{E}-17$ & $1.0 \mathrm{E}-14$ & $8.8 E-17$ & $7.8 E-17$ \\
\hline$a_{5}$ & $3.0 \mathrm{E}-17$ & $-2.2 E-19$ & $-5.3 E-20$ & $1.0 \mathrm{E}-17$ & $2.1 E-19$ & $1.9 E-19$ \\
\hline$a_{6}$ & $1.0 E-20$ & $8.7 E-23$ & $-6.1 E-23$ & $5.0 E-20$ & $3.2 E-22$ & $3.2 E-22$ \\
\hline
\end{tabular}

Table 2. Systematic and random errors ( $r \mathrm{~ms})$, in units of $\mathrm{m}^{-n}$. The systematic error is the average over all the magnets, and the random error is the standard deviation of the same set. The errors for $B_{0}$ have been estimated as dscribed in the text. 


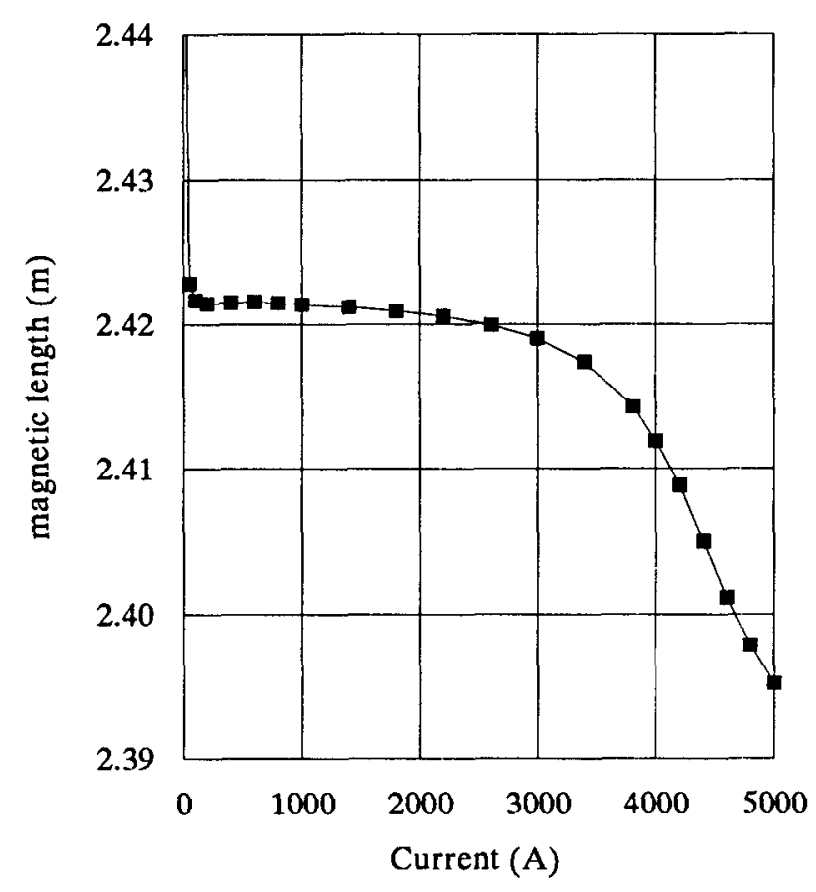

- (Integrated B dl) / B_middle

Figure 1. Measured magnetic length (average magnet).

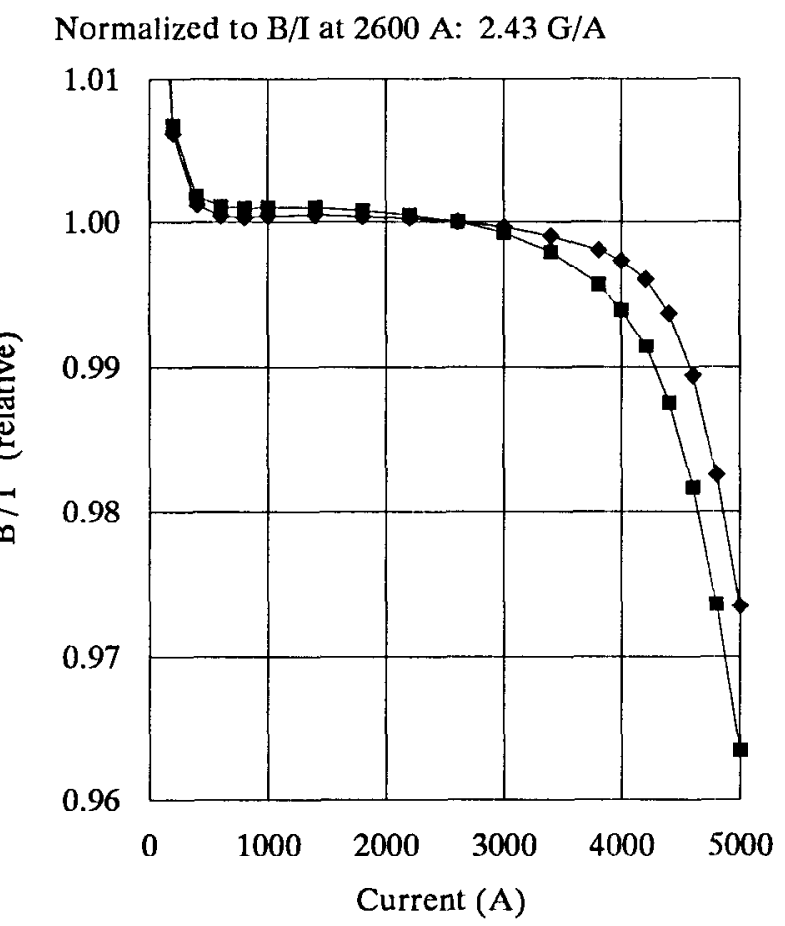

- Entire Magnet

$\uparrow$ Middle of Magnet

Figure 3. Excitation curve plotted as B / I.

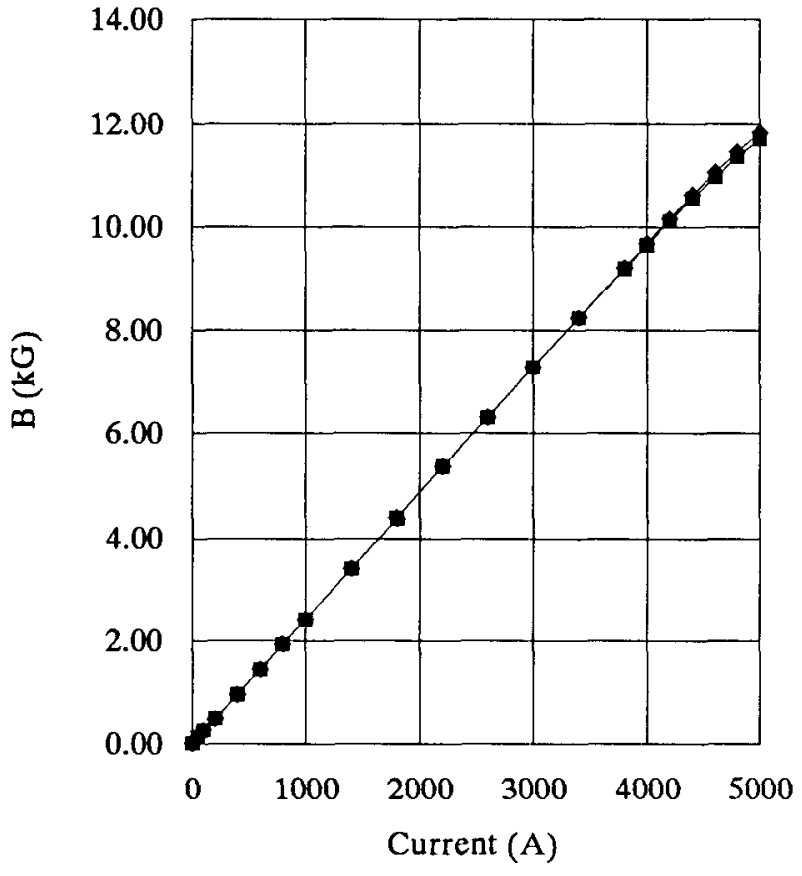

- Entire Magnet $\quad$ Middle of Magnet

Figure 2. Booster dipole excitation curve.

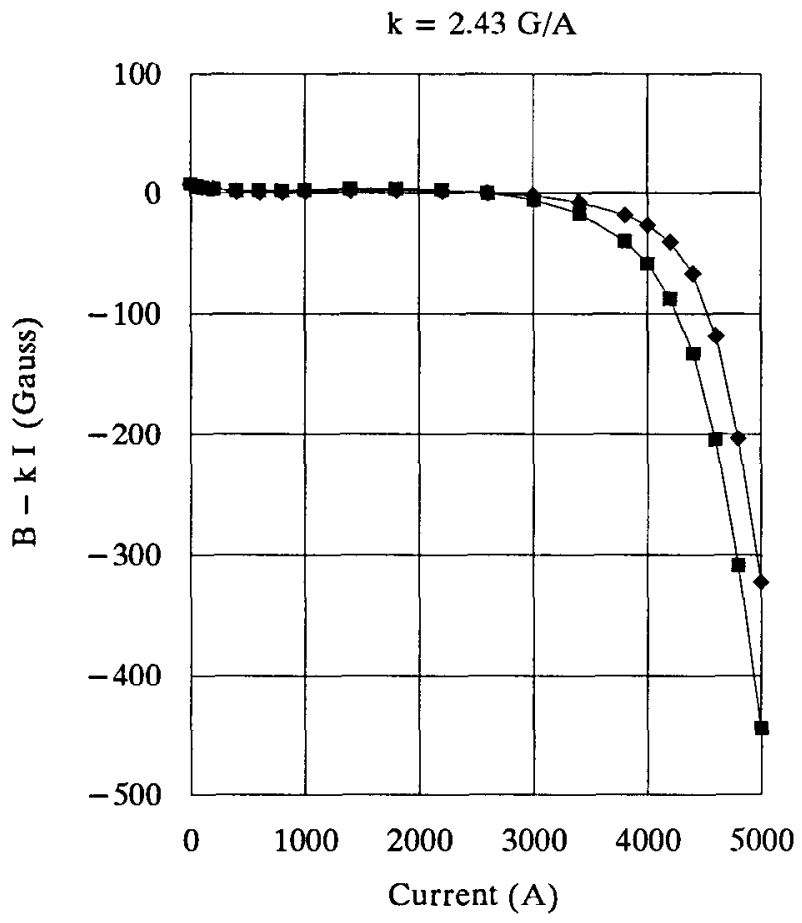

- Entire Magnet

- Middle of Magnet

Figure 4. Excitation curve plotted as $B-2.431$. 


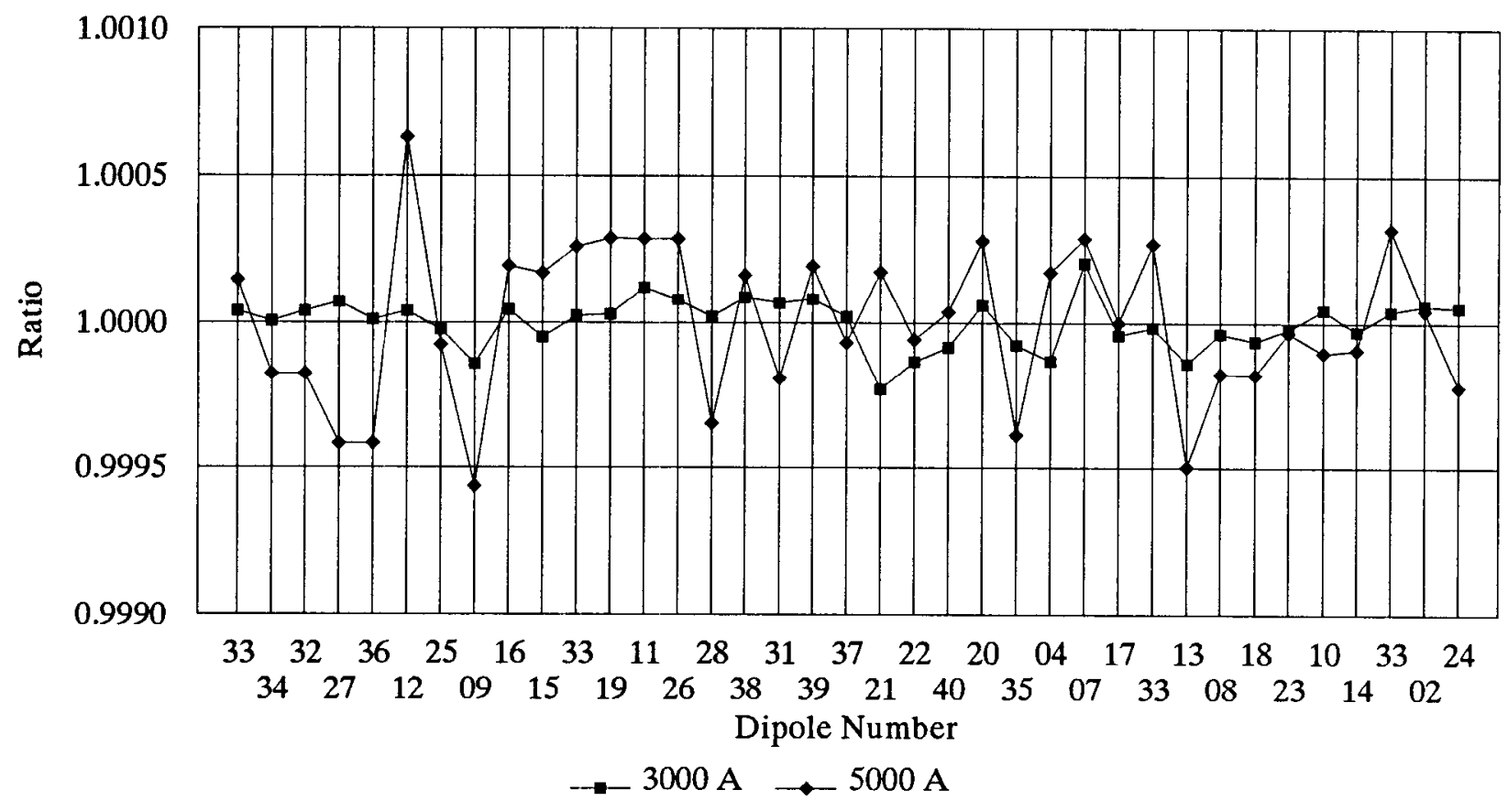

Figure 5. Ratio of measured dipole strength of each magnet to the average, for the NMR measurement in the middle of the magnet. The magnets are ordered by the date of the measurement.

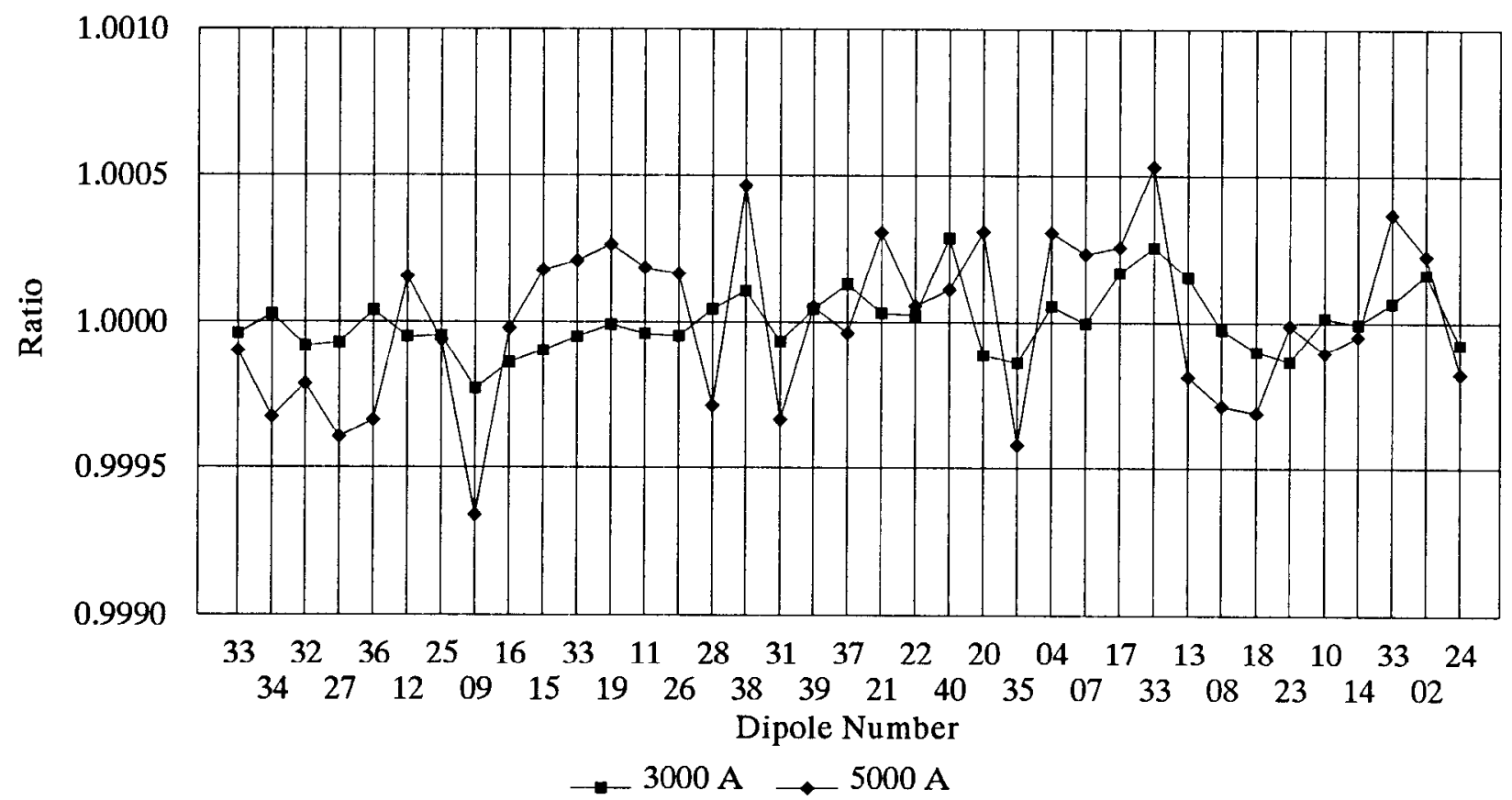

Figure 6. Same as Figure 5, but for the short coil measurement in the middle of the magnet only. 


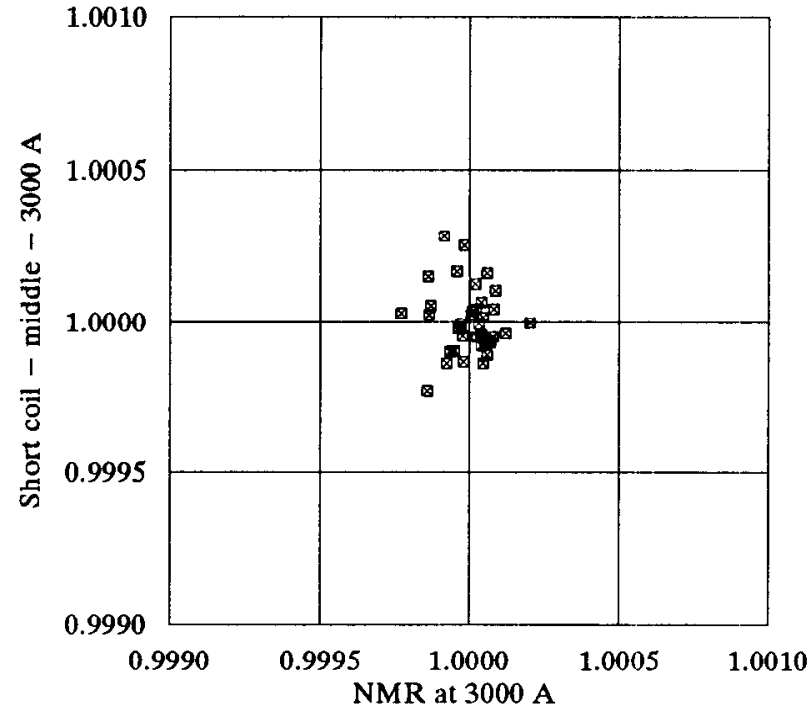

Figure 7. Scatter plot of short coil data vs. NMR data, at $3000 \mathrm{~A}$.

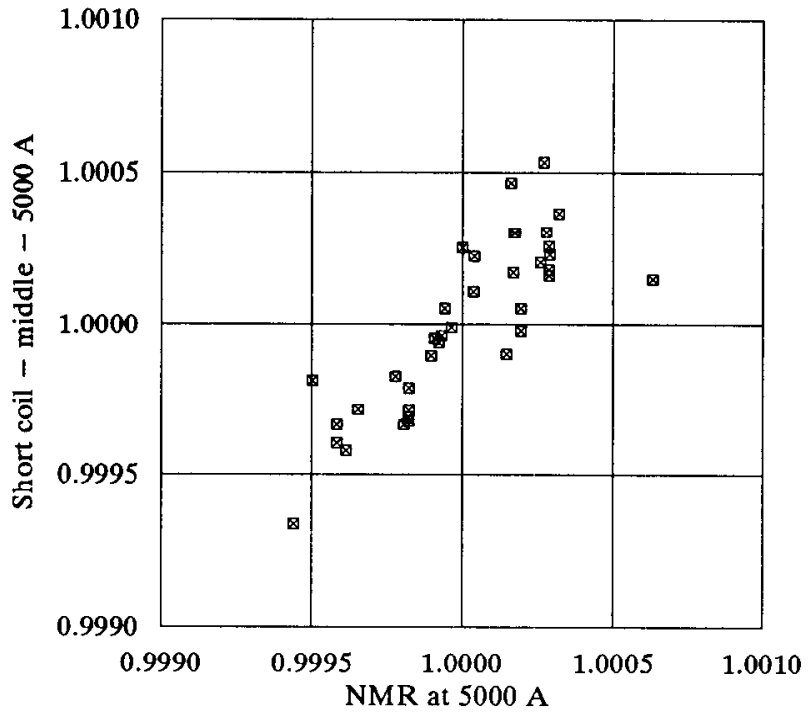

Figure 8. Scatter plot of short coil data vs. NMR data, at $5000 \mathrm{~A}$.
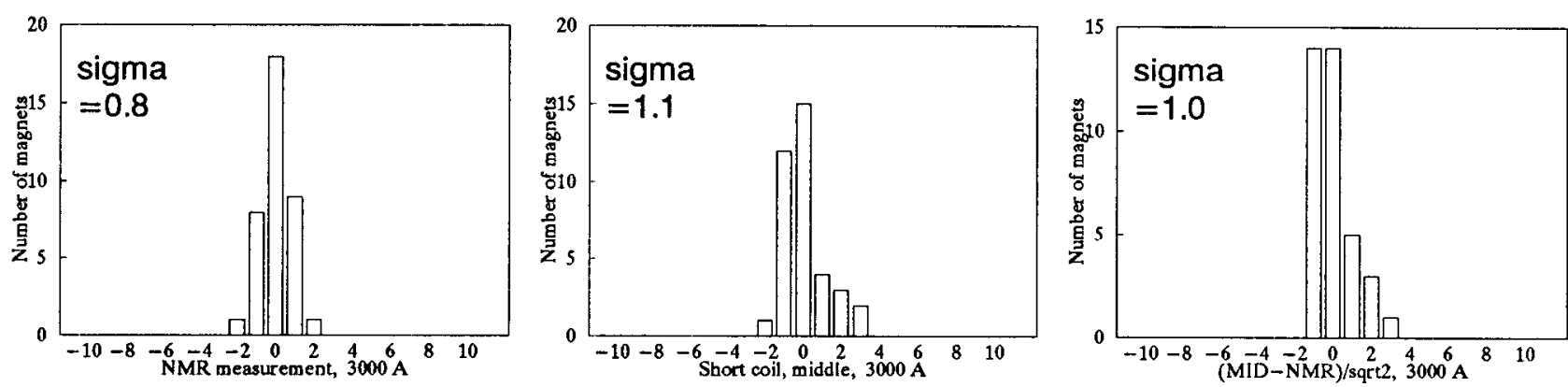

Figure 9. Projections of Figure 7: vertical, horizontal, and 45 degree. The abscissa scale and sigma is parts per 10000.
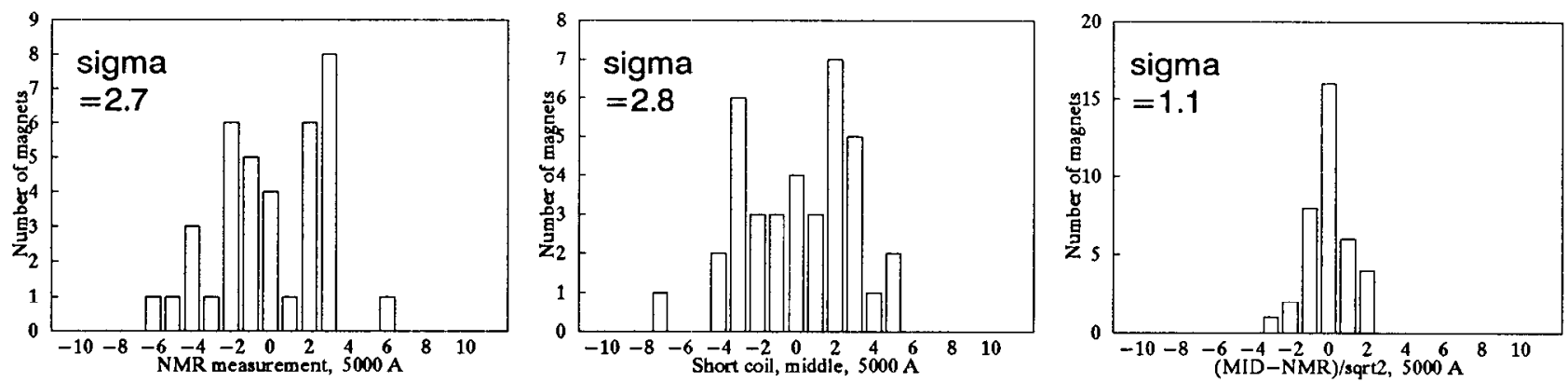

Figure 10. Projections of Figure 8: vertical, horizontal, and 45 degree. The abscissa scale and sigma is parts per 10000. 


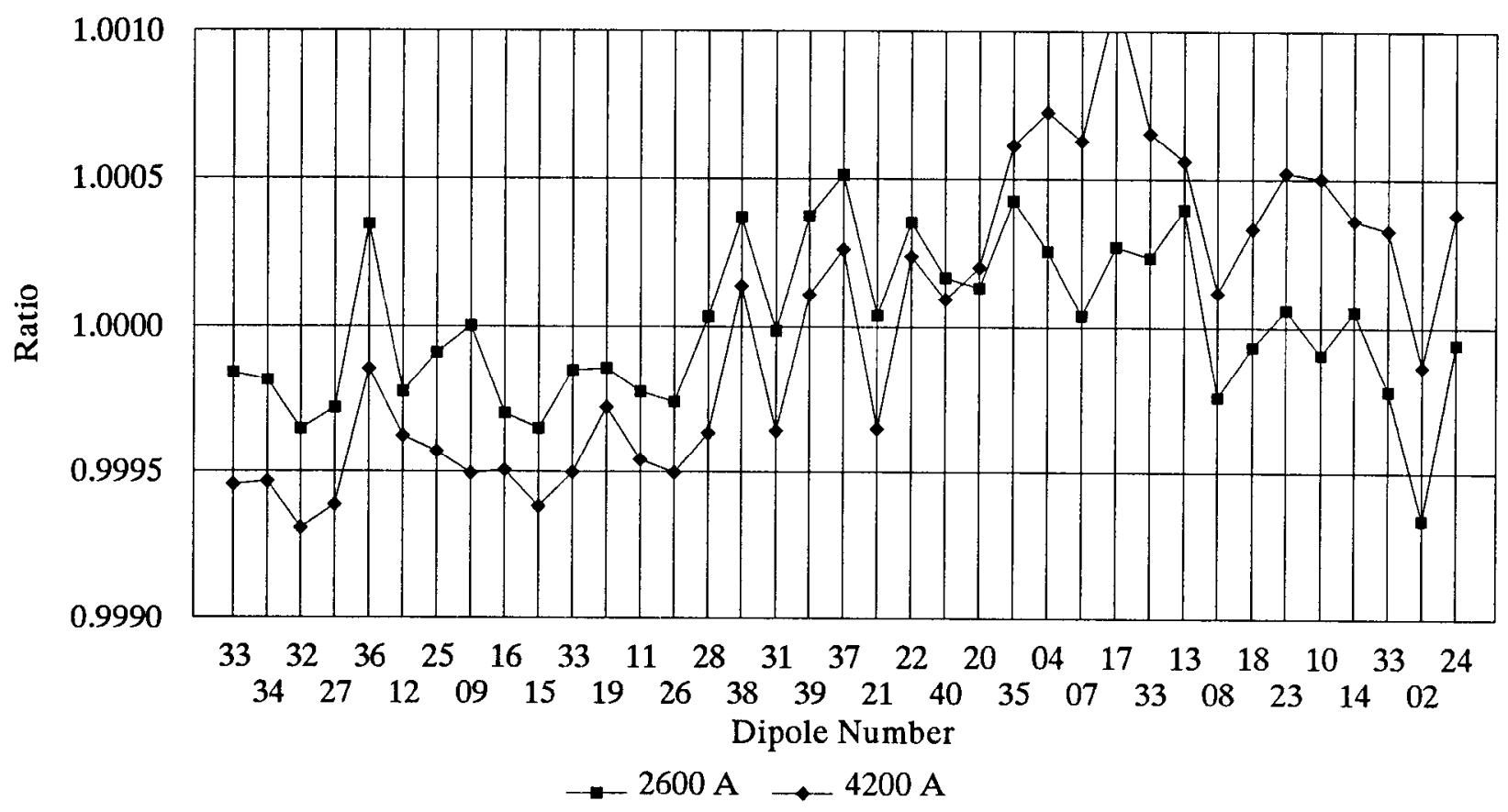

Figure 11. Ratio of measured dipole strength of each magnet to the average, for the long coil measurement. The magnets are ordered by the date of the measurement.

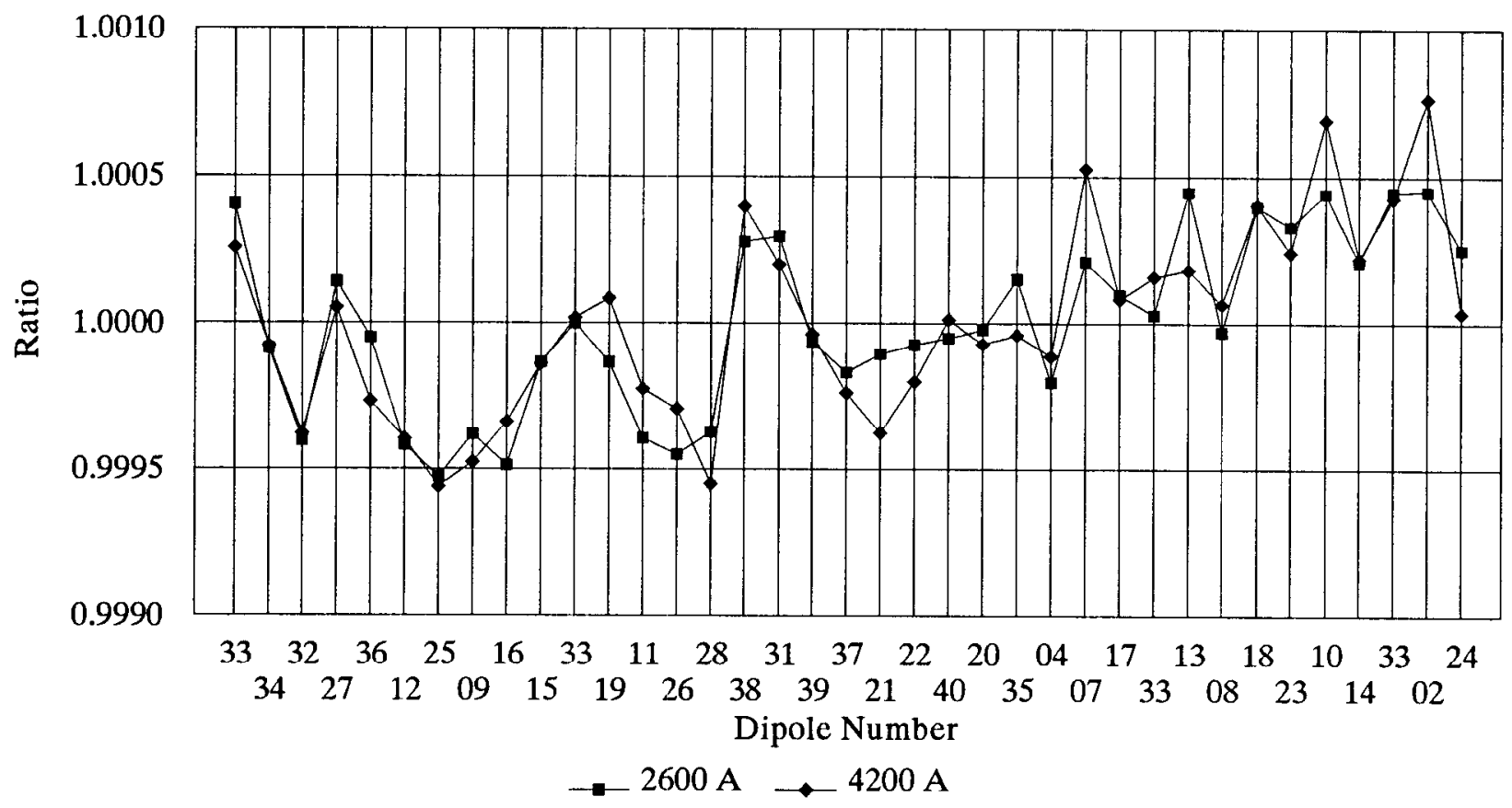

Figure 12. Same as Figure 11, but for the short coil measurements combined for the entire magnet. 


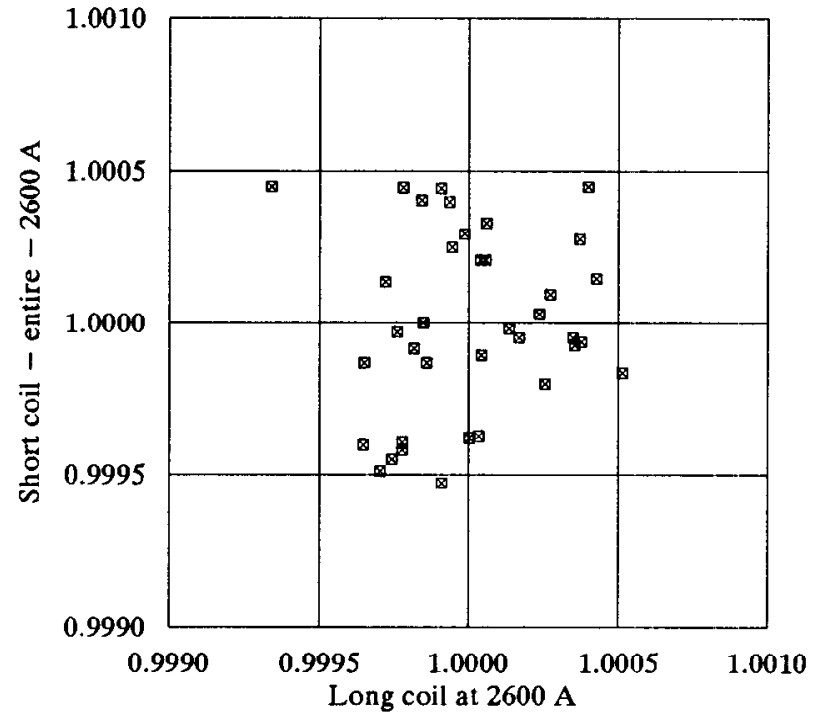

Figure 13. Scatter plot of short coil data (entire magnet) vs. long coil data, at $2600 \mathrm{~A}$.

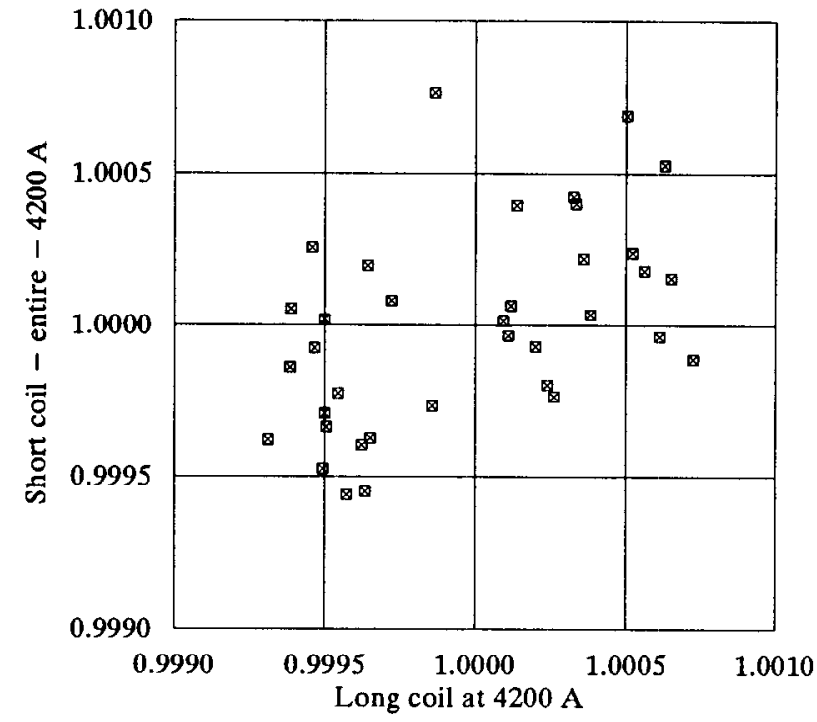

Figure 14. Scatter plot of short coil data (entire magnet) vs. long coil data, at $4200 \mathrm{~A}$.
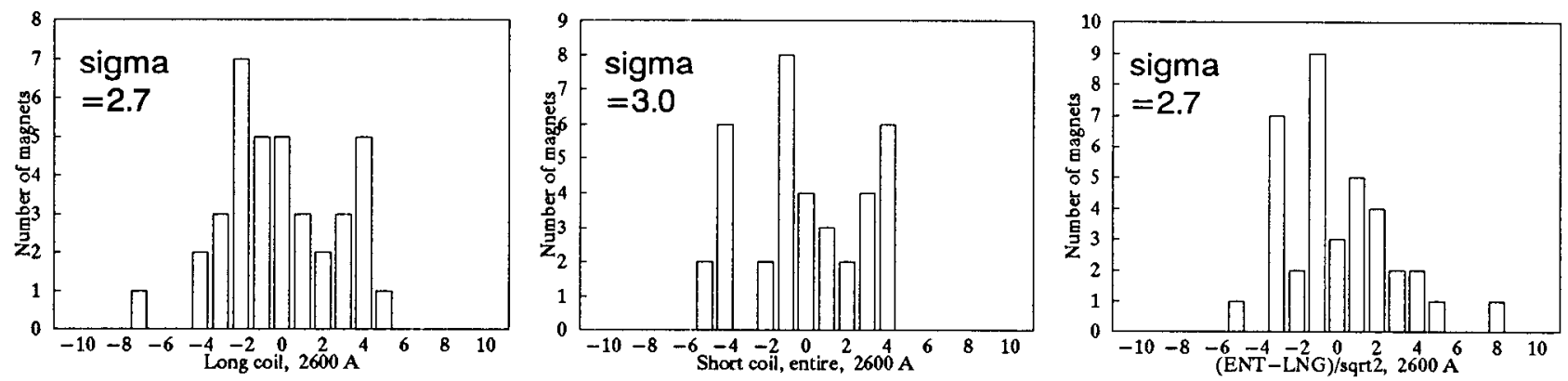

Figure 15. Projections of Figure 13: vertical, horizontal, and 45 degree. The abscissa scale and sigma is parts per 10000 .
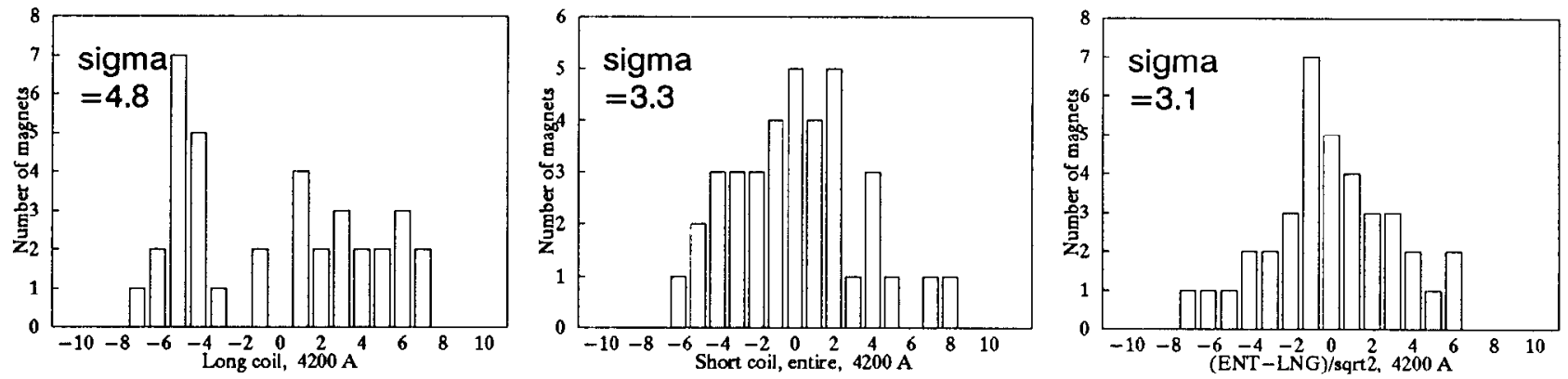

Figure 16. Projections of Figure 14: vertical, horizontal, and 45 degree. The abscissa scale and sigma is parts per 10000 . 


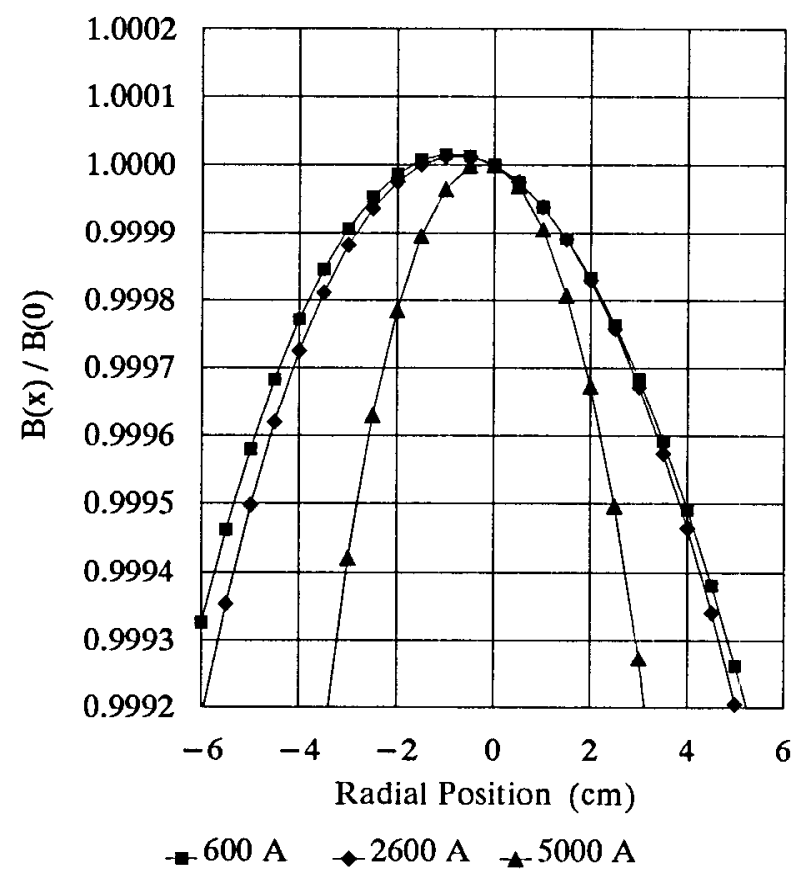

Figure 17. Magnetic profile, entire magnet, as measured (average magnet).

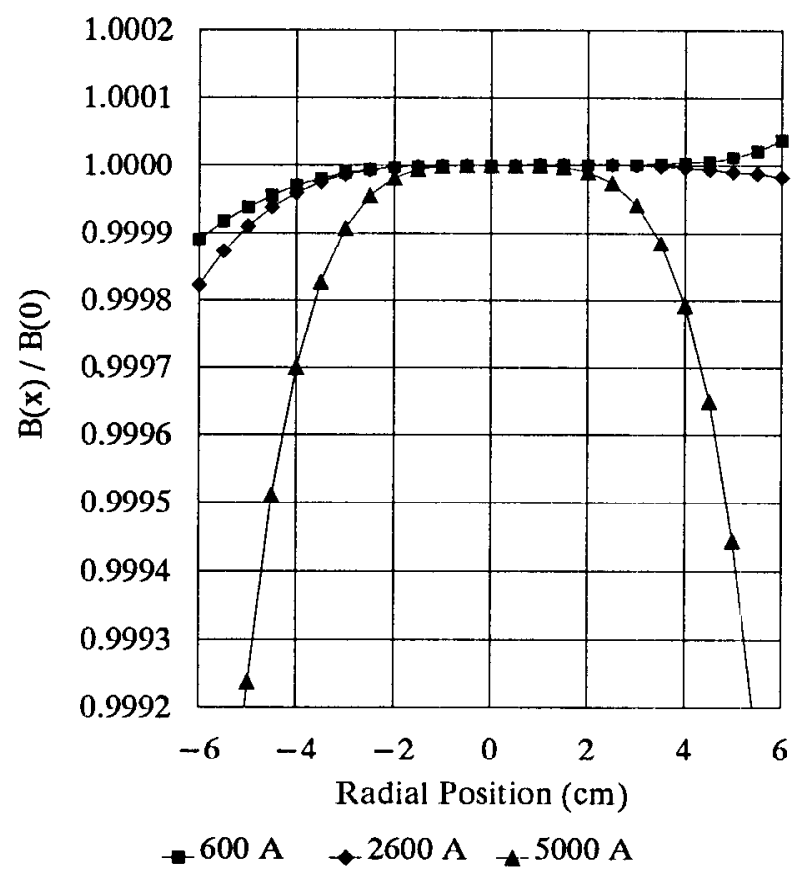

Figure 19. Magnetic profile, entire magnet, with average quadrupole and sextupole removed.

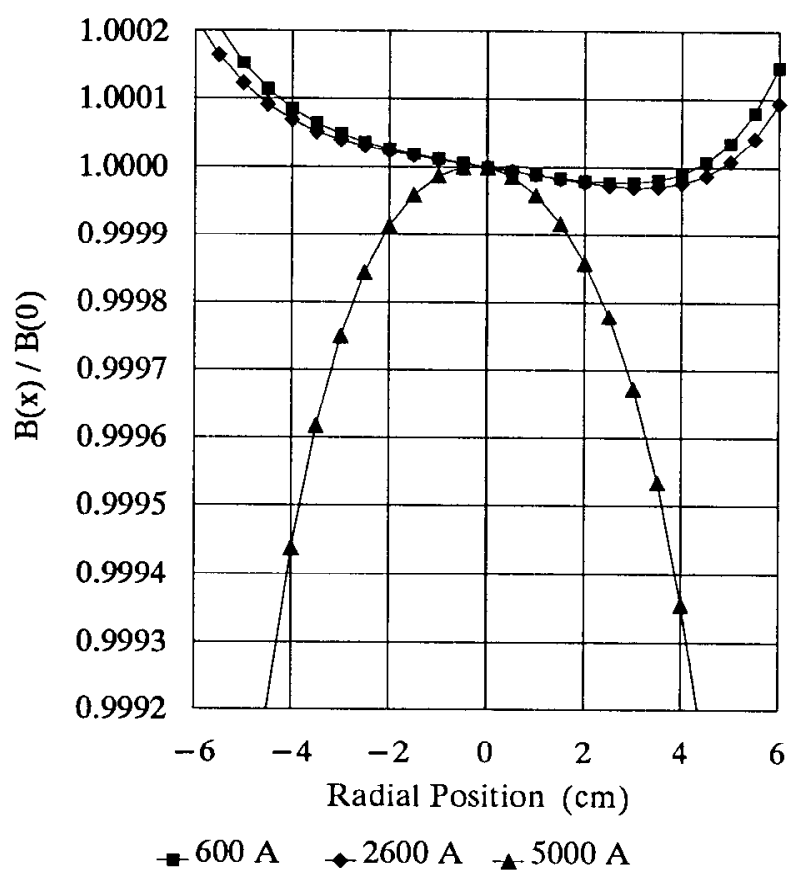

Figure 18. Magnetic profile, middle of magnet, as measured.

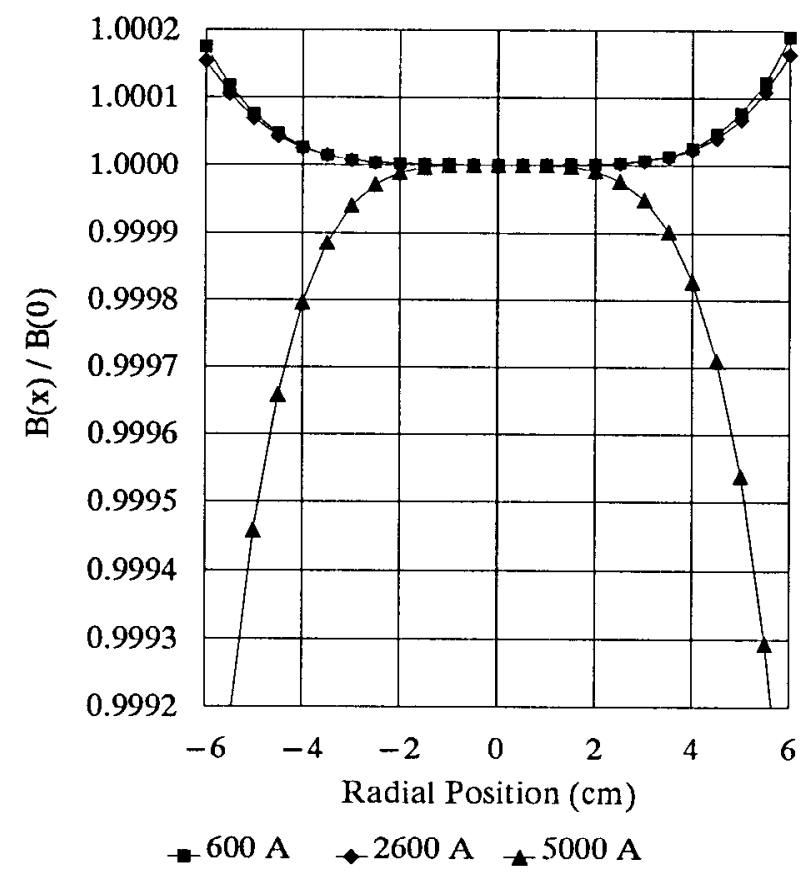

Figure 20. Magnetic profile, middle of magnet, with average quadrupole and sextupole removed. 

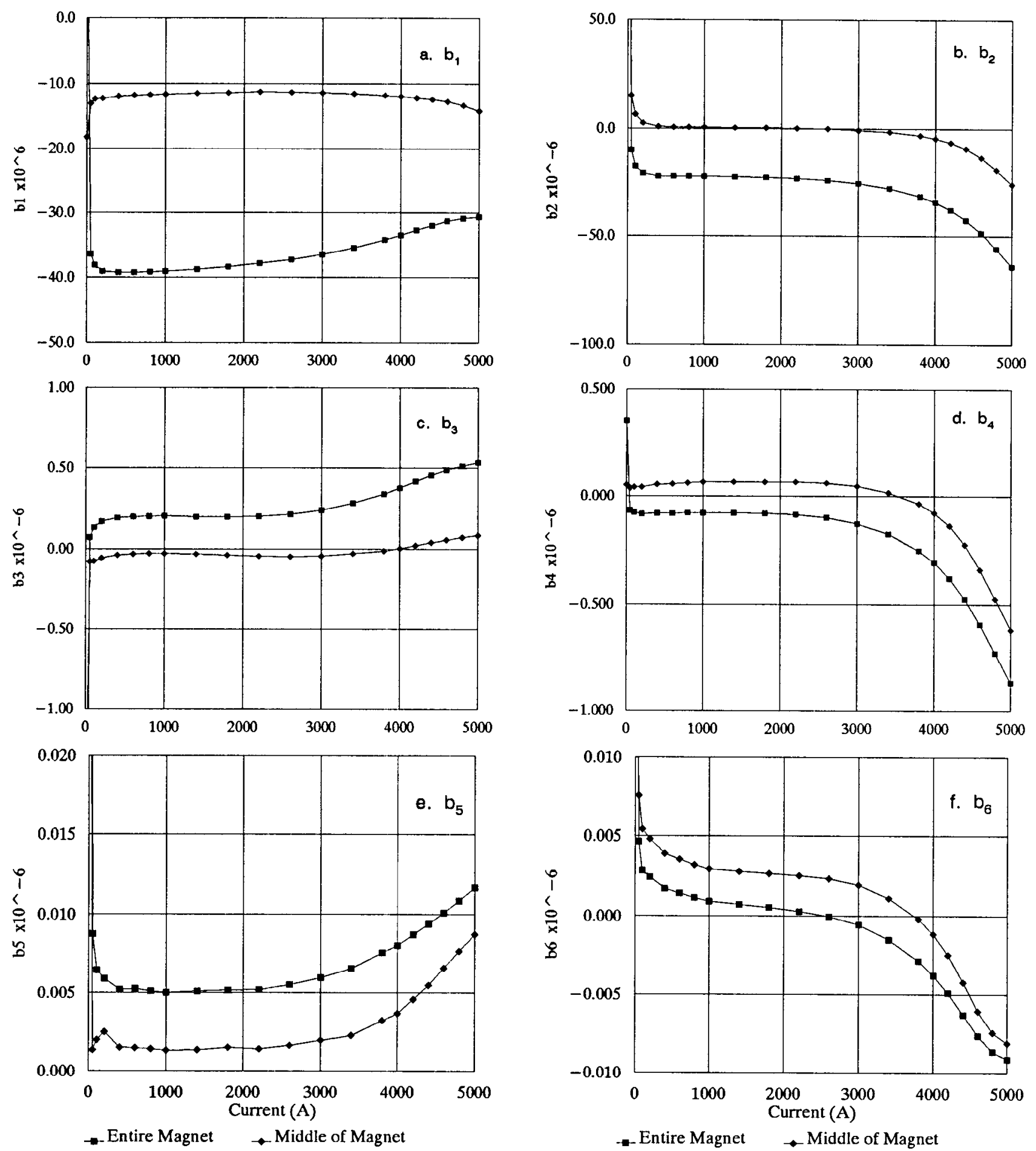

Figures 21 a-f. Harmonics as a function of current, for both the entire magnet and for the middle of the magnet. All scales are units of $\mathrm{cm}^{-n}$ multiplied by $10^{6}$. 


\section{APPENDIX A. DATA FILES.}

The measurement data for all the Booster magnets measured by the Testing and Measurement Group exists in several repositories, at different stages of progression from 'raw' to 'analyzed'. This note here is by no means a complete description of the data, but can serve as a guide for any future users who want to get their hands on the machine-readable numbers.

\section{Hewlett-Packard 9836}

This computer ran the apparatus, and the data in its most fundamental form is available on the backup tapes kept for this machine. This data comprises the coil parameters and the raw readings of magnet current, coil angle, and coil voltage. It is possible to transfer this data to a PC and make sense out of it.

The program that takes the data also performs the harmonic analysis and outputs an ASCII file with currents and harmonic coefficients.

VAX

The 'raw' current/coefficient files from the HP-9836 are stored on a VAX computer-presently BNLWAG-where they will be stored 'forever'. These files are processed on a VAX to create the data summary files ('dsf') which are the source for creating the TMG reports. The dsf files have essentially the same data as the 'raw' files, with a few corrections. They are fortran binary files, and thus difficult to read on a foreign computer, and impossible without a map of their arrangement. The dsf files are also stored on BNLWAG.

A short ASCII report with the numbers from the NMR and long coil measurements is also stored on BNLWAG.

$\underline{\mathrm{PC}}$

The raw, dsf, and nmr files have been copied from the VAX to a PC, where they have been reanalyzed for this report. The first step is a program which reads the raw or dsf files, combines the data from the nine coil positions, and writes field coefficients in ASCII files which are formatted in a way to make them easy to import into a spreadsheet. The individual magnet reports, and the analysis and graphs for this tech note, are done using Lotus 1-2-3.

\section{APPENDIX B. FITTING AND COMBINING SHORT COIL DATA.}

The magnet measurements with the short coil were made at nine locations in the magnet aperture as shown in Figures B1 and B2. The coil is .866" diameter and 36.5" long, so the region measured in one coil position does not cover the full width or length of interest. Thus to get the best picture of the entire magnet, the data from the separate measurements must be combined, both sideways and lengthwise. This has been done in several steps. 


\section{Adjust to a common current.}

The currents for the data in different positions vary slightly, as the power supply was not set to exact values (typical values are about 10 A below 'round' numbers, like 4191.54 for the nominal $4200 \mathrm{~A}$ data). Before combining data from different positions, they were scaled to the exact current values (e.g., $4200 \mathrm{~A}$ ) using parabolic interpolation. (This current adjustment is also necessary, of course, to compare different magnets.)

2. Join the side-by-side measurements.

The three side-by-side coil positions overlap, as shown in Figure B2. The fields measured at these adjacent coil positions fail to match in their overlapping region by a small amount, typically $<10^{-4}$ (relative). At currents where the field is flat this gives obvious breaks in the profile that are large and unphysical. Figure B3 shows a typical case. To correct this, the data from the side positions are scaled slightly to match the vertical field components $\left(B_{y}\right)$ of the side and center data at the midplane point midway between the coil centers. Figure B4 shows the result. The fact that the slopes match at the overlap helps justify this procedure.

The horizontal field components $B_{x}$ must also match. The measuring angle is not carefully controlled, and, to the extent that the magnet is a pure vertical field dipole, a small angle error gives a constant additive error, not a scale error, to $\mathrm{B}_{\mathrm{x}}$. This is corrected by rotating the side data by a small angle to match $B_{x}$ at the overlap point.

3. Fit the harmonics for the side-by-side data.

The harmonic coefficients that cover the entire transverse area are the average of the coefficients for the three side-by-side measurements. But the average must be done properly, taking into account the correlations between the different harmonics introduced when the coefficients, each originally around its own coil center, are translated to a common center. There will be a need for careful bookkeeping in such a program.

An alternative approach would be to go back to the original data of coil voltages and angles and redo the harmonic analysis using all three coil positions at once. What we have chosen to do is equivalent to this, but uses the harmonic data on hand. The harmonics for each measurement are used to reconstruct radial fields around the coil arc. Then these reconstructed fields-for all three coil positions at once-are used to make a least-squares fit for new harmonic coefficients that cover the entire transverse area.

While doing this fit, two extra degrees of freedom are used for each of the two side positions to tidy up the match done in step 2, making the match global instead of just at a point. It is still desirable to do step 2 first, because the match done in the fit has been linearized to make the mathematics more tractable and is appropriate only for a small correction.

The profile using this fitted set of coefficients is shown in Figure B5, along with the profiles given by the original sets of coefficients. 
4. Reconstruct the entire magnet.

At the ends of the magnets (positions 4-1-7 and 3-6-9) the measuring coil is placed with its center (lengthwise) at the end of the laminations, and measures a mixture of end field and interior field of the magnet. As the magnet is $2.4 \mathrm{~m}$ long and the coil only $.927 \mathrm{~m}$ long, there are regions in the magnet not covered by any of the positions. We assume that the field there is the same as that in the center of the magnet (positions 5-2-8). Then the integrated field of the magnet is

$$
\int B d l=B_{1} L+B_{3} L+B_{2}\left(\left|z_{3}-z_{1}\right|-L\right)
$$

where $z_{1}, z_{2}$, and $z_{3}$ are the three longitudinal positions of the center of the coil, $B_{1}, B_{2}$, and $B_{3}$ are the fields measured at these positions (actually the fitted result for the three side-by-side positions), and $L$ is the length of the coil ( $0.9721 \mathrm{~m}$ or $36.5 ")$.

These results do not include the effects of the curvature of this magnet. That will be accounted for in modelling by a poleface rotation of $5^{\circ}$ at each end.

\section{APPENDIX C. VARIATION IN SATURATION.}

Two dipoles very similar to the Booster ring dipoles were assembled for use in the BTA transfer line. At 5000 A these magnets showed about $15 \times 10^{-4}$ less field than the regular dipoles. These dipoles do not have the correction coil assembly, so the main excitation coils are recessed about $8 \mathrm{~mm}$ farther from the pole tip than normal. This indicates a sensitivity of the $5000 \mathrm{~A}$ field on the coil position of about $2 \times 10^{-4} / \mathrm{mm}$. This is, perhaps somewhat fortuitously, exactly the sensitivity found by a POISSON calculation ${ }^{6}$.

The coil spacing was measured on a few magnets; this is shown in Figure C1. Although there are probably other contributing causes, the observed $2.6 \times 10^{-4} \mathrm{rms}$ variation in $5000 \mathrm{~A}$ field could be caused by a coil spacing variation of just over $1 \mathrm{~mm} \mathrm{rms,} \mathrm{which} \mathrm{is} \mathrm{consistent} \mathrm{with} \mathrm{the}$ observed scatter in the figure.

\section{APPENDIX D. ERRORS IN TIIE INTEGRATED FIELD MEASUREMENTS.}

For the long coil measurement, the measuring coil is stationary and the magnet current ramped at $8.3 \mathrm{kA} / \mathrm{s}$. The voltage in the coil is integrated and read out after the ramp. At the end of this ramp, the current overshoots and settles back before the readings are made. This will move the field away from its intended value on the rising leg of the hysteresis curve-how much will depend on the details of the power supply behavior. The total width of the hysteresis curve, at low fields, is about 15 Gauss (twice the remnant field), which is $20 \times 10^{-4}$ at intermediate $(7500 \mathrm{G})$ fields - a large amount compared to the desired accuracy. Over the yearand-a-half that these measurements have been going on, the power supply has been repaired or reconfigured several times, so it is likely that the exact behavior at the end of the ramp varied enough to cause some of the variation in the long coil measurements. 
There are in fact several apparent systematic shifts in the data in Figure 11. Some-but not all-of them can be correlated with known power supply work. The remeasures of magnet BMD033 give some data which might be used to correcting these shifts, but there is not enough data to do it unambiguously, so it has not been attempted here.

The short coil measurements, on the other hand, were intended to give the field shape, but not to give a precision answer for the integrated field. The fact that the results are as good as they are is a tribute to the care the technicians have used in placing the coil in the magnet. The longitudinal placement of the coil at the ends of the magnet (positions 1, 3, 4, 6, 7, and 9) is the critical operation-an error of $10^{-4}$ in field corresponds to a placement error of $0.24 \mathrm{~mm}$ (10 mils). Over time, the screw which serves as a stop in positioning the coil at the ends of the magnet has worn and loosened, so the positioning inaccuracy, estimated to be several times this amount, makes a large contribution to the magnet variation measured with the short coil. 


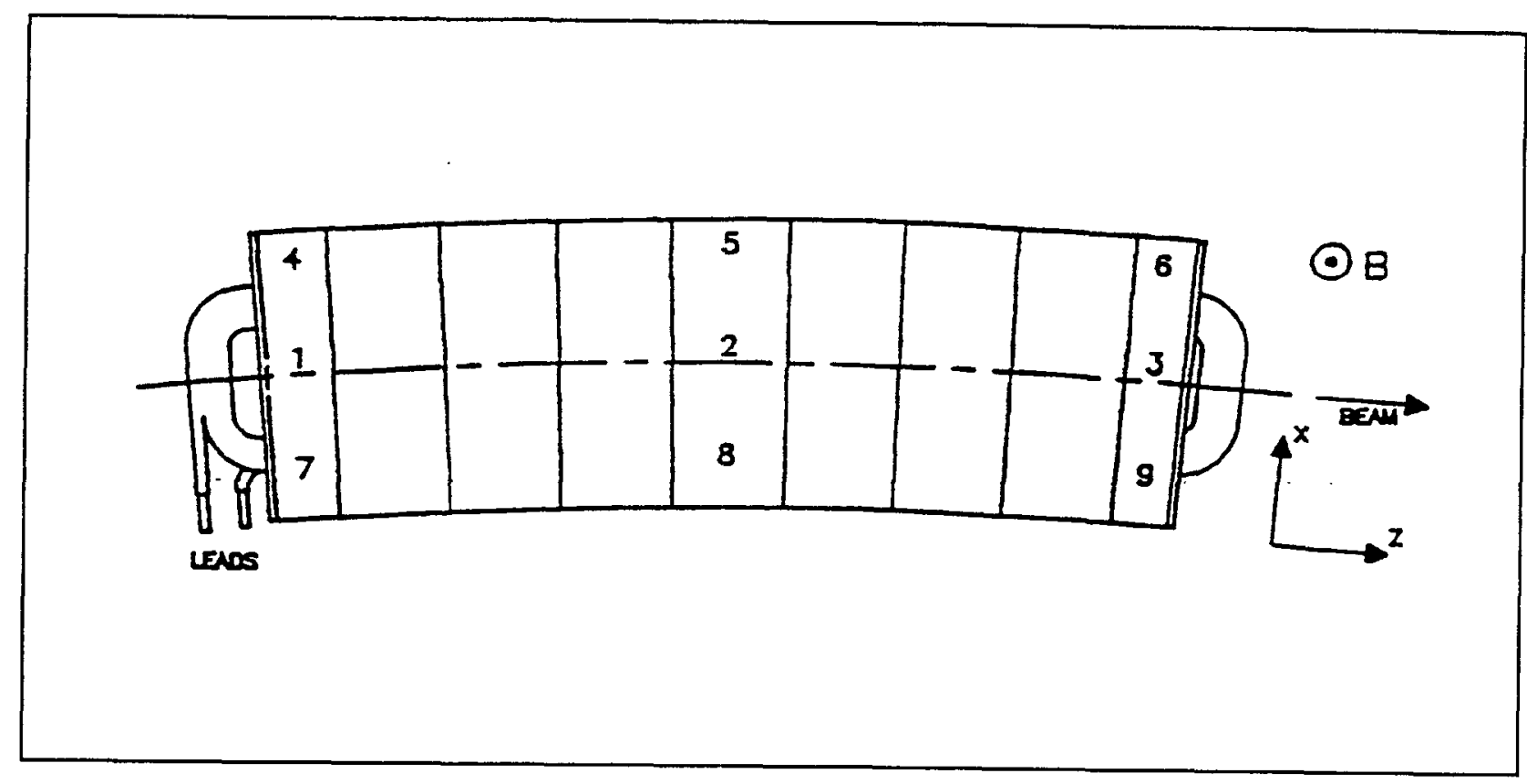

Figure B1. Schematic view of the measuring coil positions in the Booster dipole.

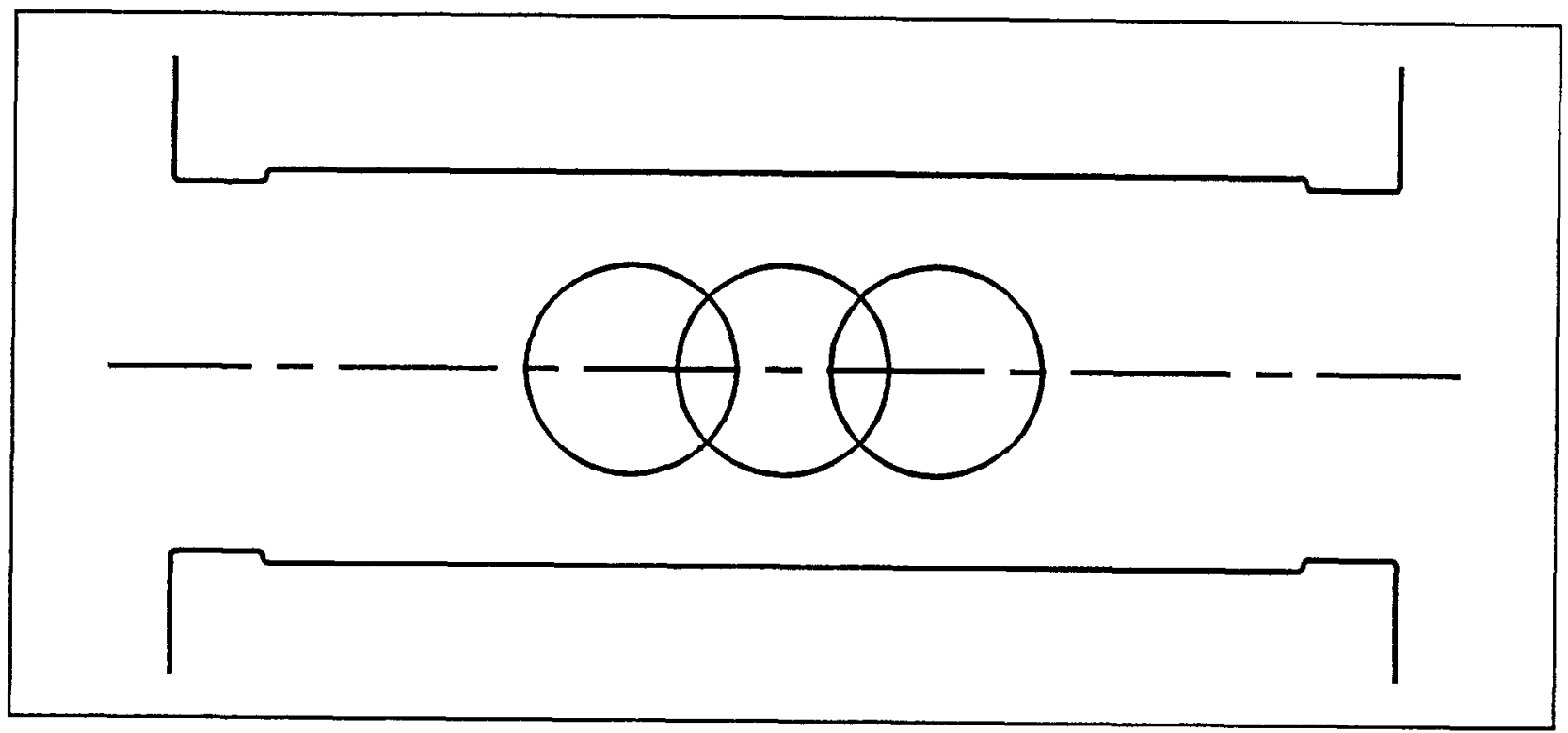

Figure B2. Scale drawing showing the positions of the measuring coil in the magnet aperture. 


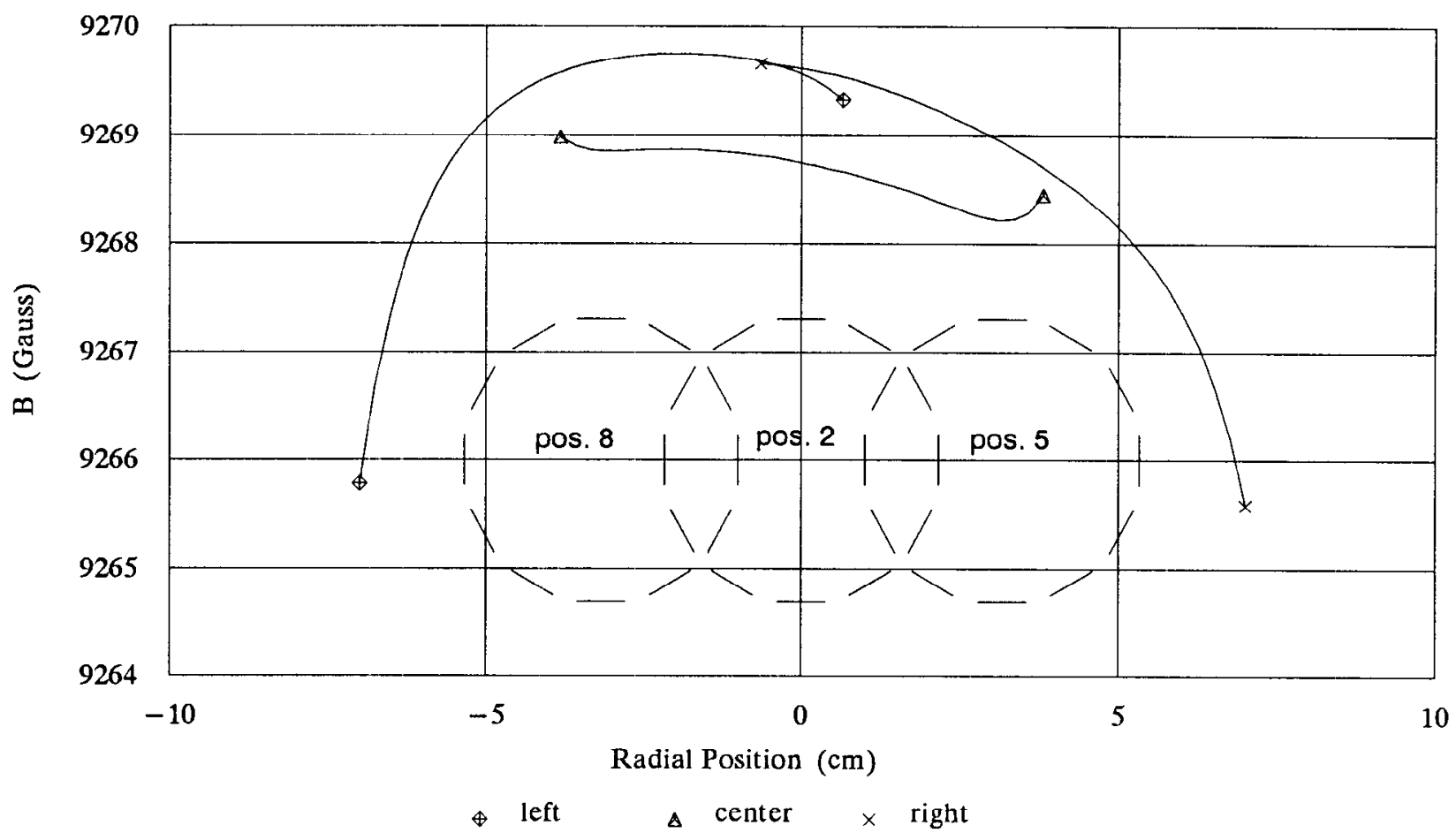

Figure B3. Field profiles for each of the three coil positions separately. For illustrative purposes, the data for each coil has been plotted somewhat beyond the region where it can be expected to give good results. The data are from $\mathrm{BMD033}$, run 2, middle position, $3800 \mathrm{~A}$. The dashed circles show the coil positions and its radius.

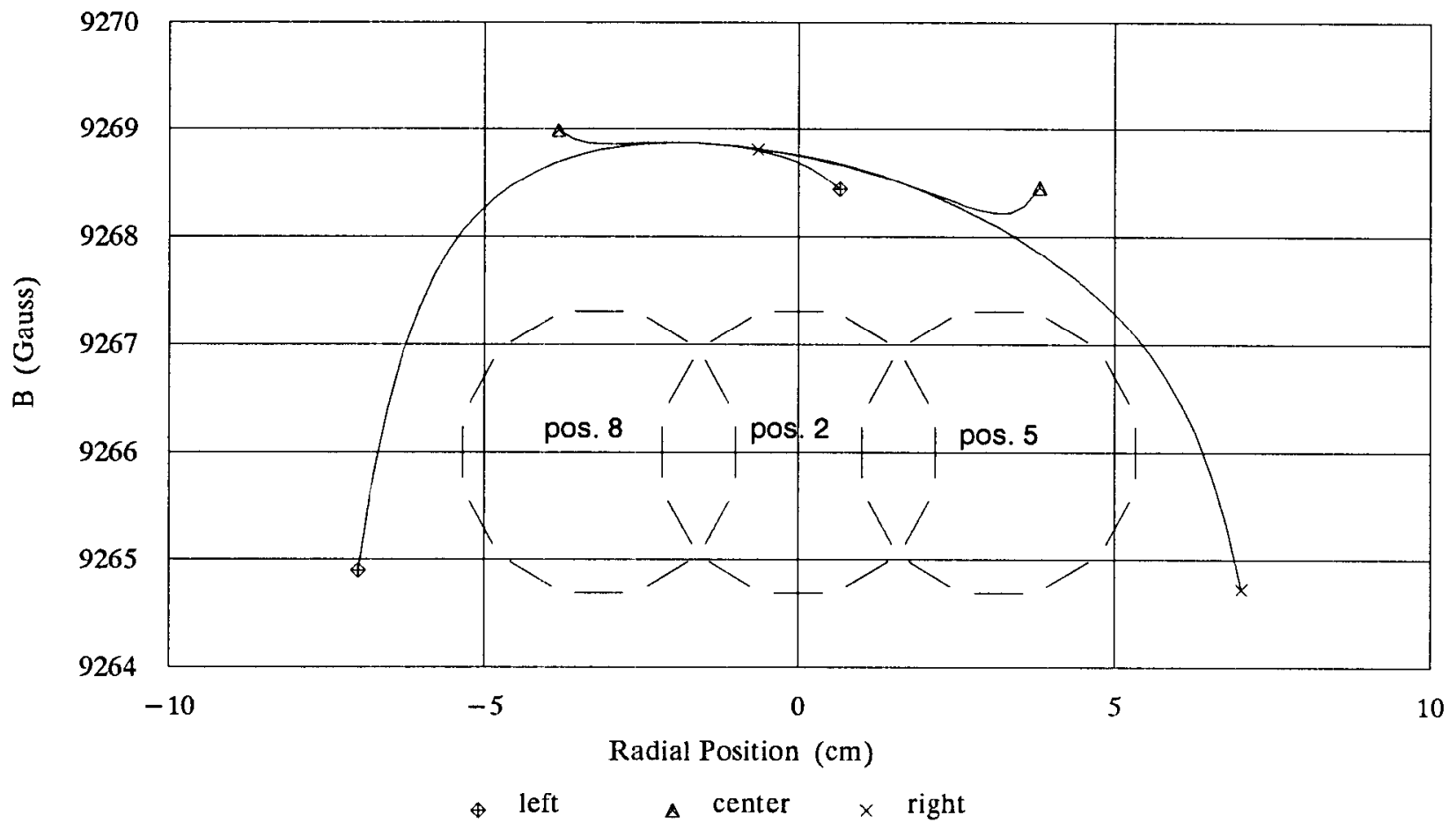

Figure B4. The data of Figure B3 after scaling the left and right data to match the center data at the points midway between the coil positions. 


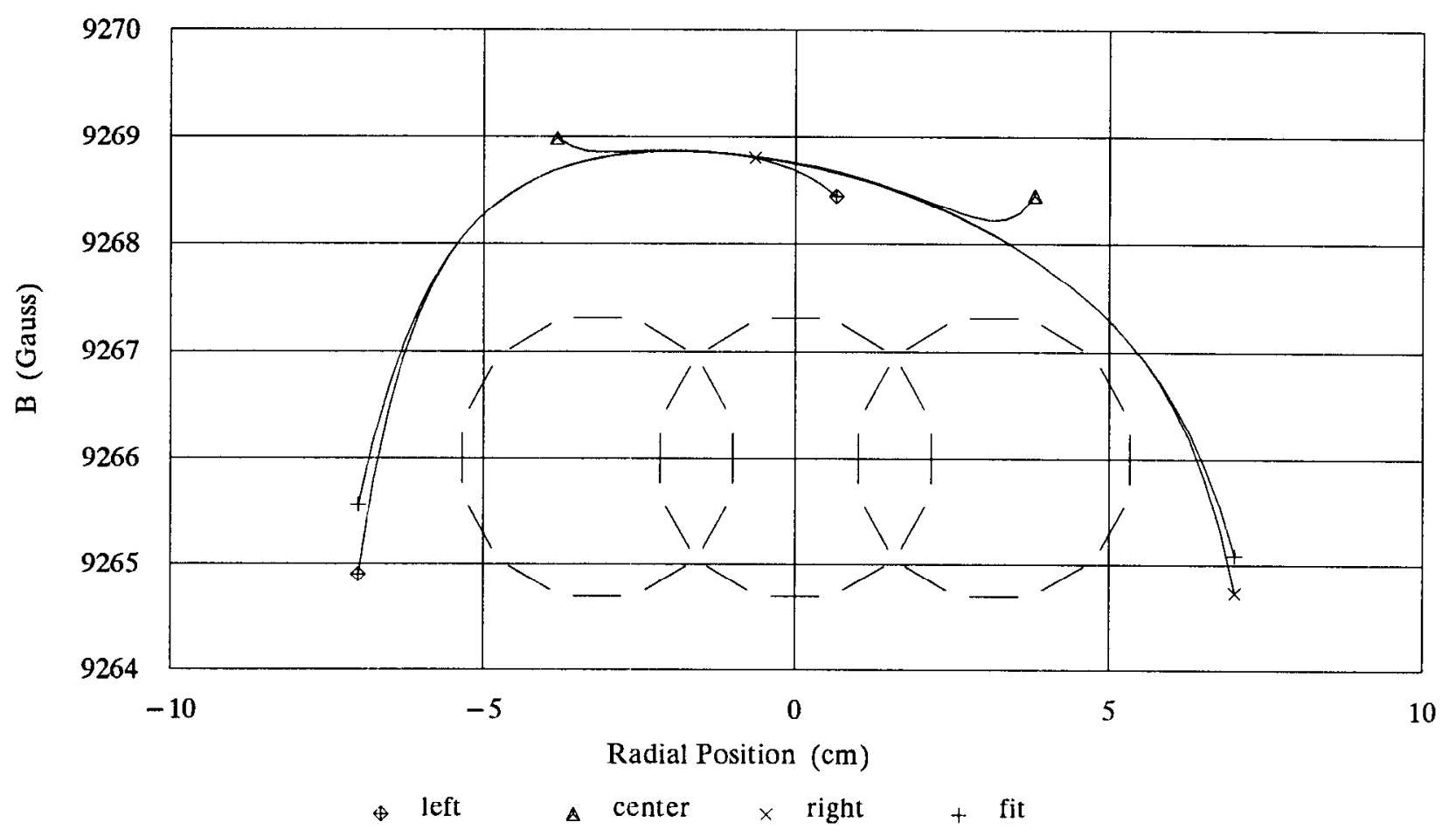

Figure B5. The result of the fit combining the data from all three coil positions.

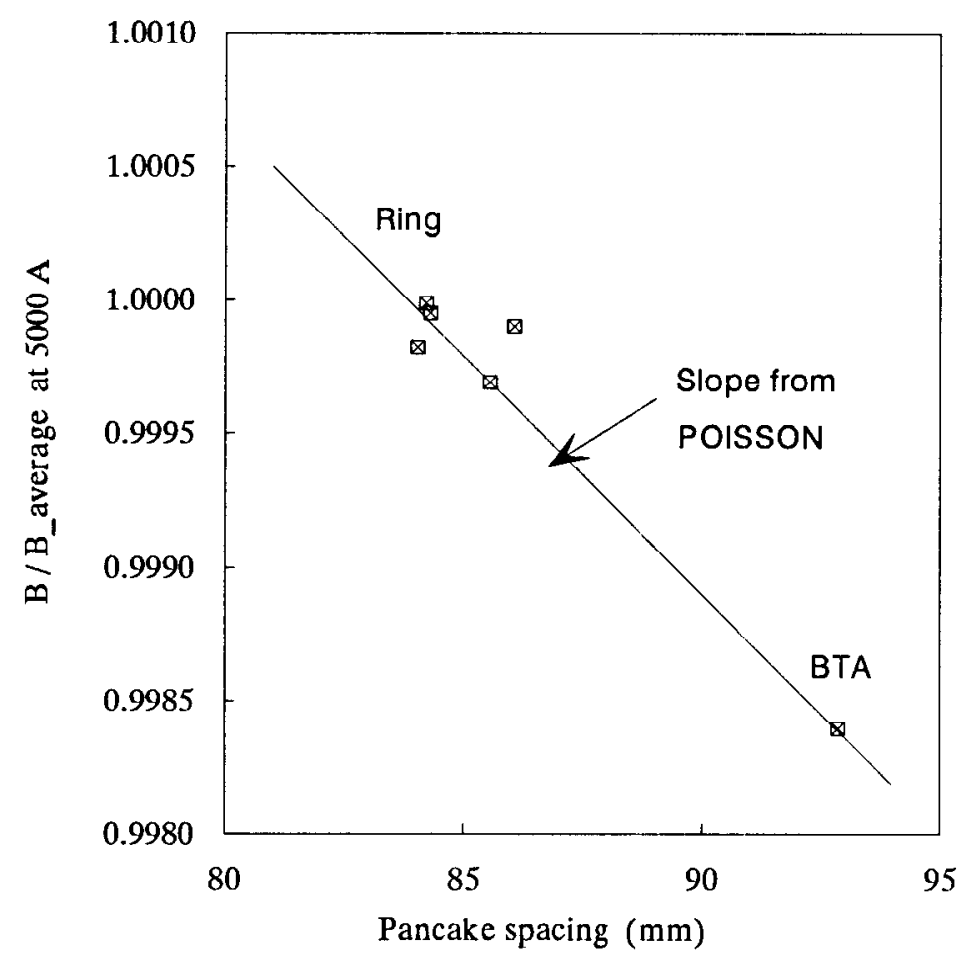

Figure $\mathrm{C}_{1}$. Correlation between upper and lower pancake spacing, and the field at $5000 \mathrm{~A}$, for ring dipoles and a BTA dipole. The slope of the line is calculated using POISSON. 


\section{APPENDIX E. STANDARD REPORT}

A standard report will be generated and permanently stored for each magnet. Two examples are appended here-the first is a sample for a typical magnet (BMD033), and the second is for a fictitious magnet, formed by averaging the data from most of the measurements.

It should be noted that all the data are available as computer files from the author or from the other sources mentioned in Appendix A. The data in these files have more precision and higher harmonics (up to $b_{10}$ ) than the printed standard report.

\section{ACKNOWLEDGMENTS}

The program to individually test each Booster magnet has required the efforts and talents of many people over several years. The measurements were carried out by the Testing and Measuring Group of the Accelerator Development Division under the guidance of Erich Willen and Peter Wanderer. The excellent performance of the system is due to the efforts of George Ganetis, Carl Schultheiss, and Rich Hogue, with physics questions answered by John Herrera. The daily work of hooking up the magnets and doing the measurements has been the task of Rich Riesen and Andy Sauerwald. Barb Smith has been analyst and librarian for the many megabytes of data files.

The very good performance and uniformity of the magnets is due to the design work of Gordon Danby and John Jackson ${ }^{7}$, and the engineering and construction under the guidance of Rudy Damm, John Koehler, Gene Kelly, and Bill Stokes.

The particular analysis in this note, and the conclusions drawn herein, are the responsibility of the author alone, and for the most part represent his sole contribution to this effort.

\section{REFERENCES}

1. J. Herrera et. al., Measurement of the Magnetic Field Coefficients of Particle Accelerator Magnets, BNL 41897, 1989.

2. E. Willen, P. Dahl and J. Herrera, Superconducting Magnets, BNL 39684, 1985.

3. W. H. Press et. al., Numerical Recipes: The Art of Scientific Computing (Cambridge: Cambridge University Press, 1986), Chapter 3.

4. J. Koehler, Private Communication.

5. A. Ruggiero, Memo to W. Weng, 1/23/90.

6. M. Goldman, Private Communication.

7. G. Danby et. al., AGS Booster Prototype Magnets, Proceedings of the 1987 IEEE Particle Accelerator Conference, p. 1422. 


\section{Booster Dipole: BMD033 run* 02}

SOURCE OF REPORT: F:MAGMEASIDIPOLE.WK3 10-Mar-91 00:57:18 SHEET 19

\section{INTRODUCTION AND DEFINITIONS}

The midplane fields are: $B_{x}=A_{0}+A_{1} x+A_{2} x^{2}+\ldots, B_{y}=B_{0}+B_{1} x+B_{2} x^{2}+\ldots$

"MIDDLE OF MAGNET" refers to measurements centered lengthwise in the iron, away from the ends.

"ENTIRE MAGNET" refers to measurements along the entire length of the magnet, including the fringe field. These are either made directly with the long coil, or synthesized from several short coil measurements.

The MAGNETIC LENGTH is taken by definition to be $2.42 \mathrm{~m}=95.2756 \mathrm{in}$. This is a rounded figure which is close to the average of integral $(B \mathrm{dl}) / \mathrm{B}_{\text {middle }}$ at $2600 \mathrm{~A}$.

"AVERAGE" refers to the average of the short coil data over all the measured magnets.

Absolute measurements of the dipole angle are not available; the data for each magnet have been rotated so that $\left\langle A_{0} / B_{0}\right\rangle=0$.

Calibration factors - - NMR: 1.00000 Short coil: 0.99425 Long coil: 1.00482

\section{DIPOLE TRANSFER FUNCTION AND SATURATION SUMMARY}

[ ] = deviations from average of all magnets, in parts per $10^{4}$

NMR Measurement:

$\mathrm{B}_{0} / 1 @ 3000 \mathrm{~A}$

Long Coil Meas:

$B_{0} / I @ 2600 A$

Short Coil Meas:

$B_{0} / 1 @ 600 A$

$B_{0} / 1 @ 2600 A$

$B_{0} / 1 @ 5000 A$

Saturation (2600/5000):

Residual Fields:

\section{FIELD SHAPE SUMMARY}

Deviations from central field, in parts per $10^{4}$

\begin{tabular}{|c|c|c|c|c|c|c|c|c|c|}
\hline \multirow{3}{*}{$\begin{array}{l}\text { This magnet as } \\
\text { measured: }\end{array}$} & \multirow{2}{*}{$\begin{array}{c}\text { Current } \\
\text { (A) }\end{array}$} & \multicolumn{4}{|c|}{$\begin{array}{l}\text { ENTIRE MAGNET } \\
\text { radial position in } \mathrm{cm}\end{array}$} & \multicolumn{4}{|c|}{$\begin{array}{l}\text { MIDDLE OF MAGNET } \\
\text { radial position in } \mathrm{cm}\end{array}$} \\
\hline & & -5.0 & & 2.5 & 5.0 & -5.0 & & & 5.0 \\
\hline & & $\begin{array}{r}-3.8 \\
-4.6 \\
-21.6\end{array}$ & & $\begin{array}{l}-2.8 \\
-2.9 \\
-5.5\end{array}$ & $\begin{array}{r}-8.5 \\
-9.2 \\
-24.4\end{array}$ & $\begin{array}{r}1.5 \\
1.3 \\
-11.0\end{array}$ & $\begin{array}{r}0.4 \\
0.3 \\
-1.5\end{array}$ & $\begin{array}{l}-0.2 \\
-0.3 \\
-2.3\end{array}$ & $\begin{array}{r}0.4 \\
0.1 \\
-12.0\end{array}$ \\
\hline $\begin{array}{l}\text { agnet with b1 } \\
\text { nd b2 removed: }\end{array}$ & $\begin{array}{r}600 \\
2600 \\
5000\end{array}$ & $\begin{array}{l}-0.6 \\
-0.8 \\
-7.4\end{array}$ & $\begin{array}{l}-0.1 \\
-0.1 \\
-0.4\end{array}$ & $\begin{array}{r}0.0 \\
-0.0 \\
-0.3\end{array}$ & $\begin{array}{r}0.1 \\
-0.1 \\
-5.7\end{array}$ & $\begin{array}{r}0.7 \\
0.7 \\
-5.4\end{array}$ & $\begin{array}{r}0 . \\
0 . \\
-0 .\end{array}$ & $\begin{array}{r}0 . \\
0 . \\
-0\end{array}$ & $\begin{array}{r}0.8 \\
0.7 \\
-4.8\end{array}$ \\
\hline RAGE b1 & $\begin{array}{r}600 \\
2600 \\
5000 \\
\end{array}$ & $\begin{array}{l}-0.2 \\
-0.5 \\
-7.1\end{array}$ & $\begin{array}{r}0.2 \\
0.2 \\
-0.2 \\
\end{array}$ & $\begin{array}{l}-0.5 \\
-0.5 \\
-0.8\end{array}$ & $\begin{array}{l}-1.0 \\
-1.3 \\
-6.8 \\
\end{array}$ & $\begin{array}{r}0.8 \\
0.7 \\
-5.2 \\
\end{array}$ & $\begin{array}{r}0.0 \\
0.0 \\
-0.2 \\
\end{array}$ & $\begin{array}{r}0.0 \\
0.0 \\
-0.3 \\
\end{array}$ & $\begin{array}{r}0.8 \\
0.7 \\
-4.8 \\
\end{array}$ \\
\hline
\end{tabular}

\section{ENTIRE MAGNET}

MIDDLE OF MAGNET

$$
2.42930[0.23] \text { G/A }
$$

$$
\begin{aligned}
& 2.42967 \text { [ -1.54] }
\end{aligned}
$$

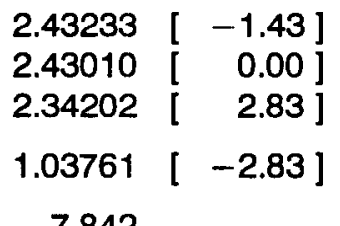$$
\text { G/A }
$$

2.43074

2.43004

2.36605

$1.02704[-2.39]$

7.814

$$
\left.\begin{array}{r}
-1.49] \\
-0.33] \\
2.07 \\
-2.39
\end{array}\right]
$$$$
G / A
$$

G 


\section{Booster Dipole: BMD033 run\# 02}

p. 2

\section{SUMMARY OF HARMONIC CONTENT}

Units are Gauss and $\mathrm{cm}^{-n}$.

For allowed harmonics, [ ] is the ratio with average of all magnets

\section{ENTIRE MAGNET}

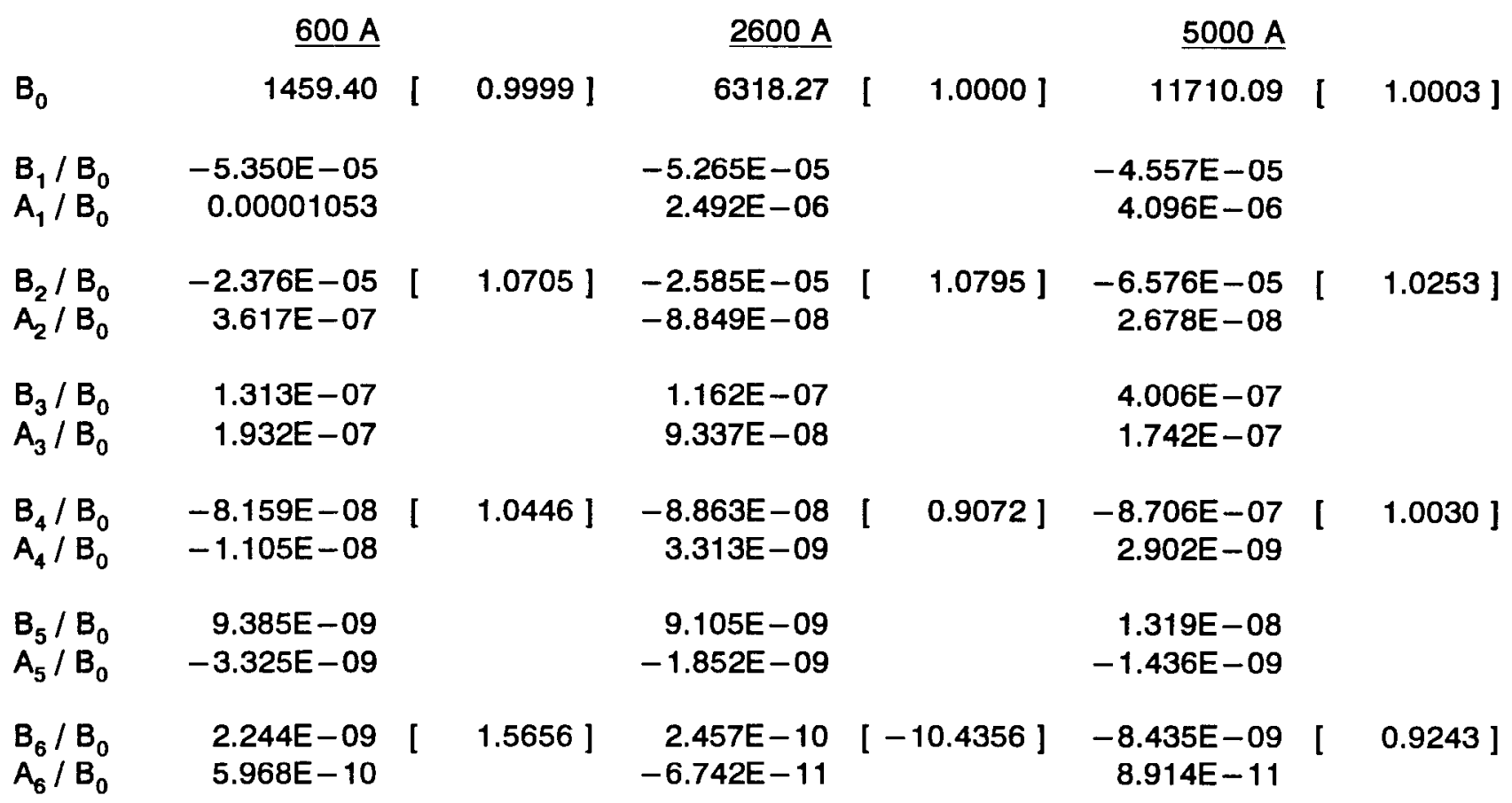

\section{MIDDLE OF MAGNET}

\begin{tabular}{|c|c|c|c|c|c|c|c|c|c|}
\hline & $600 \mathrm{~A}$ & & & $\underline{2600 \mathrm{~A}}$ & & & $5000 \mathrm{~A}$ & & \\
\hline$B_{0}$ & 1458.44 & [ & 0.9999 ] & 6318.09 & [ & $1.0000]$ & 11830.25 & [ & $1.0002]$ \\
\hline $\begin{array}{l}B_{1} / B_{0} \\
A_{1} / B_{0}\end{array}$ & $\begin{array}{l}-1.188 E-05 \\
-7.213 E-08\end{array}$ & & & $\begin{array}{l}-1.139 E-05 \\
-2.750 E-07\end{array}$ & & & $\begin{array}{r}-1.615 E-05 \\
6.960 E-07\end{array}$ & & \\
\hline $\begin{array}{l}B_{2} / B_{0} \\
A_{2} / B_{0}\end{array}$ & $\begin{array}{r}7.584 E-07 \\
-1.767 E-07\end{array}$ & [ & $1.0496]$ & $\begin{array}{r}3.414 E-08 \\
-2.873 E-07\end{array}$ & [ & $-0.4384]$ & $\begin{array}{l}-2.561 E-05 \\
-2.909 E-07\end{array}$ & [ & 0.9888 ] \\
\hline $\begin{array}{l}B_{3} / B_{0} \\
A_{3} / B_{0}\end{array}$ & $\begin{array}{r}-1.280 E-08 \\
3.392 E-08\end{array}$ & & & $\begin{array}{r}-4.712 E-08 \\
1.593 E-08\end{array}$ & & & $\begin{array}{l}2.850 E-08 \\
7.433 E-08\end{array}$ & & \\
\hline $\begin{array}{l}B_{4} / B_{0} \\
A_{4} / B_{0}\end{array}$ & $\begin{array}{r}6.087 E-08 \\
-3.018 E-09\end{array}$ & [ & 1.0408 ] & $\begin{array}{r}6.239 E-08 \\
-1.843 E-09\end{array}$ & [ & $1.0141]$ & $\begin{array}{l}-6.304 E-07 \\
-1.131 E-09\end{array}$ & [ & 1.0163 ] \\
\hline $\begin{array}{l}B_{5} / B_{0} \\
A_{5} / B_{0}\end{array}$ & $\begin{array}{r}7.528 E-10 \\
-1.135 E-09\end{array}$ & & & $\begin{array}{r}1.912 E-09 \\
-1.890 E-10\end{array}$ & & & $\begin{array}{l}7.818 E-09 \\
3.814 E-10\end{array}$ & & \\
\hline $\begin{array}{l}\mathrm{B}_{6} / \mathrm{B}_{0} \\
\mathrm{~A}_{6} / \mathrm{B}_{0}\end{array}$ & $\begin{array}{l}3.507 E-09 \\
2.086 E-10\end{array}$ & [ & $0.9879]$ & $\begin{array}{l}2.284 E-09 \\
7.180 E-11\end{array}$ & [ & 0.9691 ] & $\begin{array}{l}-7.825 E-09 \\
-1.476 E-11\end{array}$ & [ & $0.9651]$ \\
\hline
\end{tabular}


MEASUREMENT RESULTS (Absolute) for ENTIRE MAGNET (Gauss at $1 \mathrm{~cm}$ )

NORMAL FIELDS:

\begin{tabular}{|c|c|c|c|c|c|c|c|c|}
\hline & $I(A)$ & $\mathrm{B}_{0}$ & $B_{1}$ & $B_{2}$ & $B_{3}$ & $B_{4}$ & $B_{5}$ & B \\
\hline 1 & 0 & 7.84 & $-7.646 E-04$ & 1.899E-03 & $-1.166 E-05$ & $3.752 \mathrm{E}-06$ & $8.137 E-07$ & 719E-07 \\
\hline 2 & 50 & 127.61 & $-6.723 E-03$ & $-1.459 E-03$ & $-5.940 E-06$ & $-4.061 E-06$ & $1.617 E-06$ & $3.200 E-07$ \\
\hline 3 & 100 & 248.00 & $-1.326 E-02$ & $-4.804 E-03$ & $8.248 E-06$ & $-6.920 E-06$ & 21E-06 & 93E-07 \\
\hline 4 & 200 & 39.26 & $-2.614 E-02$ & $-1.104 E-02$ & $.095 E-05$ & $-2.979 E-05$ & 4.333E-06 & $1.090 E-06$ \\
\hline 5 & 400 & 973.61 & $-5.210 E-02$ & $-2.308 E-02$ & 1.501E-04 & $-6.865 E-05$ & 7.300E-06 & $1.989 E-06$ \\
\hline 6 & 600 & 1459.40 & $-7.808 E-02$ & $-3.467 E-02$ & $1.916 E-04$ & $-1.191 E-04$ & $1.370 E-05$ & $3.275 E-06$ \\
\hline 7 & 800 & 1945.75 & $-1.037 E-01$ & $-4.630 \mathrm{E}-02$ & $2.102 \mathrm{E}-04$ & $-1.445 E-04$ & 1.924E-05 & 3.173E-06 \\
\hline 8 & 1000 & 2432.30 & $-1.300 E-01$ & $-5.763 E-02$ & $2.813 E-04$ & $-2.025 E-04$ & $2.220 E-05$ & $4.670 E-06$ \\
\hline 9 & 1400 & 3405.22 & $-1.825 E-01$ & $-8.152 \mathrm{E}-02$ & 3.420E-04 & $-2.752 E-04$ & 3.303E-05 & 5.450 \\
\hline 10 & 1800 & 4377.31 & $-2.343 E-01$ & $-1.069 E-01$ & $4.116 E-04$ & $-3.282 \mathcal{E}-04$ & $4.220 E-05$ & 4.87 \\
\hline 11 & 2200 & 48.73 & $-2.856 E-01$ & $-1.336 E-01$ & $5.849 E-04$ & $-4.120 E-04$ & 4.765E-05 & 3.50 \\
\hline 12 & 2600 & 27 & $7 E-01$ & -1.634 & -04 & $-5.600 E-04$ & $=-05$ & 1.55 \\
\hline 13 & 3000 & .79 & $-3.750 E-01$ & -1.5 & $\mathrm{E}-03$ & $3 E-04$ & -05 & -5.710 \\
\hline 14 & 3400 & 8245.17 & $-4.143 E-01$ & $-2.432 E-01$ & -03 & $E-03$ & -05 & -06 \\
\hline 15 & 3800 & 9194.34 & $-4.482 \mathrm{E}-01$ & $-3.060 E-01$ & $2.326 E-03$ & $-2.245 E-03$ & -05 & -2.23 \\
\hline 16 & 4000 & 9661.42 & $-4.621 E-01$ & $-3.478 E-01$ & $2.780 E-03$ & $-2.903 E-03$ & -05 & -3.13 \\
\hline 17 & 4200 & 10118.91 & $-4.761 E-01$ & $-4.005 E-01$ & $3.253 E-03$ & $-3.779 E-03$ & $1.115 E-04$ & -4.377 \\
\hline 18 & 4400 & 10560.16 & $-4.886 E-01$ & $-4.672 \mathbb{E}-01$ & $3.688 E-03$ & $-4.986 E-03$ & 1.210 & $-6.062 \mathrm{E}-05$ \\
\hline 19 & 4600 & 75.94 & $-5.022 E-01$ & $-5.506 \mathrm{E}-01$ & 4.138E-03 & 20E-03 & -04 & -7.71 \\
\hline 20 & 4800 & 11358.90 & -5.17 & $-6.515 E-01$ & $4.500 E-03$ & $-8.306 E-03$ & $E-04$ & $-9.055 E-05$ \\
\hline 21 & 5000 & 11710.09 & $-5.336 E-01$ & $-7.701 E-01$ & $4.691 \mathrm{E}-03$ & $-1.020 E-02$ & $1.544 E-04$ & $-9.877 E-05$ \\
\hline
\end{tabular}

\begin{tabular}{|c|c|c|c|c|c|c|c|c|}
\hline \multicolumn{9}{|c|}{ SKEW FIELDS: } \\
\hline & I (A) & $A_{0}$ & $A_{1}$ & $A_{2}$ & $A_{3}$ & $A_{4}$ & $A_{5}$ & $A_{6}$ \\
\hline 1 & 0 & 0.06 & $1.831 E-02$ & $2.946 \mathrm{E}-05$ & $-4.989 \mathrm{E}-05$ & $-6.681 E-06$ & $2.659 E-06$ & $6.011 E-07$ \\
\hline 2 & 50 & 0.07 & $1.818 E-02$ & 2.287E-04 & $6.225 E-06$ & $-1.363 E-05$ & $6.995 E-07$ & $4.964 E-07$ \\
\hline 3 & 100 & 0.03 & $1.775 E-02$ & $2.265 E-04$ & $4.735 E-05$ & $-3.364 E-06$ & $-8.498 E-07$ & $-1.564 E-07$ \\
\hline 4 & 200 & 0.25 & $1.818 E-02$ & $4.186 E-04$ & 5.412 E-05 & $-1.516 E-05$ & $3.846 \mathrm{E}-07$ & $6.308 \mathrm{E}-07$ \\
\hline 5 & 400 & 0.02 & 1.732 E-02 & $4.619 E-04$ & $1.481 E-04$ & $-1.821 E-05$ & $-1.523 E-06$ & $8.998 E-07$ \\
\hline 6 & 600 & -0.11 & $1.536 E-02$ & $5.278 E-04$ & $2.820 E-04$ & $-1.613 E-05$ & $-4.852 E-06$ & $10 E-07$ \\
\hline 7 & 800 & 0.03 & $1.388 E-02$ & $3.406 E-04$ & $56 E-04$ & $-7.063 E-06$ & $-5.956 E-06$ & 4.983E-07 \\
\hline 8 & 1000 & -0.22 & $1.296 E-02$ & $4.479 E-04$ & OEE-04 & $-2.850 E-06$ & $-5.729 E-06$ & $21 E-07$ \\
\hline 9 & 1400 & -0.29 & $\pi E-02$ & $3.325 E-04$ & $70 E-04$ & $30 E-06$ & $-1.170 E-05$ & D9E-07 \\
\hline 10 & 1800 & -0.36 & $1.078 E-02$ & 1.764E-04 & $5.735 E-04$ & $-8.266 E-07$ & $979 E-06$ & $26 E-08$ \\
\hline 11 & 2200 & -0.25 & $1.395 E-02$ & $-5.651 E-05$ & $5.138 E-04$ & 5.132E-06 & $-6.371 E-06$ & $71 E-08$ \\
\hline 12 & 2600 & -0.44 & $1.574 E-02$ & $-5.591 E-04$ & $5.900 E-04$ & $2.094 E-05$ & $-1.170 E-05$ & $-4.260 E-07$ \\
\hline 13 & 3000 & -0.46 & $1.712 \mathbb{E}-02$ & $-5.109 E-04$ & $6.716 E-04$ & $-2.076 E-07$ & $-1.259 E-05$ & $1.157 E-06$ \\
\hline 14 & 3400 & -0.73 & $2.013 E-02$ & $-8.760 E-04$ & 7.469E-04 & $1.725 E-05$ & $-1.362 E-05$ & $4.384 E-07$ \\
\hline 15 & 3800 & -0.73 & $4 E-02$ & -9 . & $E-04$ & 4E-06 & $-1.314 E-05$ & $1.122 \mathrm{E}-06$ \\
\hline 16 & 4000 & -0 & $1.992 \mathbf{E}-02$ & $-9.262 \pm-04$ & XE-03 & SOE -05 & OE-05 & $7.522 \mathrm{E}-07$ \\
\hline 17 & 4200 & -0.92 & $2.078 E-02$ & $3 E-04$ & $2 E-03$ & $9 E-06$ & $39 E-05$ & $75 E-06$ \\
\hline 18 & 4400 & -0.96 & $2.311 E-02$ & $-9.058 E-04$ & $1.335 E-03$ & $5.643 E-06$ & $-1.429 E-05$ & $1.349 E-06$ \\
\hline 19 & 4600 & -1.00 & $2.77 \not \mathbb{E}-02$ & $-7.076 E-04$ & 1.533E-03 & $6.085 E-06$ & $-1.403 E-05$ & $1.704 E-06$ \\
\hline 20 & 4800 & -0.93 & $3.668 E-02$ & $-6.266 E-04$ & $1.728 E-03$ & $4.922 \approx-05$ & $-1.270 E-05$ & $2.367 \mathrm{E}-07$ \\
\hline 21 & 5000 & -0.94 & 4.797E-02 & $3.136 E-04$ & $2.040 E-03$ & $3.398 E-05$ & $-1.681 E-05$ & $1.044 E-06$ \\
\hline
\end{tabular}


MEASUREMENT RESULTS (normalized to $B_{0}$ ) for ENTIRE MAGNET (at $1 \mathrm{~cm}$ )

NORMAL FIELDS:

\begin{tabular}{|c|c|c|c|c|c|c|c|c|}
\hline & $I(A)$ & $B_{0} / I$ & $B_{1} / B_{0}$ & $\mathrm{~B}_{2} / \mathrm{B}_{0}$ & $B_{3} / B_{0}$ & $B_{4} / B_{0}$ & $B_{5} / B_{0}$ & $B_{6} / B_{0}$ \\
\hline 1 & 0 & & $9.751 \mathrm{E}-05$ & $2.422 \mathrm{E}-04$ & $-1.487 \bar{E}-06$ & $4.785 E-07$ & $1.038 E-07$ & $2.193 E-08$ \\
\hline 2 & 50 & 216 & $-5.269 E-05$ & $-1.144 E-05$ & $-4.655 E-08$ & $-3.182 E-08$ & $1.267 E-08$ & 508E-0 \\
\hline 3 & 100 & 203 & -5.349E-05 & $-1.937 E-05$ & $3.326 E-08$ & $-2.790 E-08$ & 1.379E-08 & $:-10$ \\
\hline 4 & 200 & 632 & $-5.344 E-05$ & $-2.256 E-05$ & $1.246 E-07$ & $-6.088 E-0$ & 8.856E & $c<1$ \\
\hline 5 & 400 & 403 & $-5.351 E-05$ & $-2.371 E-05$ & $1.54 \mathfrak{X}-07$ & $-7.051 E-08$ & 7.497E-09 & .09 \\
\hline 6 & 600 & 233 & $-5.350 E-05$ & $-2.376 E-05$ & 1.313E -07 & $-8.159 E-08$ & $9.385 E-09$ & $2.244 E$ \\
\hline 7 & 800 & 3219 & $-5.332 E-05$ & $-2.380 E-05$ & $1.080 E-07$ & $-7.427 E-08$ & 9.887E-09 & $1.631 \mathrm{E}$ \\
\hline 8 & 1000 & & 46E-05 & $-2.369 E-05$ & 57E-07 & $-8.325 E-08$ & $9.128 E-09$ & $1.920 E-09$ \\
\hline 9 & 1400 & 230 & $-5.360 E-05$ & $-2.394 E-05$ & $1.004 E-07$ & $-8.081 E-08$ & 9.699E-09 & $1.600 E-09$ \\
\hline 10 & 1800 & 2.43184 & $-5.354 E-05$ & $-2.442 \mathrm{E}-05$ & $9.402 E-08$ & $-7.498 E-08$ & $9.640 E-09$ & $1.114 E-09$ \\
\hline 11 & 2200 & 2.43124 & $-5.339 E-05$ & $-2.498 E-05$ & $1.094 E-07$ & $-7.702 E-08$ & 8.908E-09 & $6.544 E-10$ \\
\hline 12 & 2600 & 2.43010 & $-5.265 E-05$ & $-2.585 E-05$ & $1.162 \mathrm{E}-07$ & $-8.863 E-08$ & $9.105 E-09$ & $2.457 E-10$ \\
\hline 13 & 3000 & & $-5.147 E$ & $-2.715 E-05$ & $1.407 E-07$ & $-1.202 E-07$ & $9.330 E-09$ & $-7.838 E-11$ \\
\hline 14 & 3400 & 2.42505 & $-5.025 E-05$ & $-2.950 E-05$ & 1.917E-07 & EE-07 & $9.345 E-09$ & $-1.056 E-09$ \\
\hline 15 & 3800 & & $4 E-05$ & $-3.328 E$ & E-07 & -07 & -09 & -09 \\
\hline 10 & 4000 & 535 & $-4.783 E-05$ & $-3.600 E-05$ & $E-07$ & $\mathrm{E}-07$ & $1.024 E-08$ & $-3.249 E-09$ \\
\hline 17 & 4200 & & $5 E-05$ & $-3.958 E-$ & $E-07$ & -3.7 & $1.101 \mathrm{E}$ & -4 \\
\hline 18 & 4400 & 1004 & $-4.627 E-05$ & $-4.424 E-05$ & 3.492E-07 & $E-07$ & $1.146 E-08$ & -5 \\
\hline 19 & 4600 & 2.38607 & $-4.575 E-05$ & $-5.016 E-05$ & $3.770 E-07$ & $E-07$ & $1.158 E-08$ & $-7.027 \mathrm{E}$ \\
\hline 20 & 4800 & 2.36644 & $-4.552 E-05$ & $-5.736 E-05$ & 3.962Е-07 & $-7.312 \mathrm{E}-07$ & $1.214 \mathrm{E}$ & $-7.972 E-09$ \\
\hline 21 & 5000 & 2.34202 & $-4.557 E-05$ & $-6.576 E-05$ & 4.006E-07 & $-8.706 E-07$ & 1.319E-08 & $-8.435 E-09$ \\
\hline \multirow{2}{*}{\multicolumn{3}{|c|}{$\begin{array}{l}\text { AVG.: }(600 \text { to } 3400 \mathrm{~A}) \\
\text { STD. DEVIATION: }\end{array}$}} & $-5.280 E-$ & $-2.523 E$ & 1.230E-07 & -9.2 & 9.38 & 9.19 \\
\hline & & & & & $2.780 E-08$ & & & $1.010 E-0$ \\
\hline
\end{tabular}

SKEW FIELDS:

\begin{tabular}{|c|c|c|c|c|c|c|c|c|}
\hline & $I(A)$ & $A_{0} / B_{0}$ & $A_{1} / B_{0}$ & $\mathrm{~A}_{2} / \mathrm{B}_{0}$ & $A_{3} / B_{0}$ & $\mathrm{~A}_{4} / \mathrm{B}_{0}$ & $A_{5} / B_{0}$ & $A_{6} / B_{0}$ \\
\hline 1 & 0 & 0.00738 & $2.335 E-03$ & $3.757 E-06$ & $-6.362 \mathrm{E}-06$ & $-8.521 E-07$ & $3.391 E-07$ & $7.665 E-08$ \\
\hline 2 & 50 & 0.00054 & 425E- & $1.79 \not \mathbf{E}-06$ & 4.878E-08 & $-1.068 E-07$ & 82E-09 & 3.890E-09 \\
\hline 3 & 100 & 0.00012 & $157 E-05$ & 134E-07 & DSE- & $.356 E-08$ & $-3.426 E-09$ & 10 \\
\hline 4 & 200 & & & $6 E-07$ & & & 10 & -09 \\
\hline 5 & 400 & 0.00002 & $E-05$ & $4 E-07$ & ZE-07 & $1 E-08$ & & -10 \\
\hline 6 & 600 & -0.00 & $3 E-05$ & $7 E-07$ & |32E -07 & $-1.105 E-08$ & $-3.325 E-09$ & $5.968 E-10$ \\
\hline 7 & 800 & 0.0 & $2 E-06$ & $1 E-07$ & $1.828 E-07$ & $-3.630 E-09$ & $-3.061 E-09$ & $2.561 E-10$ \\
\hline 8 & 1000 & -0.0 & $329 E-06$ & & $9 E-07$ & XE-09 & SE-09 & $09 E-11$ \\
\hline & 1400 & $-0 . c$ & $=-06$ & 9.7 & -07 & $\mathbf{E}-09$ & -3. & $E-11$ \\
\hline & 1800 & -0.0 & 2.464E-06 & $4.029 E-08$ & $E-07$ & $-1.888 E-10$ & $-2.280 E$ & $31 E-11$ \\
\hline & 2200 & -0.0 & $2.608 E-06$ & $-1.057 E-08$ & $55 E-08$ & -10 & -1.19 & $-7.050 E-12$ \\
\hline & 2600 & -0.00 & 2.492E-06 & $-8.849 E-08$ & -08 & $3.313 E$ & $-1.852 \mathrm{~F}$ & $-6.742 E-11$ \\
\hline & 3000 & -0.0 & 2.350E-06 & -7.01 & -08 & $-2.849 E-11$ & $-1.729 E-09$ & $1.588 \mathrm{E}-10$ \\
\hline & 3400 & & -06 & -1.0 & & -09 & -1.6 & 5.317E \\
\hline & 3800 & & -06 & -07 & -08 & -10 & -1 & -10 \\
\hline & 4000 & & 2.0 & & & & & -11 \\
\hline & 4200 & & & -8. & & 10 & -1 & -10 \\
\hline & 4400 & -0.0 & $E-06$ & $3 E-08$ & -07 & 5.34 & $-1.353 E$ & -10 \\
\hline & 4600 & -0.0 & $2.525 E-06$ & $-6.447 E-08$ & $=07$ & $=-10$ & $-1.278 E-09$ & $1.552 \mathrm{E}$ \\
\hline & 4800 & & 3.230 & -5.51 & & $E-09$ & $-1.118 E$ & $2.084 E-11$ \\
\hline & & & 4.000 & -00 & -07 & $E-09$ & SE-09 & $8.914 E-11$ \\
\hline \multirow{2}{*}{\multicolumn{3}{|c|}{$\begin{array}{l}\text { VG.: (600 to } 3400 \\
\text { TTD. DEVIATION: }\end{array}$}} & & & & 9 & -2.3 & \\
\hline & & & & סדים & T.000 - & & $7.524 E-10$ & $1.915 E-10$ \\
\hline
\end{tabular}




\section{Booster Dipole: BMD033 run\# 02}

MEASUREMENT RESULTS (Absolute) for MIDDLE OF MAGNET (Gauss at $1 \mathrm{~cm}$ ) NORMAL FIELDS:

\begin{tabular}{|c|c|c|c|c|c|c|c|c|}
\hline & $I(A)$ & $\mathrm{B}_{0}$ & $B_{1}$ & $B_{2}$ & $\mathrm{~B}_{3}$ & $\mathrm{~B}_{4}$ & $B_{5}$ & $B_{8}$ \\
\hline 1 & 0 & 7.81 & $-1.834 E-04$ & $2.465 E-03$ & $-3.394 E-05$ & 5.405E-06 & $1.696 E-06$ & $6.983 E-08$ \\
\hline 2 & 50 & 127.47 & $-1.524 E-03$ & $1.967 E-03$ & $-3.506 E-05$ & $8.320 E-06$ & $9.992 \mathbf{E}-07$ & 5.847E-07 \\
\hline 3 & 100 & 247.93 & $-3.208 E-03$ & $1.532 \mathrm{E}-03$ & $-3.650 E-05$ & 2.287E-05 & $2.071 E-06$ & $6.910 E-07$ \\
\hline 4 & 200 & 489.10 & $-6.077 \mathrm{E}-03$ & $1.229 E-03$ & $-5.925 E-06$ & $3.109 E-05$ & $-7.617 E-07$ & 1.727E-06 \\
\hline 5 & 400 & 973.02 & $-1.191 E-02$ & $9.811 E-04$ & $-2.860 E-05$ & $5.764 E-05$ & $1.118 E-06$ & $3.539 E-06$ \\
\hline 6 & 600 & 1458.44 & $-1.733 E-02$ & $1.106 E-03$ & $-1.867 \mathrm{E}-05$ & $8.878 E-05$ & $1.098 E-06$ & $5.114 \mathrm{E}-06$ \\
\hline 7 & 800 & 1944.51 & $-2.284 E-02$ & $1.391 E-03$ & $-7.655 E-05$ & $1.311 E-04$ & $4.761 E-06$ & 5.862F-06 \\
\hline 8 & 1000 & 2430.79 & $-2.838 E-02$ & $1.834 E-03$ & $-3.089 E-05$ & $1.608 E-04$ & $1.930 E-06$ & $7.355 E-06$ \\
\hline 9 & 1400 & 3403.45 & $-3.908 E-02$ & 2.364E-03 & $-1.048 E-04$ & $2.194 E-04$ & $6.898 \mathrm{E}$ & $1.037 E-05$ \\
\hline 0 & 1800 & 4375.39 & $-4.96 \not{E}-02$ & 2.390E-03 & $-1.727 E-04$ & $2.932 \mathrm{E}-04$ & $8.656 E-06$ & $1.231 E-05$ \\
\hline & 2200 & 5347.24 & $-6.065 E-02$ & $1.810 E-03$ & $-2.658 E-04$ & $3.573 E-04$ & $1.151 E-05$ & $1.352 F-05$ \\
\hline 2 & 2600 & 6318.09 & $-7.198 E-02$ & $2.157 E-04$ & $-2.977 E-04$ & $3.942 E-04$ & -05 & $1.443 E-05$ \\
\hline 3 & 3000 & 7287.35 & $-8.424 E-02$ & $-2.971 E-03$ & $-3.361 E-04$ & $3.281 E-04$ & $1.572 \mathrm{E}-05$ & $1.488 E-05$ \\
\hline 4 & 3400 & 8253.63 & $-9.817 E-02$ & $-1.102 E-02$ & $-2.813 E-04$ & $1.34 \pi-04$ & -05 & $9.864 E-06$ \\
\hline 5 & 3800 & 9215.45 & $-1.139 E-01$ & $-2.711 E-02$ & $-1.798 E-04$ & $-3.340 E-04$ & $3.105 E$ & $-1.356 E-06$ \\
\hline 16 & 4000 & 9693.24 & $-1.215 E-01$ & $-4.101 E-02$ & $-1.021 E-04$ & $-7.597 E-04$ & 3.623E & $-9.869 E-06$ \\
\hline 17 & 4200 & 10165.12 & $-1.313 E-01$ & $-6.242 E-02$ & $5.617 E-05$ & $-1.396 E-03$ & 4.603E-05 & $-2.309 E-05$ \\
\hline 18 & 4400 & 10624.80 & $-1.414 E-01$ & $-9.601 E-02$ & $1.882 \mathrm{E}-04$ & $-2.398 E-03$ & 5.303E-05 & $-4.285 E-05$ \\
\hline 19 & 4600 & 11061.57 & $-1.541 \mathrm{E}-01$ & $-1.457 E-01$ & $2.765 E-04$ & $-3.777 E-03$ & -05 & $-6.525 E-05$ \\
\hline & 4800 & 11462.99 & $-1.707 E-01$ & $-2.142 \mathbb{E}-01$ & $3.200 E-04$ & $-5.527 E-03$ & $E-05$ & $-8.249 E-05$ \\
\hline & 5000 & 11830.25 & $-1.910 E-01$ & $-3.030 E-01$ & $3.372 \mathrm{E}-04$ & $-7.458 E-03$ & $E-05$ & $-9.258 E-05$ \\
\hline
\end{tabular}

SKEWFIELDS:

\begin{tabular}{|c|c|c|c|c|c|c|c|c|}
\hline & $I(A)$ & $A_{0}$ & $A_{1}$ & $A_{2}$ & $A_{3}$ & $A_{4}$ & $A_{5}$ & $A_{6}$ \\
\hline 1 & 0 & -0.00 & $6.649 E-04$ & $-1.391 E-04$ & $-2.904 E-05$ & 2.483E-06 & $-3.761 E-07$ & $2.335 \mathrm{E}-07$ \\
\hline 2 & 50 & 0.08 & $-2.552 \mathrm{E}-04$ & $1.035 E-04$ & $-1.393 E-05$ & $-1.524 E-05$ & 2.381E-06 & $5.781 \mathrm{E}-07$ \\
\hline 3 & 100 & 0.04 & $-1.019 E-04$ & $-1.569 E-05$ & $-3.200 E-06$ & $3.567 E-06$ & $-3.659 E-07$ & $-5.736 E-07$ \\
\hline 4 & 200 & 0.32 & $4.368 E-04$ & $1.193 E-04$ & $5.270 E-06$ & $-1.693 E-05$ & $3.012 \mathbb{E}-07$ & $6.835 E-07$ \\
\hline 5 & 400 & 0.05 & $4.795 E-04$ & $-1.221 E-04$ & $8.316 E-06$ & $-1.517 E-05$ & $-1.457 E-06$ & $7.043 E-07$ \\
\hline 6 & 600 & -0.26 & $-1.052 \mathbb{E}-04$ & $-2.576 E-04$ & 4.946E-05 & $-4.402 E-06$ & $-1.655 E-06$ & $3.042 E-07$ \\
\hline 7 & 800 & -0.14 & $-7.377 \mathrm{E}-04$ & $-4.909 E-04$ & 7.884E-05 & $-1.087 E-06$ & $-2.187 E-06$ & $-3.348 E-08$ \\
\hline 8 & 1000 & -0.32 & 4.593E-06 & $-5.685 E-04$ & $-4.082 \mathrm{E}-05$ & $4.023 E-06$ & $3.320 E-06$ & $-3.674 E-07$ \\
\hline 9 & 1400 & -0.38 & $-3.948 E-04$ & $-9.021 E-04$ & 5.997E-05 & $-9.066 E-06$ & $-3.446 E-07$ & $5.257 \mathrm{E}-07$ \\
\hline 0 & 1800 & & 2.509E-04 & $-1.094 E$ & 4.739E-06 & $-1.660 E-05$ & 1.240E-06 & $8.520 E-07$ \\
\hline & 2200 & .23 & $-7.631 E-04$ & $-1.591 E-03$ & 1.186E-05 & $-9.442 \mathrm{E}-06$ & -06 & -07 \\
\hline $1 \%$ & 2600 & -0.34 & $-1.738 E-03$ & $-1.815 E-03$ & $1.006 E-04$ & $-1.164 E-05$ & $-1.194 E-06$ & 4.537E-07 \\
\hline 13 & 3000 & -0.47 & $-2.566 E-03$ & $-2.193 E-03$ & $1.452 E-04$ & $-1.419 E-05$ & $-9.114 E-07$ & 3.885 \\
\hline & 3400 & -0.73 & $-2.144 E-03$ & $-2.830 E-03$ & 1.607E-04 & $-1.402 E-05$ & $-1.281 E-06$ & $5.468 \mathrm{E}-07$ \\
\hline 15 & 3800 & -0.77 & $-2.281 E-03$ & $-3.005 E-03$ & $2.488 E-04$ & $-4.296 E-05$ & $-3.633 E-06$ & $1.485 E-06$ \\
\hline 16 & 4000 & -1.08 & $-7.457 E-04$ & $-3.316 E-03$ & $1.588 E-04$ & $-4.577 E-05$ & 2.683E-06 & $1.538 \mathrm{E}-06$ \\
\hline 17 & 4200 & -0.90 & $-9.932 \mathcal{E}-04$ & $-3.856 E-03$ & 2.354E-04 & $-3.408 E-05$ & 3.142E-06 & 7.185E-07 \\
\hline 78 & 4400 & 1.04 & $-7.250 \mathrm{E}-04$ & $-4.327 E-03$ & $3.130 E-04$ & $-3.348 E-05$ & 4.361E-06 & 2.57 \\
\hline 18 & 4600 & -1.01 & $-2.215 E-05$ & $-4.398 E-03$ & $4.336 E-04$ & $-4.153 E-05$ & $6.146 E-06$ & $E-07$ \\
\hline & 4800 & -1.11 & $4.296 \mathrm{E}-03$ & $-4.523 E-03$ & $5.682 E-04$ & 4.941E-06 & $7.662 E-06$ & $-6.828 E-07$ \\
\hline & 5000 & -1.09 & $8.234 E-03$ & $-3.442 \mathrm{E}-03$ & 8.793E-04 & $-1.338 E-05$ & $4.512 \mathrm{E}-06$ & $-1.746 E-07$ \\
\hline
\end{tabular}


MEASUREMENT RESULTS (normalized to $B_{0}$ ) for MIDDLE OF MAGNET (at $1 \mathrm{~cm}$ )

NORMAL FIELDS:

\begin{tabular}{|c|c|c|c|c|c|c|c|c|}
\hline & $I(A)$ & $B_{0} / I$ & $B_{1} / B_{0}$ & $\mathrm{~B}_{2} / \mathrm{B}_{0}$ & $\mathrm{~B}_{3} / \mathrm{B}_{0}$ & $\mathrm{~B}_{4} / \mathrm{B}_{0}$ & $B_{5} / B_{0}$ & $B_{8} / B_{0}$ \\
\hline 1 & 0 & & $2.348 E-05$ & $3.154 E-04$ & $-4.344 E-06$ & $6.917 E-07$ & $2.170 E-07$ & $8.936 E-09$ \\
\hline 2 & 50 & 950 & 1.196E-05 & $1.543 E-05$ & $-2.750 E-07$ & $6.527 E-08$ & $7.839 E-09$ & 4.587E-09 \\
\hline 3 & 100 & & $-1.294 E-05$ & 9EE-0 & $-1.472 E-07$ & $9.223 E-08$ & $355 E-09$ & $2.787 E-09$ \\
\hline 4 & 200 & 548 & $1.243 E-05$ & $2.512 \mathrm{E}-06$ & $-1.211 E-08$ & $6.35 \pi-08$ & $-1.557 \mathrm{E}-09$ & \\
\hline 5 & 400 & 255 & $-1.224 E-05$ & $1.008 E-06$ & $-2.939 E-08$ & $5.924 E-08$ & $1.149 E-09$ & $.637 E-09$ \\
\hline 6 & 600 & 074 & $-1.188 E-05$ & 7.584E-07 & $-1.280 E-08$ & $6.087 E-08$ & $7.528 E-10$ & $3.507 E-09$ \\
\hline 7 & 800 & 064 & 1.175E-05 & $7.15 \not 2 E-07$ & $-3.937 E-08$ & $6.742 E-08$ & 2.449E-09 & $3.015 E-09$ \\
\hline 8 & 1000 & & $7 E-05$ & 4E-07 & 71E-08 & $6.617 E-08$ & $.941 E-10$ & $3.026 E-09$ \\
\hline 9 & 1400 & 104 & $-1.148 E-05$ & $6.946 E-07$ & $8 E-08$ & $6.445 E-08$ & $2.027 E-09$ & $3.048 E-09$ \\
\hline 10 & 1800 & 2.43077 & $-1.134 E-05$ & $5.461 E-07$ & $7 E-08$ & $6.701 E-08$ & $1.978 E-09$ & $2.814 E-09$ \\
\hline 11 & 2200 & 2.43056 & $-1.134 E-05$ & 3.386E-07 & $-4.972 \mathrm{E}-08$ & $6.681 \mathrm{E}-08$ & $2.152 \mathrm{E}-09$ & $2.528 E-09$ \\
\hline 12 & 2600 & 2.43004 & $-1.139 E-05$ & $3.414 E-08$ & $-4.712 E-08$ & $6.239 E-08$ & 1.912 E-09 & $2.284 E-09$ \\
\hline 13 & 3000 & 912 & $-1.15 t$ & $-4.077 E-07$ & $1 E-08$ & $4.502 \mathrm{E}-08$ & $2.157 \mathrm{E}$ & 2.041E-09 \\
\hline 14 & 3400 & 54 & -05 & -06 & $E-08$ & $1.632 \mathrm{E}-08$ & 2.424 & $1.195 E-09$ \\
\hline 15 & 3800 & & $-1.236 E-05$ & $-2.942 E-06$ & $E-08$ & $-3.625 E-08$ & 3.369E-09 & $-1.471 \mathrm{E}$ \\
\hline 16 & 4000 & 2.42 & $-1.254 E-05$ & $-4.231 E-06$ & $-1.053 E-08$ & $-7.838 E$ & 3.737E & $-1.018 E-09$ \\
\hline 17 & 4200 & 2.42027 & $-1.292 \mathrm{E}-05$ & $-6.140 E-06$ & $6 E-09$ & $-1.374 E$ & $4.528 E-09$ & $-2.272 E-09$ \\
\hline 18 & 4400 & 2.41473 & $-1.331 E-05$ & $-9.037 E-06$ & $1.771 E-08$ & $-2.257 E-07$ & 4.991E-09 & $-4.033 E-09$ \\
\hline 19 & 4600 & 2.40469 & $-1.393 E-05$ & $-1.317 E-05$ & $2.500 E-08$ & $-3.415 E-07$ & $5.900 E-09$ & $-5.899 E-09$ \\
\hline 20 & 4800 & 2.38812 & -1.4 & $-1.869 E-05$ & $2.792 \mathrm{E}-08$ & $-4.821 E-07$ & $6.861 E-09$ & $-7.196 E-09$ \\
\hline 21 & 5000 & 2.36605 & -1.615 & $-2.001 \mathrm{IL}-00$ & $2.850 E-08$ & $-6.304 E-07$ & $7.818 E-09$ & $-7.825 E-09$ \\
\hline \multirow{2}{*}{\multicolumn{3}{|c|}{$\begin{array}{l}\text { AVG.: (600 to } 3400 \mathrm{~A}) \\
\text { STD. DEVIATION: }\end{array}$}} & -1.1 & $2.332 E-07$ & -3.4 & & & 2.60 \\
\hline & & & & $6.676 E-07$ & & $1.594 E-08$ & $6.004 E-10$ & $6.508 E-10$ \\
\hline
\end{tabular}

SKEW FIELDS:

\begin{tabular}{|c|c|c|c|c|c|c|c|c|}
\hline & $I(A)$ & $A_{0} / B_{0}$ & $A_{1} / B_{0}$ & $A_{2} / B_{0}$ & $\frac{A_{3} / B_{0}}{37165-06}$ & $\frac{A_{4} / B_{0}}{3178 F-07}$ & $A_{5} / B_{0}$ & $A_{8} / B_{0}$ \\
\hline $\begin{array}{l}1 \\
2\end{array}$ & $\begin{array}{r}0 \\
50\end{array}$ & $\begin{array}{r}-0.00044 \\
0.00065\end{array}$ & $\begin{array}{l}8.510 E-05 \\
-2.002 E-06\end{array}$ & $\begin{array}{r}-1.780 E-05 \\
8.122 \mathrm{E}-07\end{array}$ & $\begin{array}{l}-3.716 E-06 \\
-1.093 E-07\end{array}$ & $\begin{array}{l}3.178 E-07 \\
1.196 E-07\end{array}$ & $\begin{array}{r}-4.813 E-08 \\
1.867 E-08\end{array}$ & $\begin{array}{l}2.988 E-08 \\
4.535 E-09\end{array}$ \\
\hline 3 & 100 & & $9 E-07$ & $6.328 E-08$ & $-1.291 \mathrm{E}$ & 88 & 09 & \\
\hline 4 & & & E-07 & 439E- & $1.077 \mathrm{E}$ & 62E & $6.159 E$ & \\
\hline 5 & 400 & & $928 E-07$ & $5 E-0$ & 9 & $-1.559 E-08$ & $-1.497 \mathrm{E}-$ & \\
\hline 6 & 600 & & $7.213 E-08$ & $E-07$ & & & -1 & -10 \\
\hline 7 & 80 & & $E-07$ & $E-07$ & $5 E-08$ & & -1 & -11 \\
\hline 8 & 000 & & $=-09$ & -07 & $E-08$ & & $6 E-09$ & $1 E-10$ \\
\hline 9 & .00 & & $-1.160 E$ & -07 & -08 & -2.6 & $-1.01 \mathscr{E}-1$ & -10 \\
\hline 10 & 300 & & -08 & -07 & -09 & -3.7 & -10 & -10 \\
\hline 1 & 200 & & & & & & & -10 \\
\hline & & & & & & & & \\
\hline 13 & 200 & & 07 & 3 & & & & -1 \\
\hline 14 & 3400 & & $E-07$ & -3 & & -1 & & -11 \\
\hline 15 & 800 & & -2.4 & -3.2 & & -4. & -3 & \\
\hline 16 & 4000 & & -7.6 & -3.4 & -08 & $E-09$ & & -10 \\
\hline 17 & 4200 & & $E-08$ & -3 & -08 & -3 & & -11 \\
\hline 18 & 4400 & & -6.8 & -4 & & -3 & & -11 \\
\hline 19 & 4600 & & & & & & & \\
\hline 20 & & & & & & & & -11 \\
\hline & & & & & & & & \\
\hline \multirow{2}{*}{\multicolumn{3}{|c|}{$\begin{array}{l}\text { AVG.: (600 to } 3400 \mathrm{~A}) \\
\text { STD. DEVIATION: }\end{array}$}} & & & & & & \\
\hline & & & & & & & & \\
\hline
\end{tabular}




\section{Field Shape}

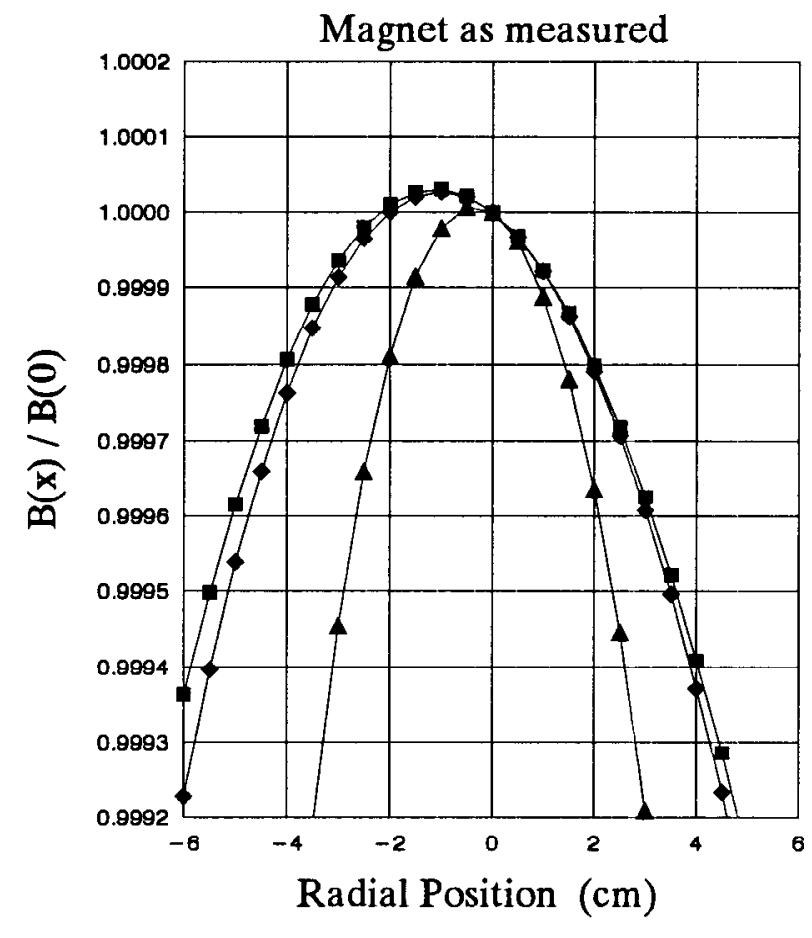

$$
-600 \mathrm{~A} \leftarrow 2600 \mathrm{~A} \leftarrow 5000 \mathrm{~A}
$$

\section{B / I vs. Current}

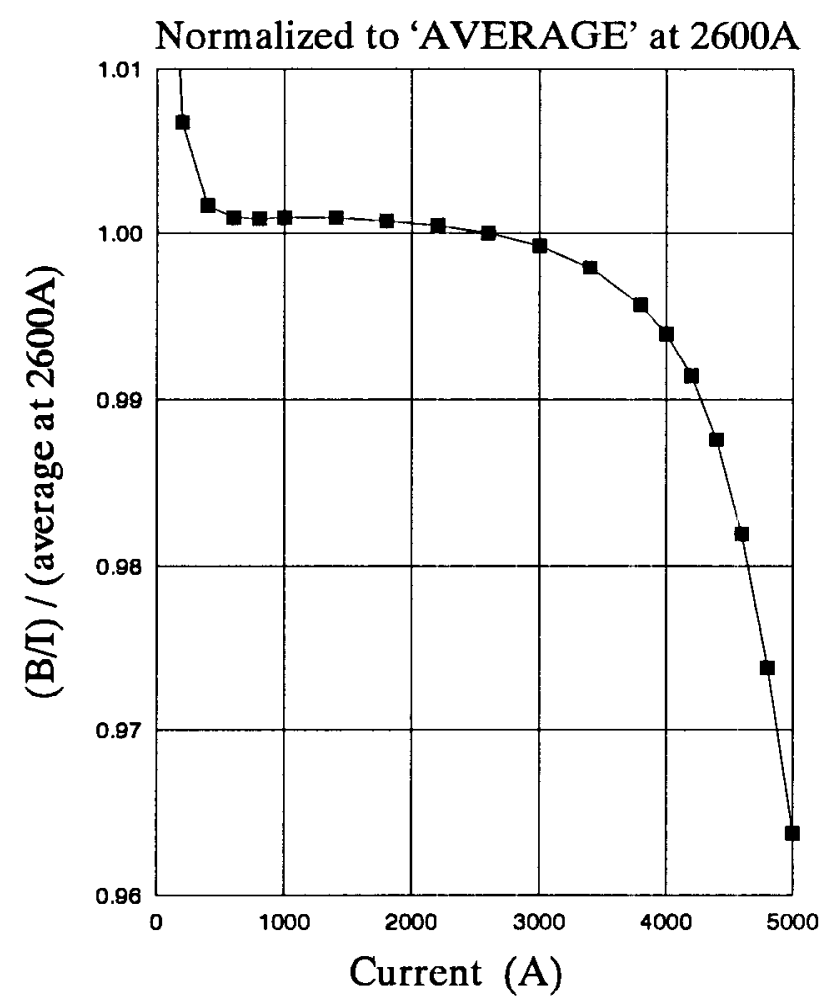

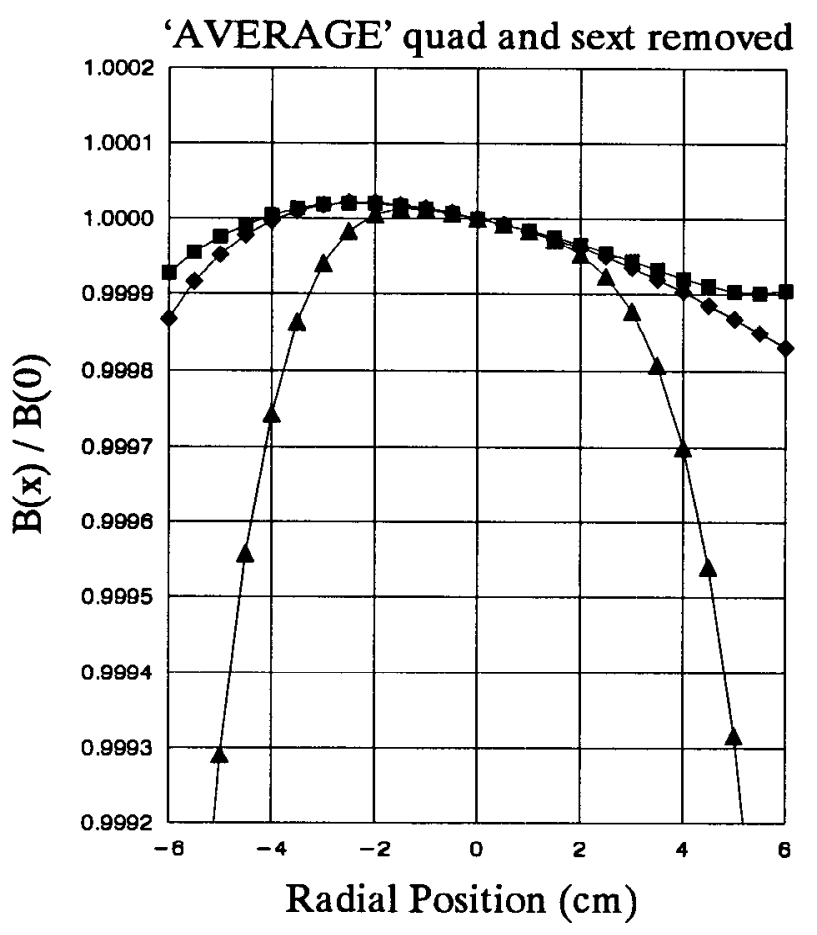

$+600 \mathrm{~A} \leftarrow 2600 \mathrm{~A} \_5000 \mathrm{~A}$

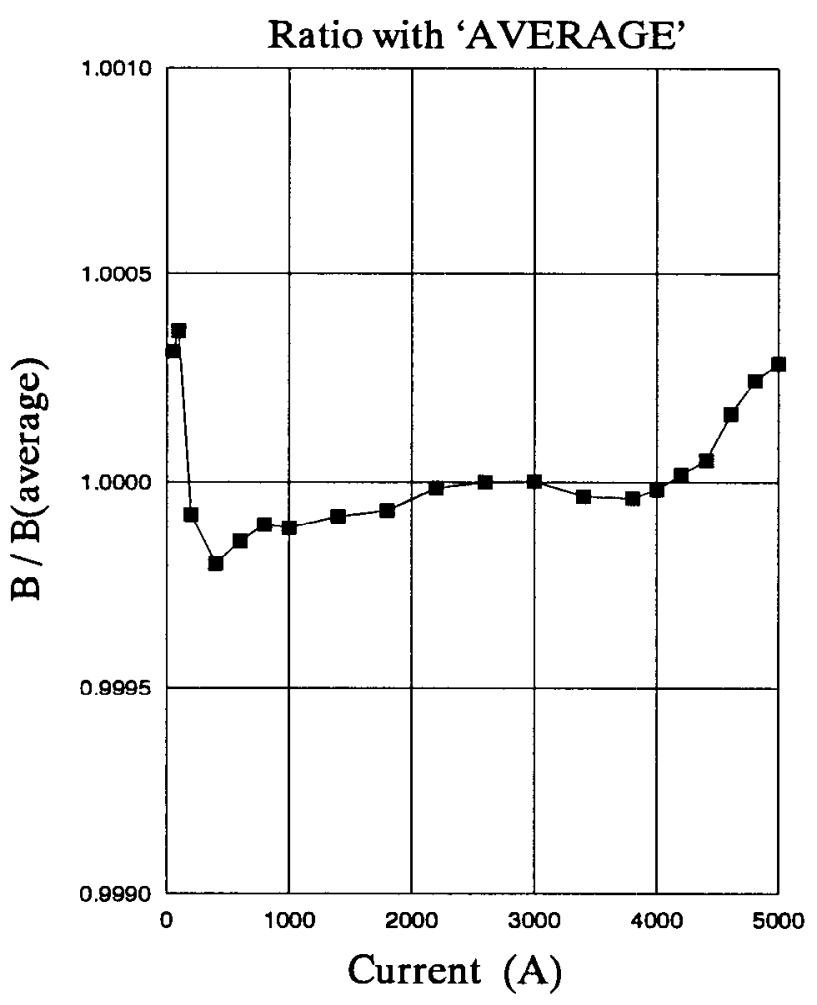




\section{Booster Dipole: AVERAGE(37 mag)}

DATE OF MEASUREMENT

0

SOURCE OF REPORT: F:IMAGMEASIDIPOLE.WK3 10-Mar-91 00:21:07 SHEET 1

\section{INTRODUCTION AND DEFINITIONS}

The midplane fields are: $B_{x}=A_{0}+A_{1} x+A_{2} x^{2}+\ldots, B_{y}=B_{0}+B_{1} x+B_{2} x^{2}+\ldots$

"MIDDLE OF MAGNET" refers to measurements centered lengthwise in the iron, away from the ends.

"ENTIRE MAGNET" refers to measurements along the entire length of the magnet, including the fringe field.

These are either made directly with the long coil, or synthesized from several short coil measurements.

The MAGNETC LENGTH is taken by definition to be $2.42 \mathrm{~m}=95.2756 \mathrm{in}$. This is a rounded figure which is close to the average of integral $(B \mathrm{dl}) / \mathrm{B}_{\text {middle }}$ at $2600 \mathrm{~A}$.

"AVERAGE" refers to the average of the short coil data over all the measured magnets.

Absolute measurements of the dipole angle are not available; the data for each magnet have been rotated so that $\left\langle A_{0} / B_{0}\right\rangle=0$.

Calibration factors - NMR: 1.00000 Short coil: 0.99425 Long coil: 1.00482

\section{DIPOLE TRANSFER FUNCTION AND SATURATION SUMMARY}

[ ] = deviations from average of all magnets, in parts per $10^{4}$

NMR Measurement:

$\mathrm{B}_{0} / \mathrm{I} @ 3000 \mathrm{~A}$

Long Coil Meas:

$B_{0} / 1 @ 2600 A$

Short Coil Meas:

$\mathrm{B}_{0} / 1 @ 600 \mathrm{~A}$

$B_{0} / 1 @ 2600 A$

$B_{0} / 1 @ 5000 A$

Saturation (2600/5000):

Residual Fields:
ENTIRE MAGNET

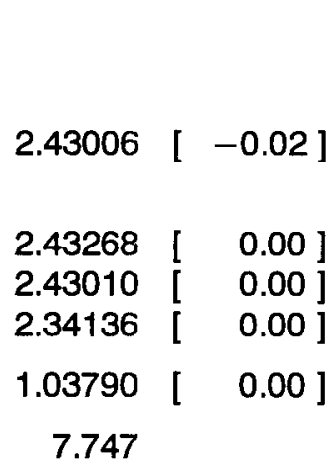

MIDDLE OF MAGNET

$2.42924[0.00]$ G/A

G/A

$\begin{array}{rrrr}2.43110 & {[} & 0.00] & G / A \\ 2.43012 & {[} & 0.00] & G / A \\ 2.36556 & {[} & 0.00] & G / A \\ 1.02729 & {[} & 0.00] & \\ 7.616 & & G\end{array}$

FIELD SHAPE SUMMARY

Deviations from central field, in parts per $10^{4}$

\begin{tabular}{l|r|rrrr|rrrr|}
\cline { 2 - 9 } & & \multicolumn{3}{|c|}{ ENTIRE MAGNET } & \multicolumn{4}{c|}{ MIDDLE OF MAGNET } \\
& $\begin{array}{l}\text { Current } \\
\text { (A) }\end{array}$ & \multicolumn{3}{|c|}{ radial position in cm } & \multicolumn{3}{c|}{ radial position in cm } \\
This magnet as & -5.0 & -2.5 & 2.5 & 5.0 & -5.0 & -2.5 & 2.5 & 5.0 \\
measured: & 600 & -4.2 & -0.5 & -2.4 & -7.4 & 1.5 & 0.4 & -0.2 & 0.4 \\
& 2600 & -5.0 & -0.6 & -2.4 & -7.9 & 1.2 & 0.3 & -0.3 & 0.1 \\
& 5000 & -22.1 & -3.7 & -5.0 & -23.1 & -11.2 & -1.5 & -2.2 & -11.8 \\
Magnet with b1 & 600 & -0.6 & -0.1 & 0.0 & 0.1 & 0.8 & 0.0 & 0.0 & 0.8 \\
and b2 removed: & 2600 & -0.9 & -0.1 & 0.0 & -0.1 & 0.7 & 0.0 & 0.0 & 0.7 \\
& 5000 & -7.6 & -0.5 & -0.3 & -5.6 & -5.4 & -0.3 & -0.2 & -4.6 \\
With AVERAGE b1 & 600 & -0.6 & -0.1 & 0.0 & 0.1 & 0.8 & 0.0 & 0.0 & 0.8 \\
and b2 removed: & 2600 & -0.9 & -0.1 & 0.0 & -0.1 & 0.7 & 0.0 & 0.0 & 0.7 \\
& 5000 & -7.6 & -0.5 & -0.3 & -5.6 & -5.4 & -0.3 & -0.2 & -4.6 \\
\hline
\end{tabular}




\section{Booster Dipole: AVERAGE(37 mag)}

p. 2

\section{SUMMARY OF HARMONIC CONTENT}

Units are Gauss and $\mathrm{cm}^{-n}$.

For allowed harmonics, [ ] is the ratio with average of all magnets

\section{ENTIRE MAGNET}

\begin{tabular}{|c|c|c|c|c|c|c|c|c|c|}
\hline & \multicolumn{2}{|l|}{$600 \mathrm{~A}$} & \multicolumn{3}{|c|}{$\underline{2600 \mathrm{~A}}$} & \multicolumn{3}{|c|}{$5000 \mathrm{~A}$} & \\
\hline$B_{0}$ & 1459.61 & I & $1.0000]$ & 6318.27 & [ & $1.0000]$ & 11706.78 & [ & $1.0000]$ \\
\hline $\begin{array}{l}B_{1} / B_{0} \\
A_{1} / B_{0}\end{array}$ & $\begin{array}{r}-3.918 E-05 \\
9.310 E-06\end{array}$ & & & $\begin{array}{r}-3.721 E-05 \\
2.358 E-06\end{array}$ & & & $\begin{array}{r}-3.060 E-05 \\
5.978 E-06\end{array}$ & & \\
\hline $\begin{array}{l}\mathrm{B}_{2} / \mathrm{B}_{0} \\
\mathrm{~A}_{2} / \mathrm{B}_{0}\end{array}$ & $\begin{array}{r}-2.219 E-05 \\
2.865 E-08\end{array}$ & [ & $1.0000]$ & $\begin{array}{l}-2.395 E-05 \\
-7.461 E-08\end{array}$ & [ & $1.0000]$ & $\begin{array}{l}-6.414 E-05 \\
-1.380 E-08\end{array}$ & [ & $1.0000]$ \\
\hline $\begin{array}{l}B_{3} / B_{0} \\
A_{3} / B_{0}\end{array}$ & $\begin{array}{l}1.956 E-07 \\
1.285 E-07\end{array}$ & & & $\begin{array}{l}2.118 E-07 \\
1.128 E-07\end{array}$ & & & $\begin{array}{l}5.334 E-07 \\
1.547 E-07\end{array}$ & & \\
\hline $\begin{array}{l}B_{4} / B_{0} \\
A_{4} / B_{0}\end{array}$ & $\begin{array}{r}-7.810 \mathrm{E}-08 \\
2.940 \mathrm{E}-09\end{array}$ & [ & $1.0000]$ & $\begin{array}{r}-9.770 \mathrm{E}-08 \\
1.408 \mathrm{E}-09\end{array}$ & [ & $1.0000]$ & $\begin{array}{r}-8.680 \mathrm{E}-07 \\
4.739 \mathrm{E}-09\end{array}$ & [ & $1.0000]$ \\
\hline $\begin{array}{l}B_{5} / B_{0} \\
A_{5} / B_{0}\end{array}$ & $\begin{array}{r}5.274 E-09 \\
-2.704 E-09\end{array}$ & & & $\begin{array}{r}5.508 E-09 \\
-2.222 E-09\end{array}$ & & & $\begin{array}{r}1.171 \mathrm{E}-08 \\
-5.279 \mathrm{E}-10\end{array}$ & & \\
\hline $\begin{array}{l}B_{6} / B_{0} \\
A_{6} / B_{0}\end{array}$ & $\begin{array}{l}1.433 E-09 \\
3.651 E-11\end{array}$ & {[} & $1.0000]$ & $\begin{array}{r}-2.354 E-11 \\
8.716 E-11\end{array}$ & [ & $1.0000]$ & $\begin{array}{l}-9.125 E-09 \\
-6.090 E-11\end{array}$ & {[} & $1.0000]$ \\
\hline
\end{tabular}

MIDDLE OF MAGNET

\begin{tabular}{|c|c|c|c|c|c|c|c|c|c|}
\hline & $600 \mathrm{~A}$ & & & $2600 \mathrm{~A}$ & & & 5000 A & & \\
\hline $\mathrm{B}_{0}$ & 1458.66 & {[} & $1.0000]$ & 6318.30 & [ & $1.0000]$ & 11827.81 & [ & $1.0000]$ \\
\hline $\begin{array}{l}B_{1} / B_{0} \\
A_{1} / B_{0}\end{array}$ & $\begin{array}{l}-1.179 E-05 \\
-1.123 E-06\end{array}$ & & & $\begin{array}{l}-1.129 E-05 \\
-8.072 E-07\end{array}$ & & & $\begin{array}{l}-1.418 E-05 \\
-4.296 E-08\end{array}$ & & \\
\hline $\begin{array}{l}B_{2} / B_{0} \\
A_{2} / B_{0}\end{array}$ & $\begin{array}{l}7.225 E-07 \\
3.915 E-08\end{array}$ & [ & $1.0000]$ & $\begin{array}{l}-7.787 E-08 \\
-1.004 E-08\end{array}$ & [ & $1.0000]$ & $\begin{array}{r}-2.590 E-05 \\
2.154 E-07\end{array}$ & [ & $1.0000]$ \\
\hline $\begin{array}{l}B_{3} / B_{0} \\
A_{3} / B_{0}\end{array}$ & $\begin{array}{r}-3.181 E-08 \\
1.850 E-09\end{array}$ & & & $\begin{array}{l}-4.806 E-08 \\
-2.034 E-09\end{array}$ & & & $\begin{array}{l}8.442 E-08 \\
4.253 E-08\end{array}$ & & \\
\hline $\begin{array}{l}B_{4} / B_{0} \\
A_{4} / B_{0}\end{array}$ & $\begin{array}{l}5.849 E-08 \\
1.902 E-09\end{array}$ & [ & $1.0000]$ & $\begin{array}{l}6.152 E-08 \\
2.907 E-09\end{array}$ & [ & $1.0000]$ & $\begin{array}{r}-6.204 E-07 \\
6.308 E-09\end{array}$ & [ & $1.0000]$ \\
\hline $\begin{array}{l}B_{5} / B_{0} \\
A_{5} / B_{0}\end{array}$ & $\begin{array}{r}1.496 E-09 \\
-6.124 E-10\end{array}$ & & & $\begin{array}{r}1.662 E-09 \\
-1.173 E-10\end{array}$ & & & $\begin{array}{l}8.740 E-09 \\
9.406 E-10\end{array}$ & & \\
\hline $\begin{array}{l}\mathrm{B}_{6} / \mathrm{B}_{0} \\
\mathrm{~A}_{6} / \mathrm{B}_{0}\end{array}$ & $\begin{array}{l}3.550 E-09 \\
1.794 E-10\end{array}$ & [ & $1.0000]$ & $\begin{array}{l}2.357 E-09 \\
1.187 E-10\end{array}$ & {[} & $1.0000]$ & $\begin{array}{l}-8.108 E-09 \\
-1.060 E-10\end{array}$ & [ & 1.0000 ] \\
\hline
\end{tabular}




\section{Booster Dipole: AVERAGE(37 mag)}

MEASUREMENT RESULTS (Absolute) for ENTIRE MAGNET (Gauss at $1 \mathrm{~cm}$ )

NORMAL FIELDS:

\begin{tabular}{|c|c|c|c|c|c|c|c|c|}
\hline & $I(A)$ & $B_{0}$ & $\mathrm{~B}_{1}$ & $\mathrm{~B}_{2}$ & $\mathrm{~B}_{3}$ & & $B_{5}$ & $B_{6}$ \\
\hline 1 & 0 & 7.75 & $1.652 \mathrm{E}-04$ & $1.878 \mathrm{E}-03$ & $-2.380 E-05$ & $2.724 E-06$ & $8.272 \mathrm{E}-07$ & $3.681 E-07$ \\
\hline 2 & 50 & 127.57 & $-4.642 E-03$ & $-1.255 E-03$ & $8.885 E-06$ & $-8.248 E-06$ & $1.118 E-06$ & $5.946 E-07$ \\
\hline 3 & 100 & 247.91 & $-9.453 E-03$ & $-4.293 E-03$ & $3.209 E-05$ & $-1.815 E-05$ & $1.601 E-06$ & $5 E-07$ \\
\hline 4 & 200 & 489.30 & $-1.91 \mathfrak{Z} \mathbf{E}-02$ & $-1.016 E-02$ & $8.224 E-05$ & $-3.986 E-05$ & $2.893 E-06$ & $92 \mathbb{E}-06$ \\
\hline 5 & 400 & 973.80 & $-3.818 E-02$ & $-2.147 \mathrm{E}-02$ & 1.847E-04 & $-7.586 \mathrm{E}-05$ & $5.058 E-06$ & 1.679E-06 \\
\hline 6 & 600 & 1459.61 & $-5.719 E-02$ & $-3.239 E-02$ & $2.855 E-04$ & $-1.140 E-04$ & $7.698 E-06$ & $2.092 E-06$ \\
\hline 7 & 800 & 5.95 & $-7.607 E-02$ & $-4.308 E-02$ & $3.889 E-04$ & $-1.507 E-04$ & $9.973 E-06$ & $2.28 \not 2 E-06$ \\
\hline 8 & 1000 & 2432.58 & $-9.488 E-02$ & $-5.382 \mathrm{E}-02$ & $4.916 E-04$ & $-1.854 E-04$ & $1.221 E-05$ & 2.293E-06 \\
\hline 9 & 1400 & 3405.51 & $-1.318 E-01$ & $-7.588 E-02$ & $6.755 E-04$ & $-2.644 E-04$ & $1.745 E-05$ & -06 \\
\hline 10 & 1800 & 4377.62 & $-1.677 \mathrm{E}-01$ & $-9.898 E-02$ & $8.650 E-04$ & $-3.476 E-04$ & 2.265E-05 & $2.421 E-06$ \\
\hline 11 & 2200 & 5348.81 & $-2.021 E-01$ & $-1.236 E-01$ & $1.076 E-03$ & $-4.518 E-04$ & 2.779E-05 & $1.532 E-06$ \\
\hline 12 & 2600 & 6318 & $E-01$ & $-1.513 E-01$ & $1.338 E-03$ & $-6.173 E-04$ & 3.480E-05 & $-1.487 E-07$ \\
\hline 13 & 3000 & 7 & -2.6 & -1.84 & 1.727E-03 & $-9.101 E$ & 51E-05 & $-4.010 E-06$ \\
\hline 14 & 3400 & 8245 & $-2.922 \mathrm{E}-01$ & $-2.288 E-01$ & -03 & -1.4 & $=-05$ & $-1.235 E-05$ \\
\hline 15 & 3800 & 9194.69 & $-3.143 E-01$ & $-2.905 E-01$ & $3.112 E-03$ & $-2.298 \mathrm{E}-03$ & $6.946 E-05$ & $-2.623 E-05$ \\
\hline 16 & 4000 & 9661.59 & $-3.230 E-01$ & $-3.319 E-01$ & $3.625 E-03$ & $-2.941 \mathrm{E}-03$ & 7.759E-05 & $-3.639 E-05$ \\
\hline 17 & 4200 & 10118.73 & $-3.305 E-01$ & $-3.838 E-01$ & $4.204 E-03$ & $-3.813 E-03$ & $8.832 E-05$ & $-4.948 E-05$ \\
\hline 18 & 4400 & 10559.60 & $-3.373 E-01$ & $-4.501 E-01$ & $4.799 E-03$ & $-5.006 E-03$ & 9.929E-05 & $-6.629 E-05$ \\
\hline 19 & 4600 & 10974.14 & $-3.435 E-01$ & $-5.327 E-01$ & $5.334 E-03$ & $-6.527 E-03$ & 1.109E-04 & $-8.370 E-05$ \\
\hline 20 & 4800 & 11356.14 & $-3.503 E-01$ & $-6.329 \mathrm{E}-01$ & $5.816 E-03$ & $-8.288 E-03$ & $1.234 E-04$ & $-9.818 E-05$ \\
\hline 21 & 5000 & 11706.78 & $-3.582 E-01$ & $-7.509 E-01$ & $6.245 E-03$ & $-1.016 \mathrm{E}-02$ & $1.371 E-04$ & $-1.068 E$ \\
\hline
\end{tabular}

SKEW FIELDS:

\begin{tabular}{|c|c|c|c|c|c|c|c|}
\hline$I(A)$ & $\mathrm{A}_{0}$ & $A_{1}$ & $A_{2}$ & $\mathrm{~A}_{3}$ & $\mathrm{~A}_{4}$ & $A_{5}$ & $A_{B}$ \\
\hline 0 & 0.05 & $1.151 E-02$ & $3.450 E-05$ & $-9.364 E-06$ & $-3.106 E-06$ & 1.164E-06 & 2.065E-07 \\
\hline 50 & 0.02 & $1.195 E-02$ & $1.055 E-05$ & $1.486 E-05$ & $-1.215 E-06$ & $2.510 E-07$ & $1.746 E-07$ \\
\hline 100 & 0.03 & $1.224 E-02$ & $5.374 E-05$ & $2.582 \mathbf{E}-05$ & $-3.307 E-06$ & $-9.885 E-08$ & $2.193 E-07$ \\
\hline 200 & 0.03 & $1.282 E-02$ & $3.368 E-05$ & $4.859 \mathrm{E}-05$ & 3.424E-07 & $-4.929 E-07$ & $9.107 E-08$ \\
\hline 400 & 0.01 & $1.334 E-02$ & $2.604 E-05$ & $1.221 E-04$ & 3.467E-06 & $-2.572 E-06$ & $2.963 E-08$ \\
\hline 600 & -0.00 & $1.359 E-02$ & $4.182 \mathrm{E}-05$ & $1.876 \mathrm{E}-04$ & $4.29 \not E-06$ & $-3.947 E-06$ & $5.330 E-08$ \\
\hline 800 & -0.03 & $1.352 \mathbf{E}-02$ & $6.290 E-05$ & $2.517 \mathrm{E}-04$ & $3.936 E-06$ & $-5.220 E-06$ & $1.164 E-07$ \\
\hline 1000 & -0.03 & $1.335 E-02$ & $7.554 E-05$ & $3.220 \mathrm{E}-04$ & $3.984 E-06$ & $-7.078 E-06$ & $1.240 E-07$ \\
\hline 1400 & -0.08 & $1.285 E-02$ & 4.484E-05 & $4.504 E-04$ & $3.661 E-06$ & $-1.002 E-05$ & $2.360 E-07$ \\
\hline 1800 & -0.09 & 1.279E-02 & $-6.715 E-05$ & $5.616 \mathrm{E}-04$ & 4.443E-06 & $-1.264 E-05$ & $3.413 E-07$ \\
\hline 2200 & -0.10 & 1.377E-02 & $-2.019 E-04$ & $6.349 E-04$ & $5.231 E-06$ & $-1.380 E-05$ & $3.609 E-07$ \\
\hline 2600 & -0.14 & $1.490 E-02$ & $-4.714 E-04$ & $7.128 E-04$ & 8.894E-06 & $-1.404 E-05$ & 5.507E-07 \\
\hline 3000 & -0.16 & 1.719E-02 & $-6.775 E-04$ & 7.959E-04 & 1.131E-05 & $-1.468 E-05$ & $6.398 E-07$ \\
\hline 3400 & -0.20 & $2.037 E-02$ & $-9.347 E-04$ & $8.808 E-04$ & 1.593E-05 & $-1.380 E-05$ & $6.013 E-07$ \\
\hline 3800 & -0.27 & $2.446 E-02$ & $-1.230 E-03$ & $1.009 E-03$ & 2.337E-05 & $-1.354 E-05$ & $3.834 E-07$ \\
\hline 4000 & -0.26 & 2.754E -02 & $-1.229 E-03$ & $1.083 E-03$ & $1.726 E-05$ & $-1.314 E-05$ & $7.603 E-07$ \\
\hline 4200 & -0.30 & 3.184E-02 & $-1.332 \mathrm{E}-03$ & $1.187 \mathrm{E}-03$ & $2.546 E-05$ & $-1.241 E-05$ & $5.270 E-07$ \\
\hline 4400 & -0.25 & $3.742 E-02$ & $-1.363 E-03$ & $1.318 E-03$ & 3.333E-05 & $-1.136 E-05$ & $1.910 E-07$ \\
\hline 4600 & -0.31 & $4.520 E-02$ & $-1.200 E-03$ & $1.468 \mathrm{E}-03$ & 3.857E-05 & $-1.004 E-05$ & $-4.791 E-08$ \\
\hline 4800 & -0.24 & $5.612 E-02$ & $-7.877 \mathrm{E}-04$ & $1.660 E-03$ & $5.031 E-05$ & $-9.159 E-06$ & $-4.674 E-07$ \\
\hline 5000 & -0.28 & $6.998 E-02$ & $-1.615 E-04$ & $1.811 E-03$ & $5.548 E-05$ & $-6.180 E-06$ & $-7.129 E-07$ \\
\hline
\end{tabular}




\section{Booster Dipole: AVERAGE(37 mag)}

MEASUREMENT RESULTS (normalized to $B_{0}$ ) for ENTIRE MAGNET (at $1 \mathrm{~cm}$ )

NORMAL FIELDS:

\begin{tabular}{|c|c|c|c|c|c|c|c|c|}
\hline & $I(A)$ & $\mathrm{B}_{0} / \mathrm{I}$ & $\mathrm{B}_{1} / \mathrm{B}_{0}$ & $\mathrm{~B}_{2} / \mathrm{B}_{0}$ & $\mathrm{~B}_{3} / \mathrm{B}_{0}$ & $\mathrm{~B}_{4} / \mathrm{B}_{0}$ & $\mathrm{~B}_{5} / \mathrm{B}_{0}$ & $B_{6} / B_{0}$ \\
\hline 1 & 0 & & & $2.424 E-04$ & $-3.072 E-06$ & $3.516 E-07$ & $1.068 \mathrm{E}-07$ & $4.752 \mathrm{E}-08$ \\
\hline 2 & 50 & 2.55136 & $-3.639 E-05$ & $-9.840 E-06$ & $6.965 E-08$ & $-6.466 E-08$ & $765 E$ & $4.661 \mathrm{E}-0$ \\
\hline 3 & 100 & 913 & $-3.813 E-05$ & $-1.731 E-05$ & $1.294 E-07$ & $-7.321 E-08$ & -09 & \\
\hline 4 & 200 & 652 & $-3.907 E-05$ & $-2.076 E-05$ & $1.681 E-07$ & $-8.147 E-08$ & $913 E-09$ & $2.436 \mathrm{E}-09$ \\
\hline 5 & 400 & 451 & OE-05 & $-2.205 E-05$ & 1.897E-07 & $-7.791 E-08$ & $5.194 E-09$ & $1.724 E-09$ \\
\hline 6 & 600 & 2.43268 & $-3.918 E-05$ & $-2.219 E-05$ & $1.956 E-07$ & $810 E-08$ & $.274 E-09$ & $1.433 E-09$ \\
\hline 7 & 800 & 2.43244 & $-3.909 E-05$ & $-2.214 E-05$ & $1.999 E-07$ & $-7.744 E-08$ & -09 & $1.172 \mathrm{E}-09$ \\
\hline 8 & 1000 & 2.43258 & $1 E-05$ & $3 E-05$ & $2.021 E-07$ & $-7.621 E-08$ & 5.021E-09 & $9.425 E-10$ \\
\hline 9 & 1400 & 2.43251 & -3.8 & $-2.228 E-05$ & $1.984 E-07$ & $-7.764 E-08$ & -09 & 7.517E-10 \\
\hline 10 & 1800 & & -05 & -2.26 & $6 E-07$ & $-7.941 E-08$ & -09 & $5.531 \mathrm{E}-10$ \\
\hline 1 & 2200 & & & & $E-07$ & -08 & -09 & $2.863 E-10$ \\
\hline 2 & 2600 & & -3 & -2 & $8 E-07$ & $-9.7 x y$ & -09 & $354 E-11$ \\
\hline 13 & 3000 & 2.42826 & -3.6 & -2.5 & $E-07$ & -1 & -09 & $505 E-10$ \\
\hline 14 & 3400 & 2.42514 & -3. & -2.7 & 2E-07 & -1.7 & & \\
\hline 5 & 3800 & 2.41966 & $E-05$ & -3.16 & 4E- -07 & $-2.499 E-07$ & $5 E-09$ & -2.8 \\
\hline 16 & 4000 & 2.41 & $E-05$ & $-3.435 E-05$ & $3.75 \not{E}-07$ & $-3.044 E-07$ & $8.031 E-09$ & $-3.767 E-09$ \\
\hline 17 & 4200 & 2.40922 & -3.2 & -3 & $E-07$ & $-3.768 E-07$ & $8.728 E-09$ & $-4.890 E-09$ \\
\hline 8 & 4400 & & -3 & $E-05$ & $E-07$ & -4.7 & -09 & $-6.278 E-09$ \\
\hline 9 & 4600 & & $E-05$ & $E-05$ & EE-07 & E-07 & $E-08$ & $-7.627 E-09$ \\
\hline 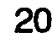 & & & $-3.085 E-05$ & -5.5 & $E-07$ & $-7.298 E-$ & $1.086 E-08$ & $-8.646 E-09$ \\
\hline 81 & 5000 & 2.34136 & $-3.060 E-05$ & -6.4 & $4 E-07$ & $-8.680 E-07$ & $1.171 E-08$ & $-9.125 E-09$ \\
\hline \multirow{2}{*}{\multicolumn{3}{|c|}{ AVG.: $(600$ to $3400 \mathrm{~A})$}} & -3.7 & 50E-05 & $2.138 E-07$ & -9.655 & & \\
\hline & & & & $1.811 E-06$ & $2.641 E-08$ & $3.087 E-08$ & & \\
\hline
\end{tabular}

SKEW FIELDS:

\begin{tabular}{rrr} 
& $I(A)$ & $A_{0} / B_{0}$ \\
\cline { 2 - 3 } 1 & 0 & 0.00623 \\
2 & 50 & 0.00015 \\
3 & 100 & 0.00014 \\
4 & 200 & 0.00005 \\
5 & 400 & 0.00001 \\
6 & 600 & -0.00000 \\
7 & 800 & -0.00001 \\
8 & 1000 & -0.00001 \\
9 & 1400 & -0.00002 \\
10 & 1800 & -0.00002 \\
11 & 2200 & -0.00002 \\
12 & 2600 & -0.00002 \\
13 & 3000 & -0.00002 \\
14 & 3400 & -0.00002 \\
15 & 3800 & -0.00003 \\
16 & 4000 & -0.00003 \\
17 & 4200 & -0.00003 \\
18 & 4400 & -0.00002 \\
19 & 4600 & -0.00003 \\
20 & 4800 & -0.00002 \\
21 & 5000 & -0.00002
\end{tabular}

AVG.: $(600$ to $3400 \mathrm{~A})$ STD. DEVIATION:

$$
A_{1} / B_{0}
$$

$1.486 E-03$

$9.368 E-05$

$4.939 E-05$

2.619E-05

$1.370 E-05$

$9.310 \mathrm{E}-06$

$6.949 E-06$

$5.489 E-06$

3.773E-06

2.922E-06

2.574E-06

2.358E-06

2.360E-06

2.470E-06

2.660E-06

$2.850 E-06$

$3.146 \mathrm{E}-06$

3.544E-06

4.119E-06

4.942E-06

$5.978 \mathrm{E}-06$

$4.245 E-06$
$2.346 E-06$
$A_{2} / B_{0}$ $8.268 \mathrm{E}-08$ $2.168 \mathrm{E}-07$ $6.882 \mathrm{E}-08$ 2.674E-08 $2.865 \mathrm{E}-08$ $3.232 E-08$ $3.105 E-08$ 1.317E-08 $-1.534 E-08$ $-3.775 E-08$ $-7.461 E-08$ $-9.300 E-08$ $-1.134 E-07$ $-1.337 E-07$ $-1.273 E-07$ $-1.316 E-07$ $-1.291 E-07$ $-1.094 E-07$ $-6.936 E-08$ $-1.380 E-08$ $-2.543 E-08$ 5.365E-08
$A_{3} / B_{0}$
$1.164 \mathrm{E}-07$
1.042E-07
9.931E-08
$1.253 \mathrm{E}-07$
$1.285 \mathrm{E}-07$
$1.294 E-07$
1.324E-07
$1.323 E-07$
$1.283 E-07$
$1.187 \mathrm{E}-07$
$1.128 \mathrm{E}-07$
$1.092 \mathrm{E}-07$
$1.068 \mathrm{E}-07$
$1.097 \mathrm{E}-07$
$1.121 \mathrm{E}-07$
$1.173 \mathrm{E}-07$
$1.249 E-07$
$1.338 \mathrm{E}-07$
$1.462 E-07$
$1.547 \mathrm{E}-07$
$1.220 E-07$
$9.650 E-09$

$\mathrm{A}_{4} / \mathrm{B}_{0}$ $-4.009 E-07$ $\mathrm{A}_{5} / \mathrm{B}_{0}$ $-9.525 E-09$ 1.334E-08 -3.987E-10 $6.998 E-10-1.007 E-09$ 3.560E-09 -2.642E-09 $2.940 E-09-2.704 E-09$ 2.023E-09 -2.683E-09 1.638E-09 -2.910E-09 1.075E-09 -2.942E-09 1.015E-09 -2.887E-09 $9.780 E-10-2.580 E-09$ $1.408 \mathrm{E}-09-2.222 \mathrm{E}-09$ 1.553E-09 -2.015E-09 1.933E-09 -1.673E-09 2.542E-09 -1.473E-09 1.786E-09 -1.360E-09 2.516E-09 -1.226E-09 3.157E-09 -1.075E-09 $3.515 E-09-9.151 E-10$ 4.430E-09 -8.065E-10 4.739E-09 -5.279E-10 1.618E-09 -2.513E-09 $5.895 E-10 \quad 4.202 E-10$
$A_{6} / B_{0}$

$2.665 E-08$

$1.368 E-09$

$8.848 E-10$

$1.861 \mathrm{E}-10$

3.042E-11

3.651E-11

$5.981 \mathrm{E}-11$

$5.097 E-11$

6.929E-11

7.797E-11

6.747E-11

8.716E-11

8.78ZE-11

7.292E-11

4.170E-11

$7.869 E-11$

$5.208 E-11$

1.809E-11

$-4.366 E-12$

$-4.116 E-11$

$-6.090 E-11$

6.777E-11

$1.575 E-11$ 


\section{Booster Dipole: AVERAGE(37 mag)}

MEASUREMENT RESULTS (Absolute) for MIDDLE OF MAGNET (Gauss at $1 \mathrm{~cm}$ )

NORMAL FIELDS:

\begin{tabular}{|c|c|c|c|c|c|c|c|c|}
\hline & $I(A)$ & $\mathrm{B}_{0}$ & $B_{1}$ & $B_{2}$ & $\mathrm{~B}_{3}$ & $B_{4}$ & $B_{5}$ & $B_{6}$ \\
\hline 1 & 0 & 7.62 & $-1.386 E-04$ & $2.417 E-03$ & $-1.813 E-05$ & $4.116 E-07$ & $3.960 E-07$ & $286 \mathrm{E}-07$ \\
\hline 2 & 50 & 127.42 & $-1.665 E-03$ & 1.957E-03 & $-1.033 E-05$ & $4.845 E-06$ & $1.747 E-07$ & $9.621 E-07$ \\
\hline 3 & 100 & 247.74 & $-3.050 E-03$ & 1.653E-03 & $-1.909 E-05$ & 1.063E-05 & 4.990E-07 & $1.344 E-06$ \\
\hline 4 & 200 & 489.01 & $-6.002 \mathrm{E}-03$ & 1.247E-03 & $-2.886 E-05$ & 2.167E-05 & $1.230 E-06$ & 2.347E-06 \\
\hline 5 & 400 & 973.19 & $-1.160 E-02$ & $9.464 E-04$ & $-3.608 E-05$ & $5.334 E-05$ & $1.484 E-06$ & $3.810 E-06$ \\
\hline 6 & 600 & 1458.66 & $-1.719 E-02$ & $1.054 E-03$ & $-4.640 E-05$ & 8.531E-05 & $2.182 E-06$ & $5.178 E-06$ \\
\hline 7 & 800 & 1944.71 & $-2.277 E-02$ & $1.379 E-03$ & $-5.754 \mathrm{E}-05$ & $1.218 E-04$ & 2.779E-06 & $6.228 E-06$ \\
\hline 8 & 1000 & 2431.13 & $-2.827 E-02$ & $1.664 E-03$ & $-6.853 E-05$ & $1.611 E-04$ & $3.245 E-06$ & $7.149 E-06$ \\
\hline 9 & 1400 & 3403.74 & $-3.911 E-02$ & $2.006 E-03$ & $-1.115 E-04$ & $2.283 E-04$ & $4.591 E-06$ & $9.507 E-06$ \\
\hline 10 & 1800 & 4375.84 & $-4.979 E-02$ & $1.817 E-03$ & $-1.758 E-04$ & $2.981 E-04$ & $6.657 E-06$ & $1.163 E-05$ \\
\hline 11 & 2200 & & $-6.030 \mathrm{E}-02$ & $1.159 \mathrm{E}-$ & $-2.403 E-04$ & 3.573E-04 & -06 & $1.352 E-05$ \\
\hline 12 & 2600 & 8.30 & $-7.13 \not 2 E-02$ & $-4.920 E-04$ & $-3.037 E-04$ & $3.887 \mathrm{E}$ & -05 & $1.489 E-05$ \\
\hline 13 & 3000 & 7287.73 & $-8.306 E-02$ & $-4.180 E-03$ & $-3.187 E-04$ & $3.477 \mathrm{E}$ & -05 & -05 \\
\hline 14 & 3400 & 8254.39 & $-9.541 E-02$ & $-1.234 E-02$ & $-2.492 \boldsymbol{E}-04$ & $1.480 E-04$ & $1.887 \mathrm{E}$ & $9.300 E-06$ \\
\hline 15 & 3800 & 9216.34 & $-1.088 E-01$ & $-2.867 E-02$ & $-1.141 E-04$ & $-3.202 \mathrm{E}-04$ & $2.995 E-05$ & $-1.691 E-06$ \\
\hline 16 & 4000 & 9693.97 & $-1.160 E-01$ & $-4.278 E-02$ & $2.809 E-05$ & $-7.337 \mathrm{E}-04$ & $3.581 E-05$ & $-1.107 E-05$ \\
\hline 17 & 4200 & 10165.59 & $-1.236 E-01$ & $-6.436 E-02$ & $2.098 E-04$ & $-1.367 E-03$ & $4.656 E-05$ & $-2.508 E-05$ \\
\hline 18 & 4400 & 10625.28 & $-1.317 E-01$ & $-9.827 E-02$ & $4.342 E-04$ & $-2.354 E-03$ & -05 & $-4.478 E-05$ \\
\hline 19 & 4600 & 50.30 & $-1.410 E-01$ & $-1.482 \mathrm{E}-01$ & $6.279 E-04$ & $-3.731 E-03$ & $7.266 E-05$ & $-6.695 E-05$ \\
\hline 20 & 4800 & 11461.03 & $-1.529 E-01$ & & $8.184 E-04$ & $-5.442 \mathrm{E}-03$ & 8.792E-05 & $-8.523 E-05$ \\
\hline 21 & 5000 & 1827.81 & $-1.677 E-01$ & & $9.985 E-04$ & $-7.337 \mathrm{E}-03$ & $1.034 E-04$ & $-9.590 \mathrm{E}-05$ \\
\hline
\end{tabular}

\begin{tabular}{|c|c|c|c|c|c|c|c|c|}
\hline \\
\hline \multicolumn{9}{|c|}{$\begin{array}{l}\text { SKEW FIELDS: } \\
\frac{\mathrm{I}(\mathrm{A})}{}\end{array}$} \\
\hline 1 & 0 & 0.00 & $-9.192 \mathrm{E}-04$ & $-1.099 \mathrm{E}-05$ & $-3.628 E-06$ & $-1.309 E-06$ & $3.144 E-07$ & $9.363 E-08$ \\
\hline 2 & 50 & -0.03 & $-1.120 E-03$ & $-3.034 E-05$ & 4.647E-06 & $-1.023 E-06$ & $3.467 E-08$ & $1.756 E-07$ \\
\hline 3 & 100 & -0.01 & $-1.144 E-03$ & $1.432 \mathrm{E}-05$ & 1.089E-06 & $-1.499 E-06$ & $-1.829 E-07$ & $1.136 E-07$ \\
\hline 4 & 200 & 0.00 & $-1.241 E-03$ & $2.458 E-06$ & $-4.148 E-06$ & $1.612 E-06$ & $-7.634 E-08$ & $3.458 E-08$ \\
\hline 5 & 400 & -0.00 & $-1.486 E-03$ & $2.571 E-05$ & $8.287 E-06$ & $2.545 E-06$ & $-1.127 E-06$ & $1.143 E-07$ \\
\hline 6 & 600 & 0.01 & $-1.638 E-03$ & $5.710 E-05$ & $2.698 E-06$ & $2.774 E-06$ & $-8.933 E-07$ & 2.617E-07 \\
\hline 7 & 800 & -0.01 & $-1.828 E-03$ & $1.153 E-04$ & $2.746 E-06$ & $1.637 E-06$ & $-9.795 E-07$ & 4.113E-07 \\
\hline 8 & 1000 & 0.03 & $-2.008 E-03$ & $1.164 E-04$ & $-2.861 E-06$ & $6.987 \mathrm{E}-06$ & $-1.042 \mathrm{E}-06$ & $2.061 E-07$ \\
\hline 9 & 1400 & 0.02 & $-2.616 E-03$ & $1.508 E-04$ & $-6.225 E-06$ & $6.388 E-06$ & $-5.790 E-07$ & 4.804E-07 \\
\hline 10 & 1800 & 0.06 & $-3.371 E-03$ & $9.186 \mathrm{E}-05$ & $-1.231 E-06$ & $8.671 E-06$ & $-1.370 E-06$ & $6.838 E-07$ \\
\hline 11 & 2200 & 0.12 & $-4.013 E-03$ & 5.336E-05 & $-6.253 E-06$ & $1.377 E-05$ & $-1.638 E-06$ & 4.760E-07 \\
\hline 12 & 2600 & 0.14 & $-5.100 E-03$ & $-6.341 E-05$ & $-1.285 E-05$ & $1.837 \mathrm{E}-05$ & $-7.412 \mathcal{E}-07$ & $7.500 E-07$ \\
\hline 13 & 3000 & 0.18 & $-6.076 E-03$ & $-4.182 \mathrm{E}-05$ & $-3.523 E-07$ & 1.917E-05 & $-1.243 E-06$ & 9.554E-07 \\
\hline 14 & 3400 & 0.22 & $7 E-03$ & $-1.928 E-05$ & $1.031 E-05$ & $3 E-05$ & -07 & $1.064 E-06$ \\
\hline 15 & 3800 & 0.1 & $-7.854 E-03$ & $2.833 \mathrm{E}-05$ & OE-05 & 9E-05 & $2.786 E-07$ & 9.304E-07 \\
\hline 16 & 4000 & 0.21 & $-8.279 E-03$ & $2.226 E-04$ & 66E-05 & $2.052 \mathrm{E}-05$ & $9.810 E-07$ & $1.438 E-06$ \\
\hline 17 & 4200 & 0.20 & $-8.304 E-03$ & 2.613E-04 & $9.227 E-05$ & 3.763E-05 & $1.908 E-06$ & 7.207E-07 \\
\hline 18 & 4400 & 0.28 & $-8.518 E-03$ & $4.565 E-04$ & $1.594 E-04$ & $4.762 E-05$ & $3.221 E-06$ & $2.679 E-07$ \\
\hline 19 & 4600 & 0.26 & $-7.742 \mathrm{E}-03$ & $8.680 E-04$ & $2.516 E-04$ & $5.148 E-05$ & $5.406 E-06$ & $1.018 E-07$ \\
\hline 20 & 4800 & 0.33 & $-4.858 E-03$ & $1.616 \mathrm{E}-03$ & $4.155 E-04$ & $6.661 \mathrm{E}-05$ & $6.599 E-06$ & $-6.494 E-07$ \\
\hline 21 & 5000 & 31 & $-5.081 E-04$ & $2.547 \mathrm{E}-03$ & $5.030 \mathrm{E}-04$ & $7.461 E-05$ & $1.113 E-05$ & $-1.254 \mathrm{E}-06$ \\
\hline
\end{tabular}




\section{Booster Dipole: AVERAGE(37 mag)}

MEASUREMENT RESULTS (normalized to $B_{0}$ ) for MIDDLE OF MAGNET (at $1 \mathrm{~cm}$ )

NORMAL FIELDS:

\begin{tabular}{|c|c|c|c|c|c|c|c|c|}
\hline & $I(A)$ & $B_{0} / 1$ & $B_{1} / B_{0}$ & $B_{2} / B_{0}$ & $\mathrm{~B}_{3} / \mathrm{B}_{0}$ & $B_{4} / B_{0}$ & $B_{5} / B_{0}$ & $B_{6} / B_{0}$ \\
\hline 1 & 0 & & $-1.820 E-05$ & $3.173 E-04$ & $-2.380 E-06$ & $5.405 E-08$ & $5.200 E-08$ & \\
\hline 2 & 50 & 2.54838 & $-1.307 E-05$ & $1.536 \mathrm{E}-05$ & $-8.105 E-08$ & $3.803 E-08$ & $1.371 E-09$ & $51 \mathrm{E}-09$ \\
\hline 3 & 100 & & $-1.231 E-05$ & $71 E-06$ & $-7.706 E-08$ & $4.291 \mathrm{E}-08$ & $2.014 E-09$ & -09 \\
\hline 4 & 200 & & $-1.227 E-05$ & $2.551 E-06$ & $-5.901 E-08$ & $4.431 E-08$ & $2.514 E-09$ & 4.799E-09 \\
\hline 5 & 400 & 297 & 2E-05 & $9.725 E-07$ & $7 E-08$ & $31 E-08$ & $25 E-09$ & $3.915 E-09$ \\
\hline 6 & 600 & 110 & $9 E-05$ & $7.225 E-07$ & $-3.181 E-08$ & 49E-C & $6 E-09$ & $.550 E-09$ \\
\hline 7 & 800 & & IE-05 & $93 E-07$ & $9 E-08$ & $263 E-08$ & $9 E-09$ & -09 \\
\hline 8 & 1000 & & $3 E-05$ & $16 E-07$ & $-2.819 E-08$ & $6.627 E-08$ & $.335 E-09$ & -09 \\
\hline 9 & 1400 & 124 & E-05 & $5.895 E-07$ & $-3.276 E-08$ & $6.707 E-08$ & $9 E-09$ & -09 \\
\hline 0 & 1800 & & -05 & -07 & $-4.018 \mathrm{E}$ & -08 & -09 & -09 \\
\hline 1 & 2200 & & & & 08 & $1 E-08$ & 2E-09 & -09 \\
\hline 2 & 2600 & & $=-05$ & & $E-08$ & .08 & & \\
\hline 3 & 3000 & & -05 & -07 & -08 & -08 & & -09 \\
\hline 4 & 3400 & & -05 & $E-06$ & $20 E-08$ & -08 & & \\
\hline 5 & 3800 & 35 & $E-05$ & $E-06$ & $-1.238 E-08$ & $-3.474 E-08$ & -09 & -10 \\
\hline 6 & 4000 & 2.4 & $E-05$ & $E-06$ & 2.898 & $-7.569 E-08$ & $3.694 E-09$ & -09 \\
\hline 17 & 4200 & 2.42 & -1.2 & $E-06$ & $E-08$ & $-1.344 E-07$ & 4.581E-09 & -2.467 \\
\hline 8 & 4400 & & -1.2 & -06 & $=-08$ & $-2.216 E-07$ & $5.475 E-09$ & -4.2 \\
\hline 19 & 4600 & 2.4 & -1.2 & -05 & 5.6 & $-3.373 E-07$ & $9 E-09$ & -6.053 \\
\hline & 4800 & & & -1 & & $-4.748 E-07$ & $7.672 E-09$ & \\
\hline & 5000 & & -1.4 & -2 & $=-08$ & $-6.204 E-07$ & 8.740E-09 & -8.1 \\
\hline \multirow{2}{*}{\multicolumn{3}{|c|}{$\begin{array}{l}\text { AVG.: (600 to } 3400 \mathrm{~A}) \\
\text { STD. DEVIATION: }\end{array}$}} & & & & & & \\
\hline & & & & 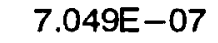 & & & & \\
\hline
\end{tabular}

SKEW FIELDS:

\begin{tabular}{|c|c|c|c|c|c|c|c|c|}
\hline & $I(A)$ & $A_{0} / B_{0}$ & $A_{1} / B_{0}$ & $A_{2} / B_{0}$ & $A_{3} / B_{0}$ & $A_{4} / B_{0}$ & $A_{5} / B_{0}$ & $A_{8} / B_{0}$ \\
\hline 1 & 0 & 0.00005 & $-1.207 \mathrm{E}-04$ & $-1.443 \mathrm{E}-06$ & $-4.765 E-07$ & $-1.719 E-07$ & $4.128 E-08$ & $1.229 E-08$ \\
\hline 2 & 50 & -0.00025 & $-8.793 E-06$ & $-2.381 E-07$ & $3.647 E-08$ & $-8.025 E-09$ & $2.721 E-10$ & $1.378 E-09$ \\
\hline 3 & 100 & -0.00004 & $-4.617 E-06$ & $5.779 \mathrm{E}-08$ & 4.394E-09 & $-6.053 E-09$ & $-7.382 E-10$ & 4.586E-10 \\
\hline 4 & 200 & 0.00000 & $-2.537 E-06$ & $5.026 E-09$ & $-8.483 E-09$ & $3.297 \mathrm{E}-09$ & $-1.561 E-10$ & $7.071 E-11$ \\
\hline 5 & 400 & 200 & $-1.527 E-06$ & $2 \mathbf{E}-08$ & $8.515 E-09$ & $2.615 E-09$ & $-1.158 E-09$ & $1.174 \mathrm{E}-10$ \\
\hline 6 & 600 & 01 & $-1.123 E-06$ & $3.915 E-08$ & $1.850 E-09$ & $1.902 E-09$ & $-6.124 E-10$ & $14 E-10$ \\
\hline 7 & 800 & -0.00000 & $-9.399 E-07$ & $5.928 E-08$ & $1.412 \mathbf{E}-09$ & $8.419 E-10$ & $-5.037 E-10$ & $5 E-10$ \\
\hline 8 & 1000 & 0.00001 & $-8.260 E-07$ & 4.787E-08 & $-1.177 E-09$ & $2.874 E-09$ & $-4.285 E-10$ & $8.479 E-11$ \\
\hline 9 & 1400 & 0.00001 & $-7.685 E-07$ & $4.432 E-08$ & $-1.829 E-09$ & 1.877E-09 & $-1.701 E-10$ & $1.412 E$ \\
\hline & 1800 & & $-7.705 E-07$ & $9 E-08$ & $-2.814 E-10$ & $1.982 \mathrm{E}-09$ & $31 E-10$ & $1.563 E$ \\
\hline & 2200 & & 汭-07 & $=-09$ & -1.1 & $2.576 E-09$ & $33 E-10$ & 8.901 \\
\hline & 2600 & & -07 & -08 & -09 & & & \\
\hline & 3000 & & 3E-07 & $E-09$ & $34 E-11$ & -09 & $5 E-10$ & -10 \\
\hline & 3400 & & E-07 & $6 E-09$ & $E-09$ & -09 & -11 & -10 \\
\hline & 3800 & & $-8.521 E-07$ & $\mathrm{E}-09$ & 3.863E-09 & $E-09$ & -11 & -10 \\
\hline & 4000 & 0.00002 & $-8.540 E-07$ & $2.297 E-08$ & $5.949 E-09$ & $7 E-09$ & $12 \mathbb{E}-10$ & -10 \\
\hline 7 & 4200 & 0.00002 & $-8.168 E-07$ & $2.570 E-08$ & $9.077 \mathrm{E}-09$ & $3.701 E-09$ & $7 E-10$ & 7.089 \\
\hline & 4400 & & $-8.017 E-07$ & $4.296 E-08$ & $1.500 E-08$ & 4.481E-09 & $3.032 E-10$ & $2.522 \mathrm{E}-11$ \\
\hline & 4600 & & -07 & -08 & 2.2 & -09 & -10 & -12 \\
\hline & 4800 & & $E-07$ & & EE-08 & $2 E-09$ & $3 E-10$ & -11 \\
\hline & & & -4.2 & & $E-08$ & 09 & $E-10$ & -10 \\
\hline & & & $\begin{array}{r}-8.54 \\
1.00\end{array}$ & $\begin{array}{l}2.26 \\
2.44\end{array}$ & $\begin{array}{r}-2.253 \\
1.368\end{array}$ & $\begin{array}{l}2.249 \mathrm{E}-09 \\
6.278 \mathrm{E}-10\end{array}$ & $\begin{array}{l}E-10 \\
E-10\end{array}$ & $\begin{array}{l}-10 \\
-11\end{array}$ \\
\hline
\end{tabular}




\section{Booster Dipole: AVERAGE(37 mag)}

\section{Field Shape}

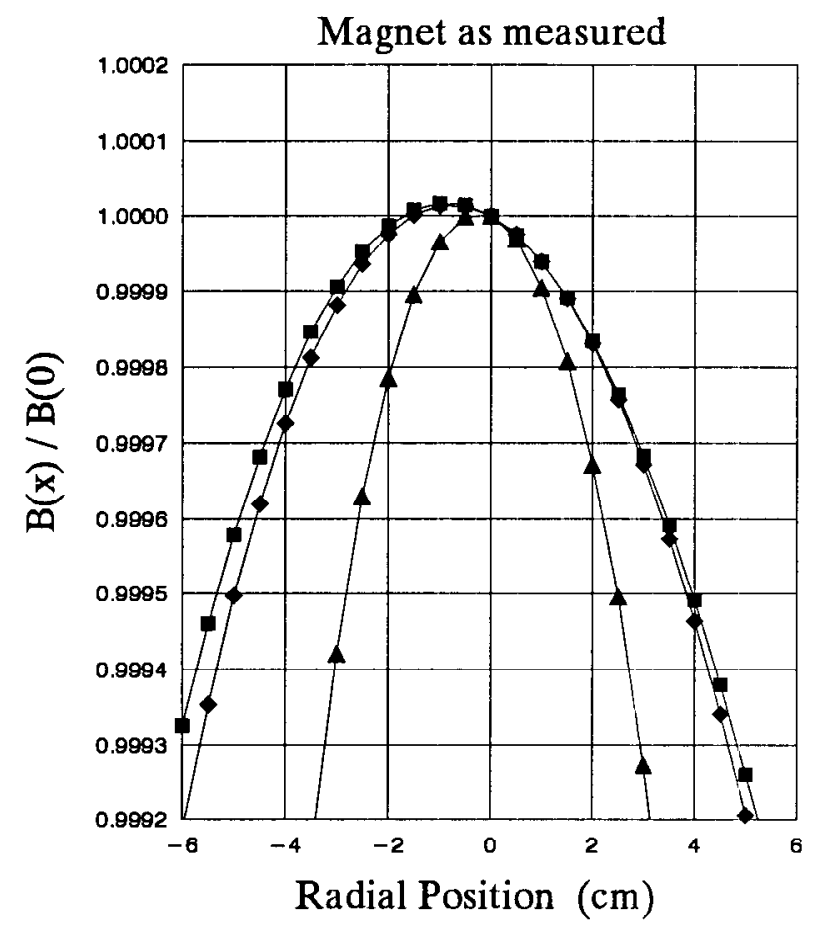

$-600 \mathrm{~A} \bullet 2600 \mathrm{~A} \leftarrow 5000 \mathrm{~A}$

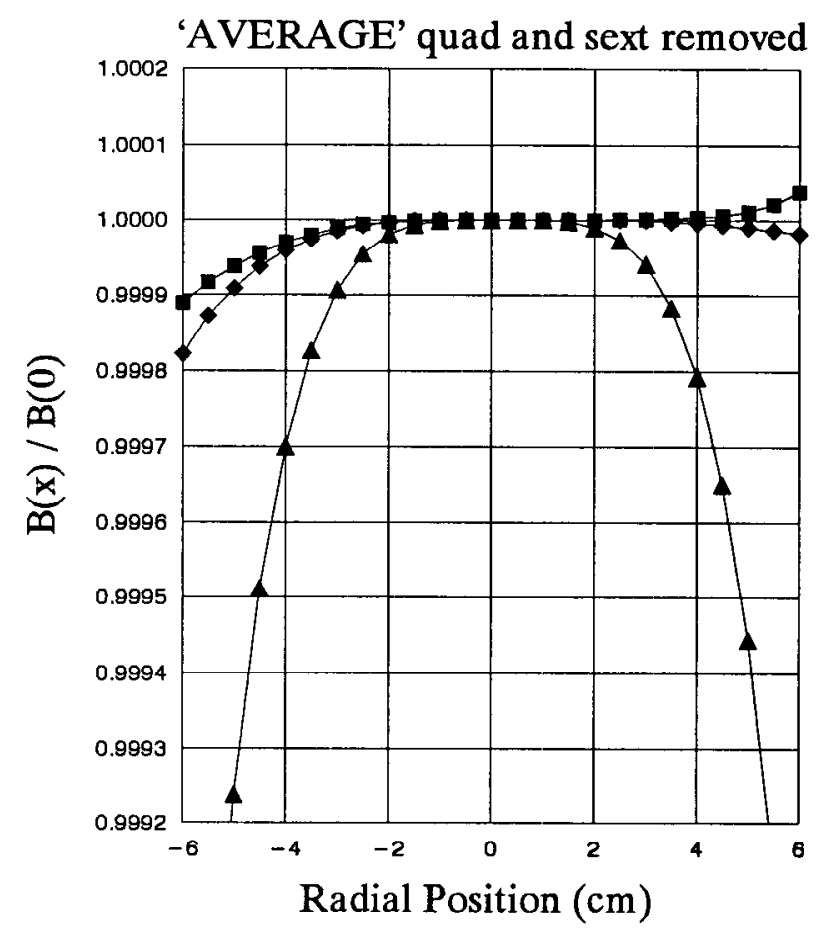

$-600 \mathrm{~A} \nrightarrow 2600 \mathrm{~A} \_5000 \mathrm{~A}$

\section{B / I vs. Current}

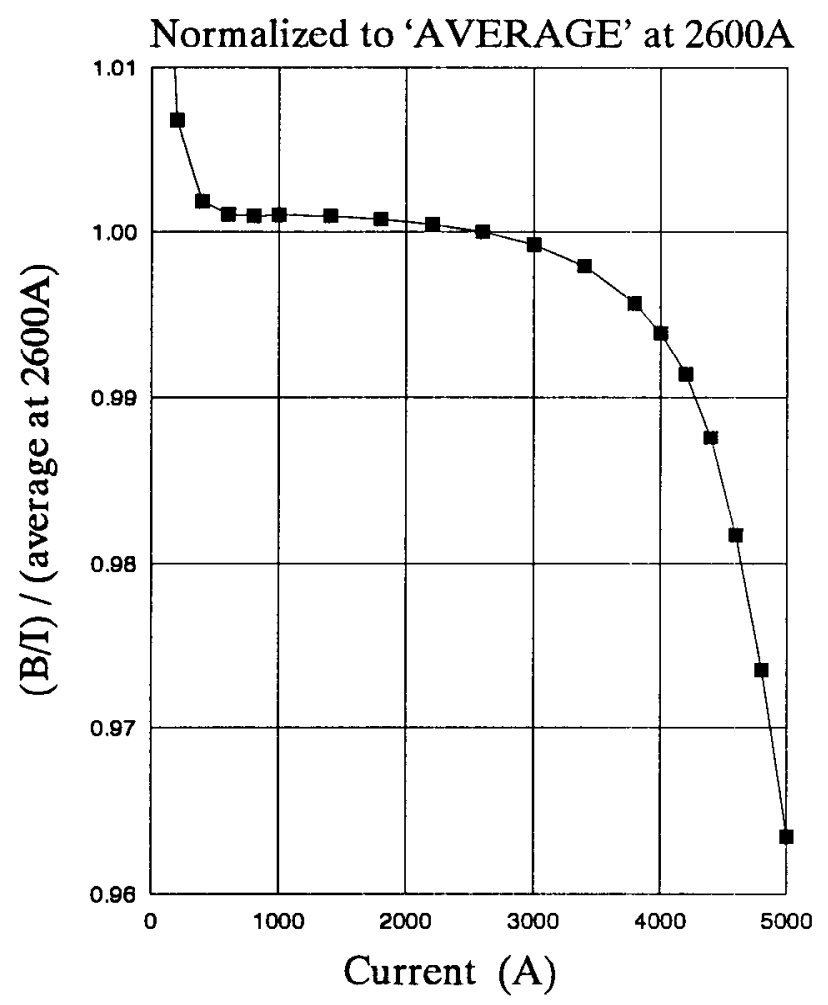

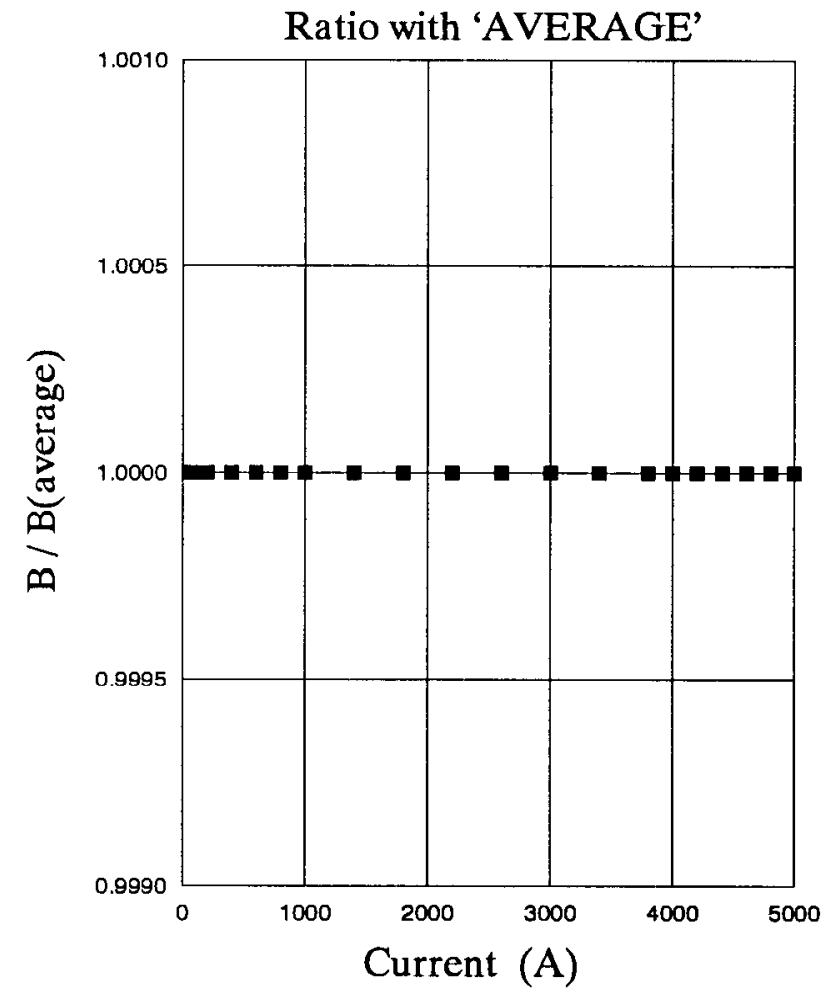


Booster Tech Note No. 190 Addendum

\title{
B OOSTER DIPOLE PRODUCTION MEASUREMENTS
}

\author{
R. Thern
}

May 20, 1994

The note describing the Booster dipole measurements was published in 1991 without a data sheet. This addendum is being published to add the data sheet.

In addition, the table of systematic and random errors in the original note was wrong. The crror data wcre originally in centimeters and were converted to meters in an attempt to use a standard set of units. Unfortunately, the conversion went the wrong direction and the error was not noticed because of the unfamiliar units - the errors given are appropriate for an accelerator with a good field aperture of several hundred meters instead of several centimeters! (The systematic $b_{3}$ and $a_{3}$ tolerance values had an additional factor-of-10 typographical error.) The corrected table is included here, using both units. 
Systematic Errors (meters)

Tolerance

$2600 \mathrm{~A} \quad 5000 \mathrm{~A}$
Random Errors (meters)

Tolerance Measured

$2600 \mathrm{~A} \quad 5000 \mathrm{~A}$

$1.5 \mathrm{E}-04 \quad 1.5 \mathrm{E}-04 \quad 3.0 \mathrm{E}-04$

$2.0 \mathrm{E}-03 \quad 9.1 \mathrm{E}-04 \quad 8.6 \mathrm{E}-04$

$5.0 \mathrm{E}-02$

$8.9 \mathrm{E}-03$

8.3E-03

$7.0 \mathrm{E}+00$

1.4E-01

1.3E-01

$1.0 \mathrm{E}+02$

$1.1 \mathrm{E}+00$

$1.1 \mathrm{E}+00$

$1.0 \mathrm{E}+03$

$5.9 \mathrm{E}+01$

$5.4 \mathrm{E}+01$

$5.0 \mathrm{E}+04$

$5.6 \mathrm{E}+02$

$4.9 \mathrm{E}+02$

$1.5 \mathrm{E}-04$

4.9E-05

5.4E-05

2.0E-03

4.0E-04

4.8E-04

$5.0 \mathrm{E}-02$

$7.0 \mathrm{E}+00$

$4.2 \mathrm{E}-03$

$5.6 \mathrm{E}-03$

$1.0 \mathrm{E}+00$

$-7.5 \mathrm{E}-04 \quad-1.4 \mathrm{E}-04$

$1.5 \mathrm{E}-01$

1.4E-01 4.7E-01

$1.0 \mathrm{E}+02$

$7.9 \mathrm{E}-02$

$9.4 \mathrm{E}-02$

$a_{4}$

$1.0 \mathrm{E}+02$

$-2.2 \mathrm{E}+01$

$-5.3 \mathrm{E}+00$

$1.0 \mathrm{E}+03$

8.8E-01

7.8E-01

$3.0 \mathrm{E}+03$

$8.7 \mathrm{E}+01$

$-6.1 E+01$

$5.0 E+04$

2.1E+01

$1.9 \mathrm{E}+01$

$a_{6}$

$1.0 \mathrm{E}+04$

Table 2a. Systematic and random errors ( $r m s)$, in units of $\mathrm{m}^{-\mathrm{n}}$. The systematic error is the average over all the magnets, and the random error is the standard deviation of the same set. The errors for $B_{0}$ have been estimated as described in the text.

Systematic Errors (cm)

Tolerance

Measured

$2600 \mathrm{~A} \quad 5000 \mathrm{~A}$

$\ldots$

$\mathrm{B}_{0}$

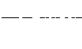

$b_{2}$

$b_{3}$

$\frac{1.0 \mathrm{E}-04}{1.5 \mathrm{E}-05}-2.4$

$\mathrm{b}_{4}$

$1.5 \mathrm{E}-05$

$1.0 \mathrm{E}-06$

3.0E-07

$1.0 \mathrm{E}-08$

$-2.4 E-05$

$2.1 \mathrm{E}-07$

$-9.8 \mathrm{E}-08$

1.5E-04

2.0E-05

$-6.4 \mathrm{E}-05$

5.0E-06

5.3E-07

$7.0 \mathrm{E}-06$

$-8.7 E-07$

$1.0 \mathrm{E}-06$

1.2E-08

$-\frac{b_{5}}{b}$

$5.5 \mathrm{E}-09$

$-9.1 \mathrm{E}-09$

1.0E-07

$5.0 \mathrm{E}-08$

1.5E-04

2.0E-05

6.0E-06

$1.0 \mathrm{E}-05$

2.4E-06

$-1.4 \mathrm{E}-08$

5.0E-06

1.5E-07

7.0E-06

4.7E-09

$1.0 \mathrm{E}-06$

$-5.3 \mathrm{E}-10$

$a_{5}$

1.0E-06

1.4E-09

3.0E-07

$-2.2 \mathrm{E}-09$

1.0E-08

8.7E-11

$-6.1 E-11$

$1.0 \mathrm{E}-07$

$5.0 \mathrm{E}-08$

Random Errors (cm)

Table 2b. Systematic and random errors (rms), in units of $\mathrm{cm}^{-n}$. The systematic error is the average over all the magnets, and the random error is the standard deviation of the same set. The errors for $B_{0}$ have been estimated as described in the text. 
PARAMETER SHEET FOR BOOSTER MAIN DIPOLE

Date: $11 / 6 / 92$

Prototype Name

BMD (Booster Main Dipole)

Magnet Class

Dipole

Number of Magnets

36 plus 3

\section{MECHANICAL}

CORE

Lamination Length (arc)

Tolerance

Lamination Length (chord)

Overall Length

Aperture Shape

Gap Height

Pole Width

Core Height

Core Width

Wedge Angle of Magnet

Weight of Dipole

Weight of Dipole and Base

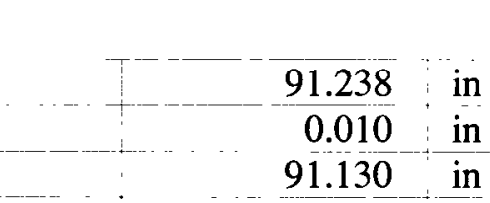

LAMINATIONS

Material

Coating

M45 Si Steel, $24 \mathrm{Ga}$.

Coating Thickness

Overall Thickness

END MODULE BLOCK

Number per Magnet

Laminations (approx)

Weight before wedging

Rectangular

0.010 in

Tolerance

C4

CENTER MODULE BLOCK

Number per Magnet

Laminations (approx)

Weight before wedging

Tolerance

2
176
858.1
0.5

VACUUM PIPE

Material

Height - Outside

3.250 in

10.000

23.75

30.00

9.656

16765

20465

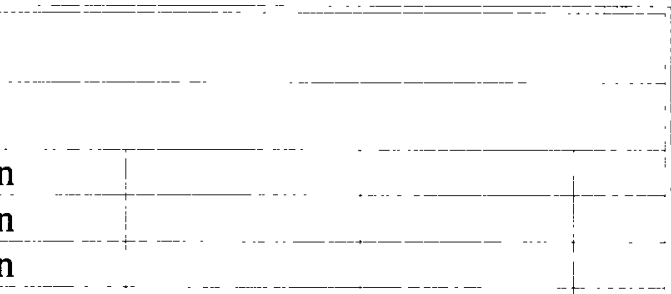

Width - Outside

Wall Thickness

Tolerance Specified

Tolerance Measured - 95\%

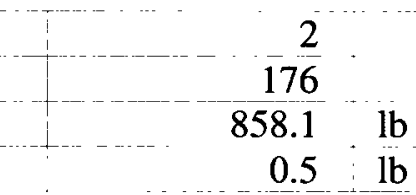

in
in
in
in
degree
b
b

\subsection{5}

$254.00 \mathrm{~mm}$

$603.25 \mathrm{~mm}$

$762.00 \mathrm{~mm}$

Half Height - Inside

Half Width - Inside

Resitivity

Tol. Specified

Tol. Measured - $80 \%$

$\frac{7}{356}$
1726.4
0.5

Iconel 625

2.752 in

6.496 in

0.079 in

0.002 in

0.002 in

1.299 in

3.169 in
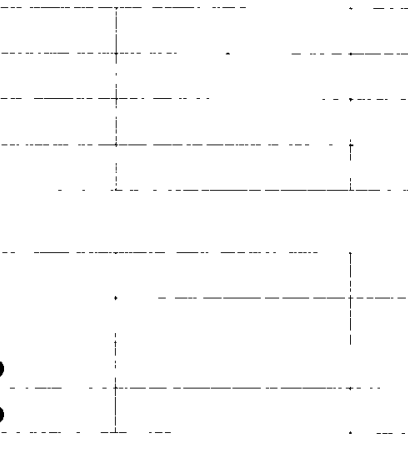

$\mathrm{mm}$


MAIN COIL

COIL

Turns per Pole

Poles per Magnet

Resistance per Magnet

Inductance per Magnet - DC

Inductance per Magnet $-1 \mathrm{kHz}$

CONDUCTOR

Material

Shape

Width

Height

Cooling Hole Dia.

Area

Length per Pole

Length per Magnet

INSULATION

Material

Thickness, turn-turn

Thickness, ground

Tolerance

Ground Test

Impulse Test

COOLING

Circuits per Magnet

Flow Rate per Magnet

Input Pressure

Temp Rise @ Ramp to Imax

CURRENT

I-max (PS Limit)

Current Density@ Imax

DC Power@Imax

Stored Energy @ Imax

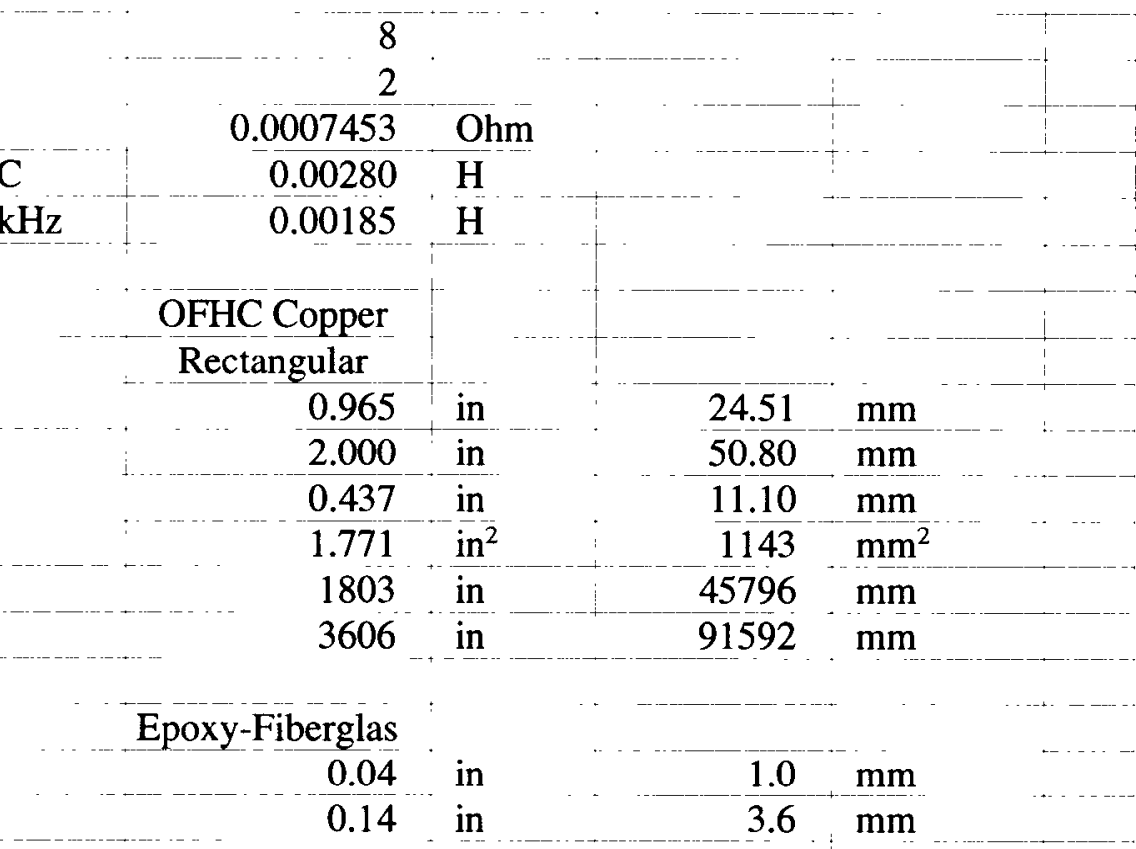

0.14 in $3.6 \mathrm{~mm}$

$12500 \quad \mathrm{~V}$

2

$6.1 ? \mathrm{GPM}$

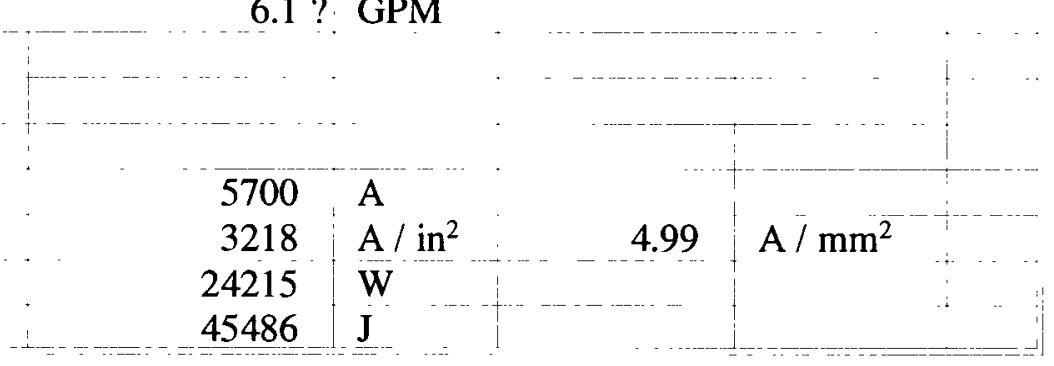


BUMP COIL

COIL

Turns per Pole

Poles per Magnet

Resistance per Magnet

Inductance per Magnet - DC

Inductance per Magnet $-1 \mathrm{kHz}$

CONDUCTOR

Material

Shape

Width

Height

Cooling Hole Dia.

Area

Length per Pole

Length per Magnet

INSULATION

Material

Thickness, turn-turn

Thickness, ground

Tolerance

Ground Test

Impulse Test

COOLING

Circuits per Magnet

none

Flow Rate per Magnet

Input Pressure

Temp Rise @ Ramp to Imax

CURRENT

I-max (PS Limit)

Current Density@ Imax

DC Power@Imax

Stored Energy@ Imax

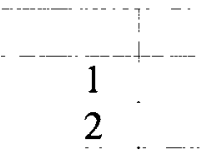

Ohm

$\mathrm{H}$

$\mathrm{H}$

OFHC Copper

Rectangular

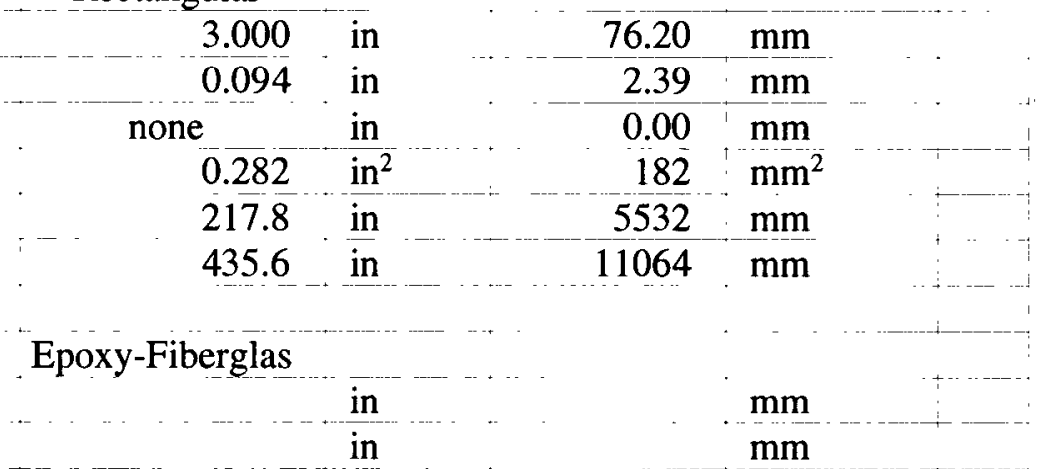

V
A

$\mathrm{A} / \mathrm{in}^{2} \quad 0.00 \mathrm{~A} / \mathrm{mm}^{2}$

W

J 
EDDY CURRENT COILS (5 circuits per magnet)

COIL

Turns per Pole

Poles per Magnet

Resistance per Magnet

Inductance per Magnet - DC

Inductance per Magnet $-1 \mathrm{kHz}$

CONDUCTOR

Material

Shape

Width

Height

Cooling Hole Dia.

Area

Length per Pole

Length per Magnet

INSULATION

Material

Thickness, turn-turn

Thickness, ground

Tolerance

Ground Test

Impulse Test

USAGE OF COILS

Eddy Current Corr. Driver

Monitor

Spare

\section{CURRENT}

I-max (PS Limit)

Current Density@ Imax

DC Power@ Imax

Stored Energy@ Imax
1

2

$\mathrm{Ohm}$

$\mathrm{H}$

$\mathrm{H}$

Copper

\#12 Wire

in mm

none

219

in

$\mathrm{mm}^{2}$

438

in

5563

$\mathrm{mm}$

in

11125

$\mathrm{mm}$

in

$\mathrm{mm}$

in

$\mathrm{mm}$

V

2 Coils

1 Coil

2 Coils

A

$\mathrm{A} / \mathrm{in}^{2}$

W

J

$\mathrm{A} / \mathrm{mm}^{2}$ 
MAGNETIC PROPERTIES (MAIN COIL)

EXCITATION CURVE

B * L-eff @ I=0

B*L-eff $/$ I @I=200

B*L-eff $/$ I @ I=600

B*L-eff $/ I @ \mathrm{I}=2600$

B*L-eff / I @I=5000

$\begin{array}{lll} & \text { Unit } & \text { Ref } \\ 0.0018755 & \mathrm{~T}-\mathrm{m} & \text { ret } \\ 0.0005921 & \mathrm{~T}-\mathrm{m} / \mathrm{A} & \text { ret } \\ 0.0005887 & \mathrm{~T}-\mathrm{m} / \mathrm{A} & \text { ret } \\ 0.0005881 & \mathrm{~T}-\mathrm{m} / \mathrm{A} & \text { ret } \\ 0.0005666 & \mathrm{~T}-\mathrm{m} / \mathrm{A} & \text { ret } \\ & \text { T-m } / \mathrm{A} & \end{array}$

B*L-eff / I @ I=5700

Saturation, 5000/2600

$$
3.65 \%
$$

\begin{tabular}{|c|c|c|c|}
\hline B @ $@ I=0$ & 0.0007620 & $\mathrm{~T}$ & ret \\
\hline $\mathrm{B} / \mathrm{I} @ \mathrm{I}=\mathbf{2 0 0}$ & 0.0002445 & $\mathrm{~T} / \mathrm{A}$ & ret \\
\hline $\mathrm{B} / \mathrm{I} @ \mathrm{I}=600$ & 0.0002431 & $\mathrm{~T} / \mathrm{A}$ & ret \\
\hline $\mathrm{B} / \mathrm{I} @ \mathrm{I}=2600$ & 0.0002430 & $\mathrm{~T} / \mathrm{A}$ & ret \\
\hline $\mathrm{B} / \mathrm{I} @ \mathrm{I}=5000$ & 0.0002366 & $\mathrm{~T} / \mathrm{A}$ & ret \\
\hline $\mathrm{B} / \mathrm{I} @ \mathrm{I}=5700$ & & $\mathrm{~T} / \mathrm{A}$ & \\
\hline Saturation, $5000 / 2600$ & $2.66 \%$ & & \\
\hline L-eff @I=0 & 2.4613 & m & ret \\
\hline L-eff @ I=200 & 2.4214 & $\mathbf{m}$ & ret \\
\hline L-eff @I=600 & 2.4216 & $\mathrm{~m}$ & ret \\
\hline L-eff @ $@=2600$ & 2.4200 & $\mathrm{~m}$ & ret \\
\hline L-eff @I=5000 & 2.3952 & $\mathrm{~m}$ & ret \\
\hline
\end{tabular}




\section{SYSTEMATIC ERRORS}

\section{LIMITS MEASURED}

@ 2600A

$\mathrm{Bn} / \mathrm{B} 0, \mathrm{n}=1$

$\mathrm{Bn} / \mathrm{B} 0, \mathrm{n}=2$

$\mathrm{Bn} / \mathrm{B} 0, \mathrm{n}=3$

$\mathrm{Bn} / \mathrm{B} 0, \mathrm{n}=4$

$\mathrm{Bn} / \mathrm{B} 0, \mathrm{n}=5$

$\mathrm{Bn} / \mathrm{B} 0, \mathrm{n}=6$

$\mathrm{An} / \mathrm{B} 0, \mathrm{n}=1$

$\mathrm{An} / \mathrm{B} 0, \mathrm{n}=2$

$\mathrm{An} / \mathrm{B} 0, \mathrm{n}=3$

$\mathrm{An} / \mathrm{B} 0, \mathrm{n}=4$

$\mathrm{An} / \mathrm{B} 0, \mathrm{n}=5$

$\mathrm{An} / \mathrm{B} 0, \mathrm{n}=6$

$\begin{array}{rr} & -2.4 \mathrm{E}-05 \\ 1.0 \mathrm{E}-04 & 2.1 \mathrm{E}-07 \\ 1.5 \mathrm{E}-05 & -9.8 \mathrm{E}-08 \\ 1.0 \mathrm{E}-06 & -9.5 \mathrm{E}-09 \\ 3.0 \mathrm{E}-07 & -2.4 \mathrm{E}-11\end{array}$

1. $0 \overline{\mathrm{E}}-\overline{0} \overline{5}$

$1.0 \mathrm{E}-04$

1.5E-05

$1.0 \mathrm{E}-06$

$3.0 \mathrm{E}-07$

1.0E-08

\section{@5000A}

$\mathrm{cm}^{-1} \quad$ ar,ret $-6.4 \mathrm{E}-05 \quad \mathrm{~cm}^{-2} \quad$ ar, ret 5.3E-07 $\mathrm{cm}^{-3} \quad$ ar,ret $-8.7 \overline{\mathrm{E}-07} \mathrm{~cm}^{-4} \quad$ ar,ret $1.2 \mathrm{E}-08 \quad \mathrm{~cm}^{-5} \quad$ ar, ret

$-9.1 \mathrm{E}-09 \quad \mathrm{~cm}^{-6}$ ar,ret

RANDOM ERRORS

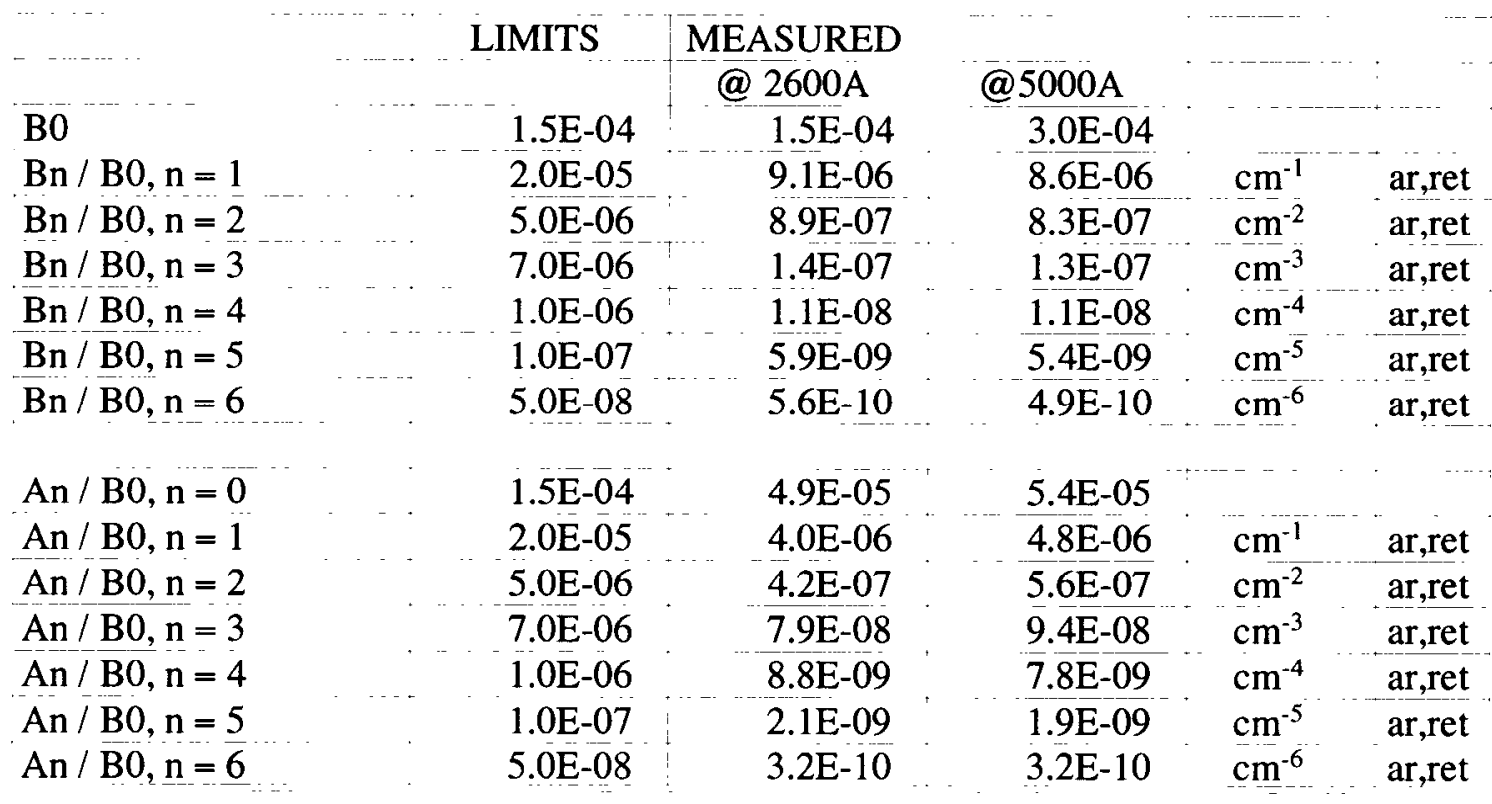

\section{REFERENCES}

hch: H. C. Hseuh

ar: A. Rugierro

as: A. Soukas

ret: $\mathbf{R}$. Thern 